\title{
BONE DENSITY MEASUREMENT VIA RADIOGRAPHIC CALIBRATION
}

\author{
A Thesis \\ presented to \\ the Faculty of California Polytechnic State University, \\ San Luis Obispo
}

In Partial Fulfillment

of the Requirements for the Degree

Master of Science in Agriculture, with Specialization in Animal Science

by

Amber Jean Bowen

June 2010 
(C) 2010

Amber Jean Bowen

ALL RIGHTS RESERVED 


\section{COMMITTEE MEMBERSHIP}

TITLE:

AUTHOR:

DATE SUBMITTED:

COMMITTEE CHAIR:

COMMITTEE MEMBER

COMMITTEE MEMBER: $\quad$ Ronald Brown, Ph.D.

COMMITTEE MEMBER: Brooke Humphrey, Ph.D.

John Craig, Ph.D.
Bone Density Measurement via Radiographic Calibration

Amber Jean Bowen

May 2010 


\section{ABSTRACT \\ Bone Density Measurement via Radiographic Calibration \\ Amber Jean Bowen}

Musculoskeletal injuries are the most common injuries sustained by athletes and military recruits and can result in decreased performance and lifelong disability. So common and costly are these injuries that the American Academy of Orthopedic Surgeons has provided guidelines for future research, including recommendations for the development of a large animal model of bone injury (USDA 2001). In human and veterinary medicine, digital radiography represents the primary diagnostic tool the physician uses to diagnose skeletal injury. Advances in digital radiography have provided the veterinarian with opportunities to make both simple and complex radiographic assessments. We investigated a simple quantitative measurement of the solar, concave aspect of the distal phalanx in the horse, termed the Palmar-Metric (PM). The PM was a significant predictor of solar cup volume $(p<0.001)$ and negatively correlated with age $\left(r^{2}=0.28, p<0.05\right)$ as determined from 544 radiographs of the distal phalanx from the left and right front feet. Therefore, veterinarians should be aware of the age related change in the solar, concave aspect of the distal phalanx in the horse.

We hypothesized that the decrease in the degree of concavity with age may be due to demineralization and subsequent loss of bone density along the solar margin of the distal phalanx. Therefore, we investigated the quantification of optical bone density (bone OD) via complex radiographic calibration. By developing a brightness/darkness index (BDI), the greyscale of radiographs, calibrated with an aluminum marker of varying known thickness, can be compared to the average density of a cross-section of bone. At 
varying radiographic exposure intensity $(\mathrm{kV})$ and exposure time (mAs), Al BDI was a significant predictor of bone BDI $\left(r^{2}=0.960, p<0.001\right)$ and bone OD $\left(r^{2}=0.971, p<\right.$ 0.001). This method of calibration can be utilized by the radiologist to accurately assess bone OD regardless of technique, and allow direct comparison of radiographs taken under different exposure settings. This method successfully quantifies bone OD via measurement of BDI from standardized digital radiographs, allowing for the opacity of radiographs to be truly comparable when taken under different circumstances.

Keywords: digital, radiograph, bone, optical density 


\section{ACKNOWLEDGMENTS}

I would like to express my sincere appreciation to Dr. Matthew Burd for his willingness to accept me as a graduate student, his continual challenging of me to achieve even more than I believed I could, and his unwillingness to accept anything less from me than what he believed I was capable of doing. I would also like to thank him for his continual support and guidance in my aspirations for veterinary school, which I couldn't have achieved without him.

I would like to thank Dr. John Craig and Monique Craig for all their support and never ending stream of new ideas. Thank you, John, for working with me every step of the way, I couldn't have done it without your remarkable insight and programming skills. Thank you and EponaTech, Inc. for coaching me in new techniques for research in the fields of radiology and biomechanics.

I would like to express my gratitude to Dr. Brooke Humphrey for agreeing to serve on my committee at the last minute.

I would like to thank Dr. Ron Brown for his willingness to serve on my committee. I am forever grateful for his support and advice. I would also like to thank him for his constant assurance that it was possible for me to do anything I put my mind to, including completion of a M.S. and admission to veterinary school, all with a B.S. in physics. 


\section{TABLE OF CONTENTS}

Page

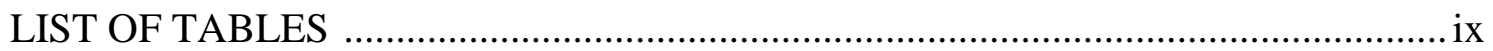

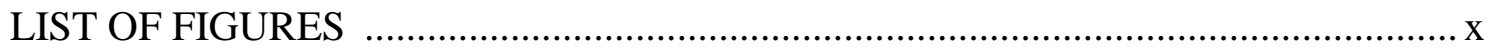

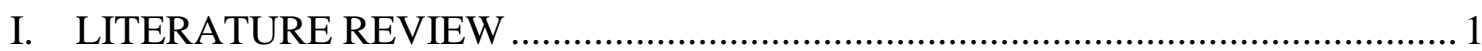

1.1 Basics of Radiology ................................................................ 1

1.2 Applications of Radiology ........................................................ 6

1.3 Determination of Bone Quality ................................................ 9

1.4 Standardization of Digital Radiographs......................................... 13

1.5 Justification for Work ........................................................... 15

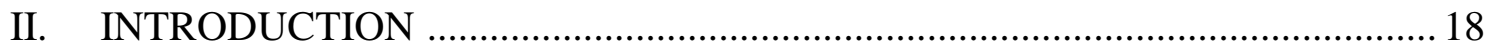

III. SIMPLE RADIOGRAPHIC STANDARDIZATION ................................... 20

3.1 Materials and Methods ............................................................. 20

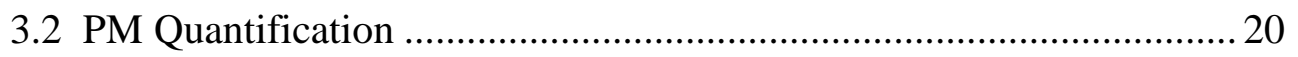

3.3 Standardization of the PM ......................................................... 20

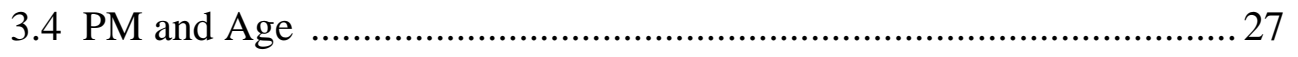

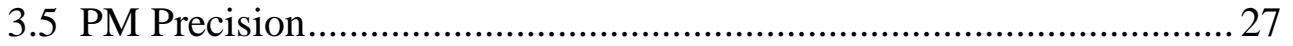

3.6 Statistical Analysis .................................................................. 30

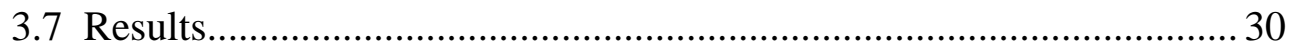

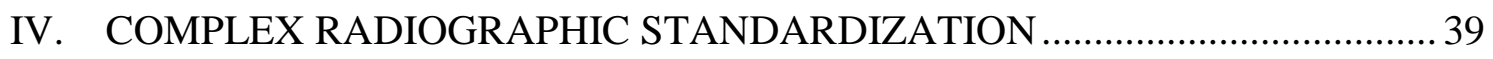

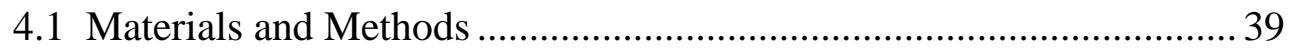

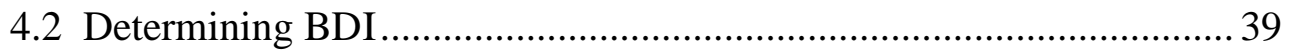

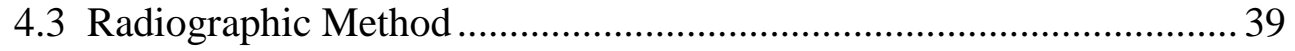

4.4 BDI at Varying Radiographic Exposures ...................................... 40

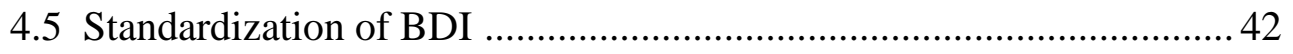


4.6 Quantification of Optical Bone Density .......................................... 46

4.7 Error Associated with Optical Bone Density ................................... 53

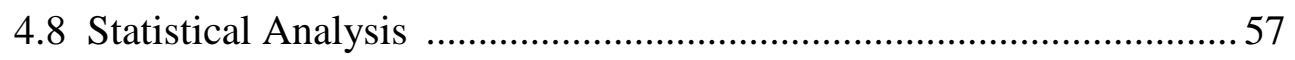

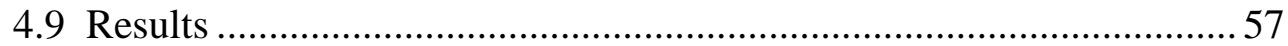

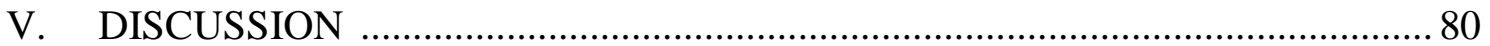

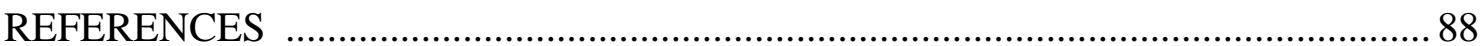




\section{LIST OF TABLES}

Table Page

1. Mean PM by age for 325 horses of various breeds ..................................... 33

2. Mean PM with varying radiograph position .................................................. 37

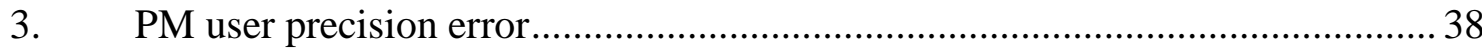

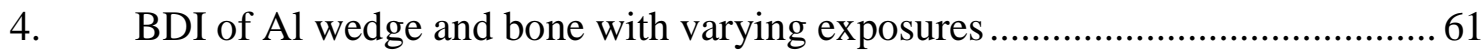

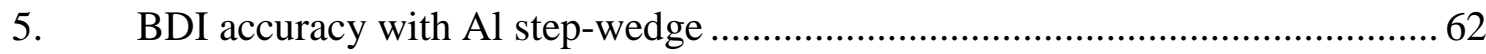

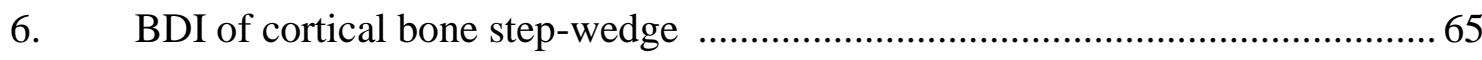

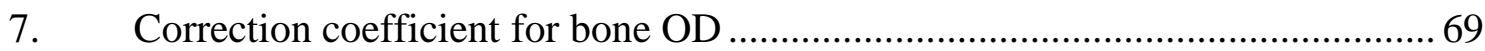

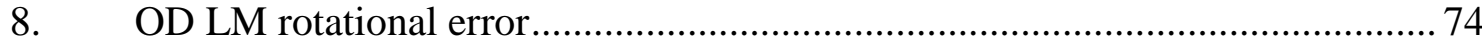

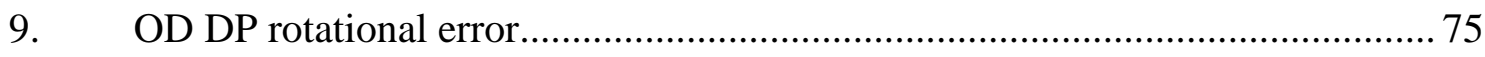

10. OD with and without soft tissue and bone marrow ....................................... 76

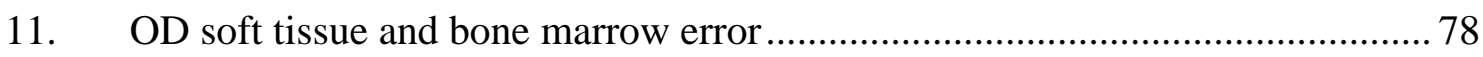

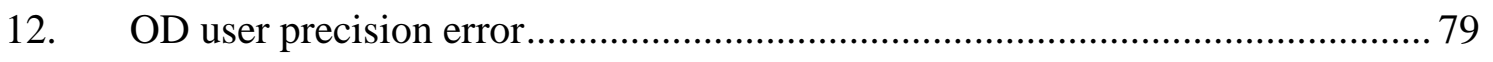




\section{LIST OF FIGURES}

Figure $\quad$ Page

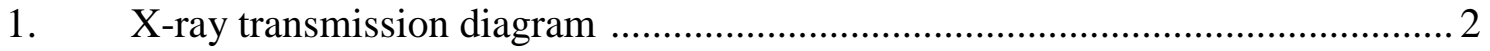

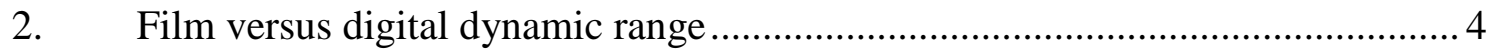

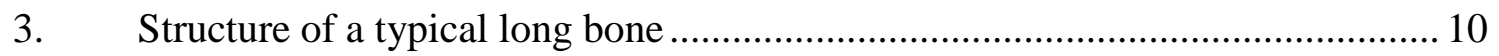

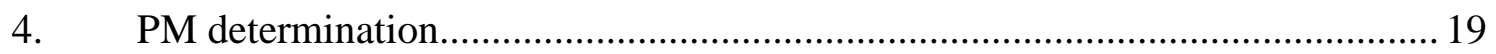

5. LM radiograph of third phalanx cadaver bone ........................................ 21

6. PM determination from a cadaver third phalanx bone.................................. 24

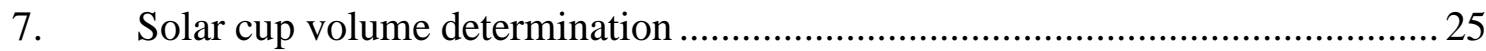

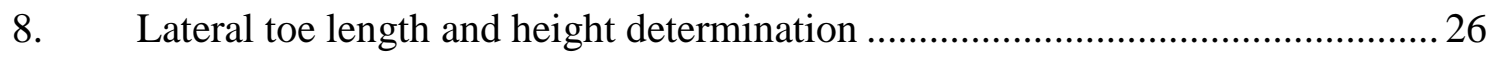

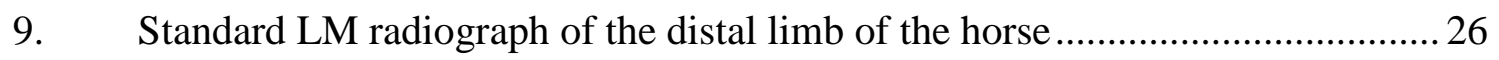

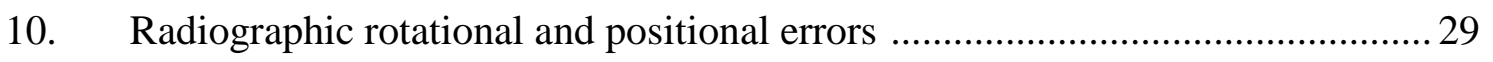

11. PM versus solar cup volume regression.................................................. 31

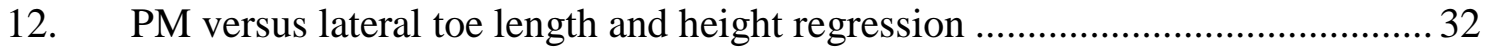

13. PM for left and right front feet by age ................................................... 35

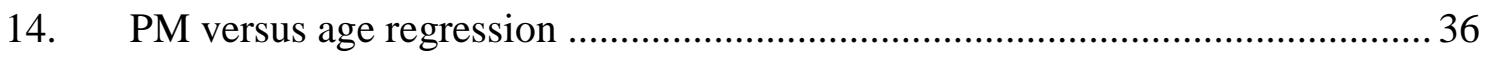

15. DP positioning of third metacarpal cadaver bone ....................................... 41

16. Regions of interest for bone and Al wedge ............................................. 43

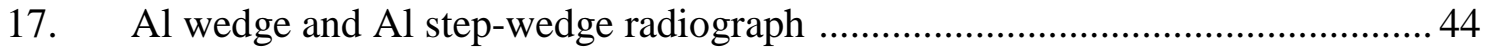

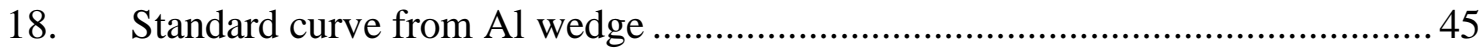

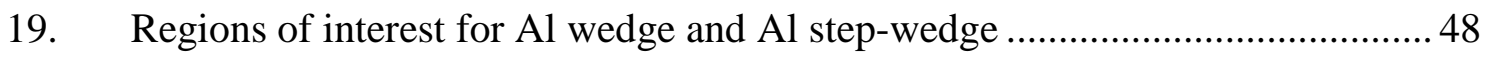

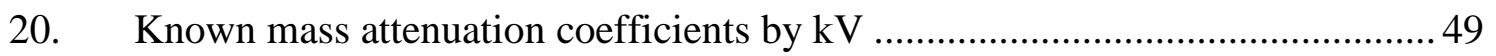

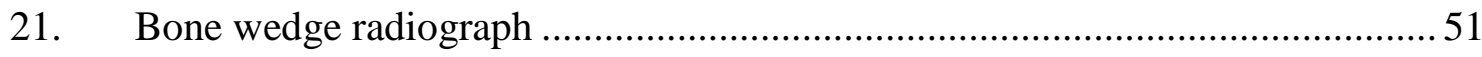

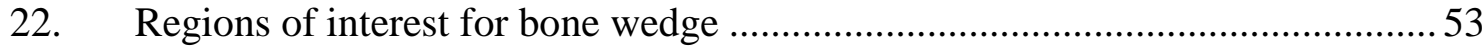

23. Regions of interest and limb diameter for density determination ......................54

24. Region of interest while varying radiographic positioning ............................56

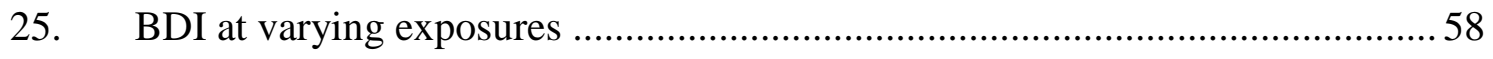


26. Bone BDI versus Al BDI at varying exposures ........................................59

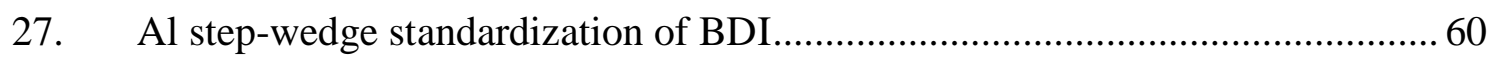

28. Bone step-wedge BDI versus areal bone density regression .......................... 61

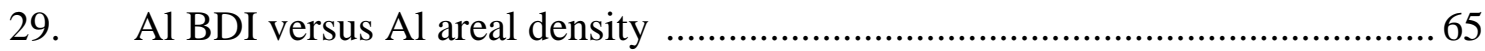

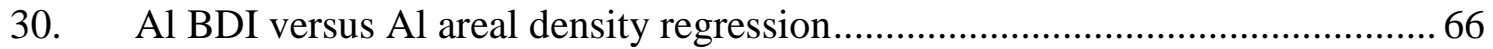

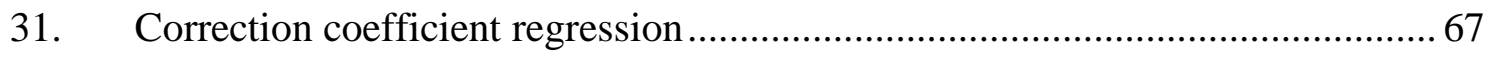

32. OD with and without soft tissue and bone marrow .................................... 71

33. Bone density with and without soft tissue and bone marrow ........................ 72 


\section{LITERATURE REVIEW}

\subsection{Basics of Radiology}

Radiography is a widely used diagnostic technique in veterinary medicine. According to the Behr-Lambert law, a radiographic image is produced when energy from an X-ray source is transmitted through a patient and detected by a sensor (Figure 1). The X-ray source or tube is a diode tube made of Pyrex glass that encloses a vacuum. A modern X-ray tube contains a heated filament (cathode) that releases X-rays which are accelerated across high voltage produced by electrodes onto a target (anode). X-rays are produced as the accelerated electrons interact with the target, emerging in all directions to be restricted by collimators. In this manner, an incident X-ray beam is produced (Hendee and Ritenour 2002).

This method of X-ray production has barely changed since Roentgen discovered $\mathrm{X}$-rays in 1895; however, the manner in which $\mathrm{X}$-ray radiation is detected has developed drastically. Traditional film radiography consists of photosensitive film requiring a time

consuming developing process. Additionally, screen-film systems are limited to a relatively small exposure range and the transfer of information from the X-ray beam to the film always results in a loss of information (Garmer et al. 2000). With the advent of digital radiology (DR), radiographic imaging has drastically improved in image quality (Yaffe and Rowlands 1997), resolution (MacMahon et al. 1986) and acquisition time (Dackiewicz et al. 2000). One of the major advantages of DR is that it allows the clinician to perform various forms of digital processing, such as optimizing image contrast after the image has already been recorded (Sprawls 1987). Diagnostic efficacy using DR has been shown to be equivalent if not better than traditional film radiography 


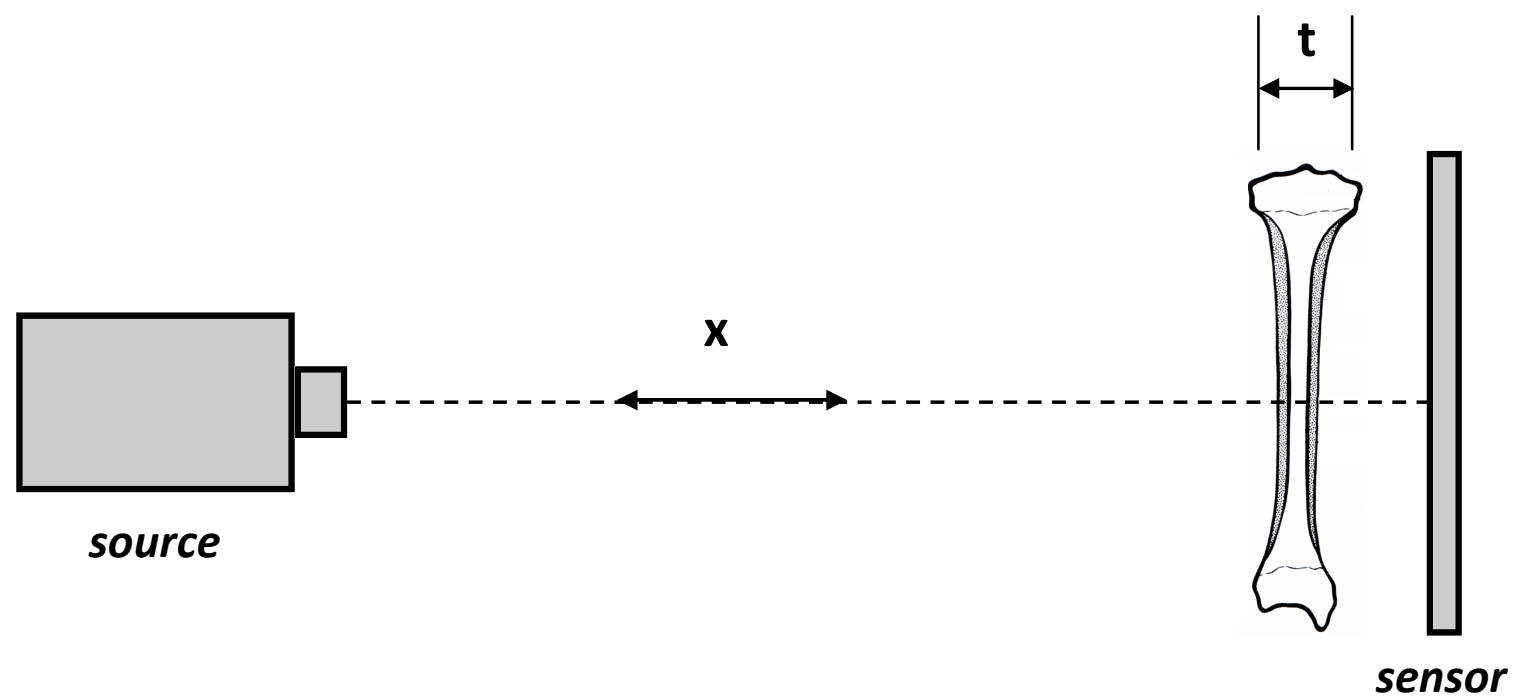

Figure 1. X-ray transmission from the source is detected by the sensor along the horizontal axis $(x)$ is dependent on density, thickness $(t)$ and absorption coefficient of the sample. 
in evaluation of chest (Garmer et al. 2000, Fink et al. 2002, Hirsch et al. 2001), pulmonary (MacMahon et al. 1986) and skeletal (Zahringer et al. 2001, Strotzer et al. 1995) abnormalities.

Additionally, DR provides a wide dynamic range while traditional X-ray film is somewhat limited due to silver halide crystals. The wide dynamic range found in DR is due to the large dynamic range of the digital receptors, meaning that there is a wider functional range of receptor exposure. When using X-ray film outside of the limited dynamic range the film easily becomes over or under exposed. This is not a problem in DR as the image is less likely to be over or under exposed at relatively low or high exposures (Figure 2) (Sprawls 1987, Garmer et al. 2000).

Similar to film radiography, an image is produced in DR when energy is transmitted through a patient and detected by a sensor; the measured difference in transmission is displayed as a digital image. Each data point acquired is a transmission measurement through the patient along a given line between the source and the sensor's detector pixel (Figure 1). The transmitted radiation detected by each pixel is converted to an electrical signal and displayed on a computer screen as a greyscale, with brighter pixels detecting less transmitted radiation (Curry et al. 1990).

In the veterinary imaging industry, the most commonly used direct-conversion $\mathrm{X}$ ray image detector is an active-matrix area (AMA) or large-area flat panel detector. An AMA is composed of individual pixels, each containing a sensing element that converts the incident X-rays to a digital output signal or electric charge. Sensing elements are composed of switches, such as diodes or thin-film transistors (TFTs), and a data line to 

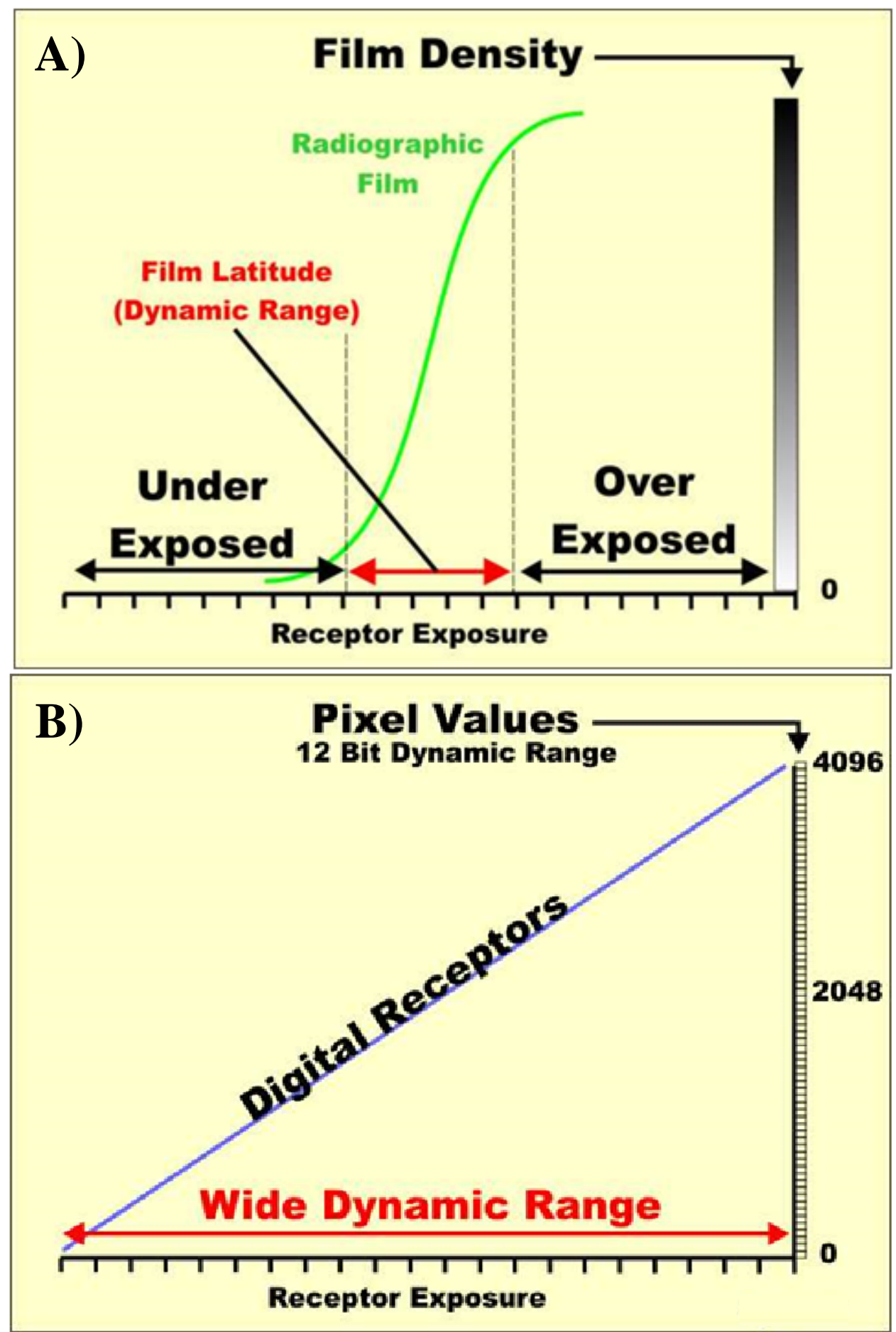

Figure 2. From Sprawls 1987, film radiography (A) has a limited dynamic range due to the silver halide in film that is easily over or under exposed at receptor exposure extremes. Digital radiography (B) provides a wide dynamic range due to the response of digital receptors to a wider range of exposures. 
the external electronics where the signal is digitized and stored. The most commonly used sensing element is composed of an amorphous silicon (a-Si) photodiode layer (Beutel et al. 2000).

The amount of radiation detected by the sensor is equal to the amount of radiation transmitted through an object and is known as optical density (OD). X-ray attenuation through a material is dependent on density, thickness, and mass attenuation coefficient of the material. The value of the mass attenuation coefficient is affected by several different mechanisms such as energy of the incident X-rays, the attenuator's atomic mass number, Rayleigh or coherent scattering, Compton or incoherent scattering, photoelectric absorption, and electron/positron pair production. The energy of the X-ray beam is dependent on exposure intensity $(\mathrm{kV})$ and time (seconds) which normally range from 40$100 \mathrm{kV}$ and $0.04-0.12$ seconds and can be set by the user. Increased exposure results in increased radiation detected by the sensor and a darker image. In medical radiography, the effects of coherent scatter and pair production are relatively insignificant as the average atomic numbers of bone and soft tissue are low (Graham and Cloke 1982, Hubbell and Seltzer 2004). When evaluating a radiograph, compact and trabecular bone have significantly larger mass attenuation coefficients than soft tissue and water and consequently are the main contributors to any change in radiographic opacity. Therefore, the amount of radiation transmitted to a detector, or the radiographic opacity, is mainly due to bone and, more specifically, bone quality, morphology, size, density and mineral content (Hubbell and Seltzer 2004). 


\subsection{Applications of Radiology}

Radiology is the most commonly used technique to assess bone quality by subjective evaluation for bone fractures, pathology, or any change from normality in bone size, shape and ossification. Radiology is used for a wide array of diagnoses, including detection of osteoporosis (Szulc 2006), cancer (Hirsch et al. 2001) and stress fractures in soldiers and athletes (Pentecost et al. 1964, Krause and Thompson 1943). DR represents the primary diagnostic tool the physician uses to diagnose skeletal injury.

In horses, the most common application of DR is in evaluation of the cause of lameness, the most important origin of loss of use for the horse (Lindner and Dingerkus 1993). Musculoskeletal injuries account for the majority of racing and training deaths in both Thoroughbreds and Quarter Horses (Johnson 1993, Estberg et al. 1993, 1996, Palmar 1986). In performance horses, fractures not due to a specific traumatic event occur often, and are considered to be fatigue or stress fractures. Pre-existing stress fractures are often seen in severe pelvic, scapular, humeral and tibial fractures (Stover et al. 1991, 1993, Johnson 1993, Johnson et al. 1994). Microfractures and stress fractures can be caused by normal physiological strain if stress is repetitive or applied in a different plane than normal, or by physiological strain beyond the normal limits (Nielsen et al. 1997). In 1990, Frost theorized that if enough micro-damage occurs cortical bone remodeling will be triggered. Despite many studies that have been conducted to determine risk factors associated with stress fractures in performance horses, even today, there exists relatively little insight into the prevention of these performance related injuries.

According to Wolff's law, bone is a dynamic tissue that changes depending on the stresses placed upon it. Bones of both juvenile and mature horses are adapted by 
modeling when overloaded (Jones et al. 1977, Goodship et al. 1979, Woo et al. 1981, Bloomfield 1995, Lanyon 1984, Meade et al. 1984, Rubin and Lanyon 1984, 1985, Burr et al. 1989). Remodeling due to increased strain occurs via increased deposition of bone on the periosteal surface (Goodship et al. 1979) and also by decreased resorption of bone from the endosteal surface (Jones et al. 1977, Woo et al. 1981). Bones that are underloaded are remodeled to decrease the amount of bone present such as occurs in astronauts during space flight (Cavolina et al. 1997), cases of disuse (Lanyon 1984, Rubin and Lanyon 1984, 1985, Skerry and Lanyon 1995, Thomas et al. 1996) and during deconditioning (Porr et al. 1998).

One of the most commonly radiographed bones in the racehorse is the third metacarpal bone. The third metacarpal has a high frequency for fracture and is the site where dorsal metacarpal disease, or bucked shins, occurs (Stover et al. 1992). In the United States during 1992, $0.32 \%$ of Thoroughbred 2 year olds suffered an injury (Wilson et al. 1996), five of the injuries were diagnosed as bucked shins and another 7 of the total 57 reported were fractures of the third metacarpal. Nunamaker et al. in 1990 reported that fatigue fracture of the third metacarpal occurs in $70 \%$ of Thoroughbred racehorses within their first year of racing. Increased bone density associated with training has been known to be a factor improving stress-bearing characteristics and preventing or delaying structural damage of bone (Raub et al. 1989, Carter 1987). The third metacarpal of the horse has been shown to increase in average mass, cortical thickness, diameter and structural strength due to increased exercise (Forwood and Parker 1986, Carter 1982, Jeffcott et al. 1999, Smith et al. 1985, Williams et al. 1984, Welch 1999). Further, the third metacarpal has been shown to experience changes in bone mineral density (BMD) related to exercise in juvenile racehorses (McCarthy and Jeffcott 
1992, Nielsen et al. 1997, Porr et al. 1998, 2000). Change in the size and shape of the bone as well as increasing the BMD should result in decreased strain placed upon that bone by stress (Carter 1984). The third metacarpal bone reaches skeletal maturity at a relatively young age, is easily accessible via radiography, has very little associated soft tissue and is frequently injured, making it an obvious choice for elucidation of variables associated with calibration of bone density and OD. 


\subsection{Determination of Bone Characteristics}

The structural unit of compact bone is called the osteon or Haversian system. Each osteon is an elongated cylinder oriented along the long axis of the bone which group together to form lamella. Collagen fibers in a lamella are able to withstand mechanical stress and attribute to bone strength. Collagen and other organic material makes up $1 / 3$ of the matrix, and contribute to the structure, flexibility and tensile strength of bone. The inorganic components consist of hydroxyapatites the majority which is calcium phosphate. Hydroxyapatites account for bone hardness and are the major contributors to bone density (Ensminger 1994).

A typical long bone consists of a cortex or a dense outer layer and an inner medulla. A long bone has a shaft or a diaphysis in the middle region and each end is expanded into a region termed the epiphysis. The diaphysis consists of cortical or compact bone containing the Haversian system and a hollow middle called the medullary cavity which is filled with marrow. The epiphyses are composed largely of trabecular or spongy bone. At the diaphysis, there is cortical bone surrounding bone marrow, and very little associated soft tissue (Figure 3).

Characteristics of bone such as mass, density, size, and molecular makeup can easily be measured through basic laboratory techniques. Clinically, it is not practical to biopsy bone to evaluate simple morphology, as it is a painful procedure with associated risks. Further, it does not give insight into the entire structure of the bone. Therefore, several techniques have been investigated to evaluate bone morphology in vivo. These include DR, allowing a clinician can evaluate bone size and shape and identify areas of decreased or increased opacification. 


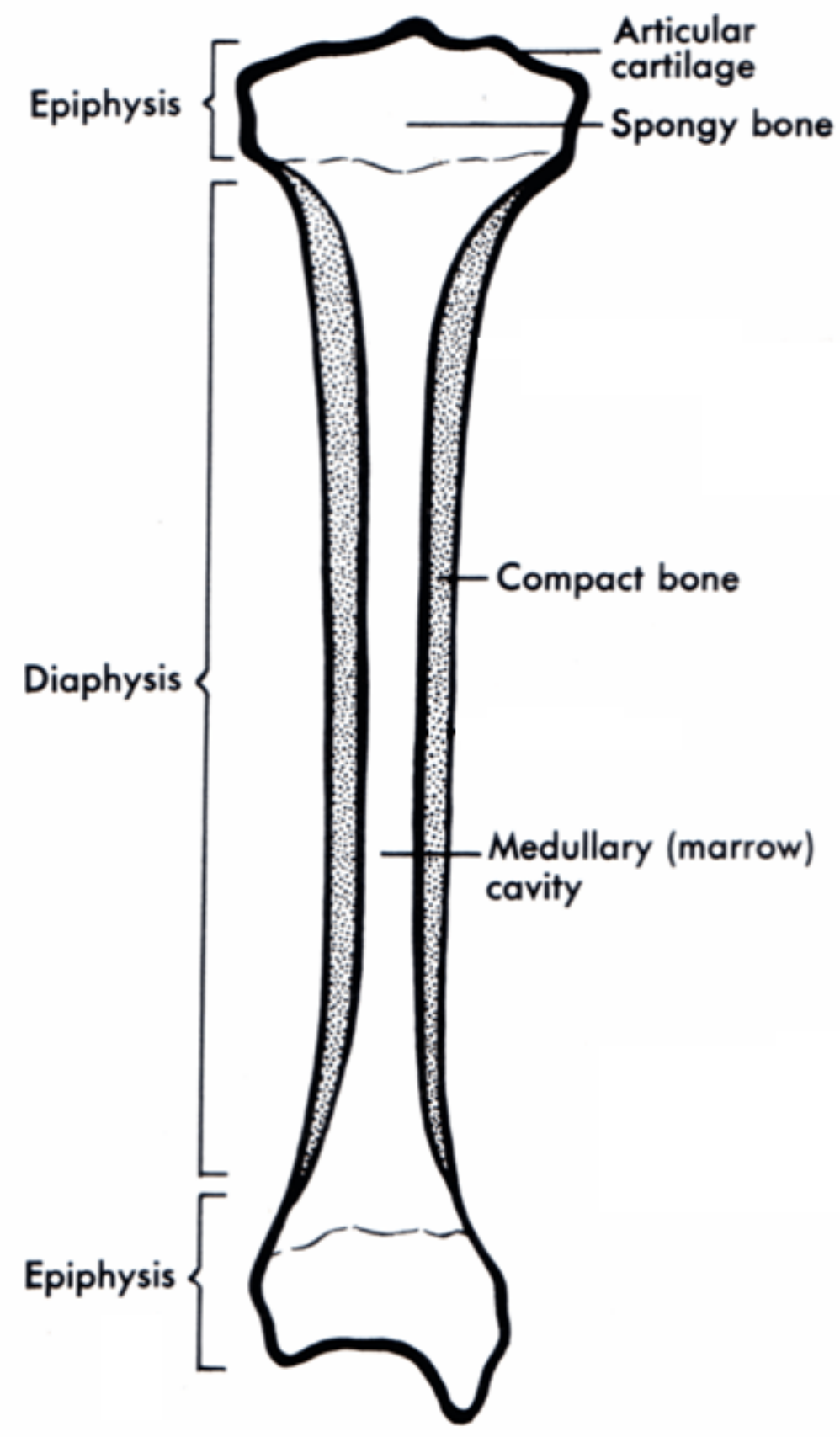

Figure 3. A longitudinal cross-section of a typical long bone, containing a middle shaft or diaphysis and expanded ends or epiphyses. At the diaphysis, there is cortical or compact bone surrounding bone marrow. From Arthur's Medical Clipart 2009. 
More advanced techniques including quantitative ultrasound, computed tomography and MRI aid in assessing bone modalities such as stiffness (Moris et al. 1995), 3D bone structure and micro-architecture (Feldkamp et al. 1989), change in bone geometry due to exercise (Daly et al. 2004), and BMD (Chappard et al. 1997). However, these methods are limiting as the clinician can only make a subjective appraisal of bone quality and comparison of images is difficult when taken with different techniques such as exposure setting, focal distance and equipment, or taken overtime.

True bone density can be measured by determination of bone weight and volume. Compact bone has a measured density of $1.85 \mathrm{~g} / \mathrm{cm}^{3}$, accurate to the $\mu \mathrm{g} / \mathrm{cm}^{3}$. Trabecular bone density ranges from 0.2 to $0.6 \mathrm{~g} / \mathrm{cm}^{3}$ while soft tissue has the same density as water at $1.00 \mathrm{~g} / \mathrm{cm}^{3}$ (Berger et al. 2000). However, it is unpractical to use this method to measure bone density in vivo and alternate techniques have been developed that are good indicators of bone density. Ex vivo, studies report an increase in bone ash weight $(\mathrm{g} / \mathrm{cc})$ or percent bone mineralization during periods of bone growth (Hammett 1925), and decrease with increased age (Leichter et al. 1981, Riggs et al. 1981). Weaver and Chalmers 1966 and Bell et al. 1967 demonstrated a significant correlation between compressive strength and ash weight. However, the use of ash weight as a significant predictor for bone density and strength may be affected by the method of bone preservation, drying, and testing techniques (Sedlin 1965, Sedlin and Hirsch 1966, Walmsley 1953).

Methods for measurement of BMD in vivo would eliminate these sampling effects, and today BMD is most commonly measured using DEXA (Chappard et al. 1997, Larcos and Wahner 1991). With DEXA, BMD is quantified in units of $\mathrm{g} / \mathrm{cm}^{2}$, and many 
studies acknowledge the confounding effect of bone size on BMD measurements (Raub et al. 1989). In humans, DEXA is the medical standard for evaluation of osteoporosis. BMD results are considered normal or abnormal after comparison to a national average, and error occurs with use of different DEXA machinery and radiographic technique (Bonnick 2010, Hui et al. 1997, Krølner and Pors Neilsen 1982). Although DEXA is the standard assessment in humans, it is expensive and not mobile, and therefore is not used at near the frequency as DR to assess bone quality in animals. 


\subsection{Calibration of Digital Radiographs}

To make accurate dimensional and complex measurements, the method of medical imaging needs to be calibrated. With the frequency and ease of use with DR, radiography is an ideal method for digital imaging standardization. For the veterinarian, DR offers a compact, portable method to evaluate bone quality. As bone characteristics and opacification is often subjectively compared to assess bone structure abnormalities and pathology, quantitative assessment of various aspects of bone morphology via radiography would be extremely valuable.

Many methods have successfully generated basic dimensional measurements from a radiograph by scaling the image to an object of known size, allowing for reproducible radiographic measurements equivalent to actual size (Kummer et al. 2004, Rocha et al. 2004, White et al. 2008). This is accomplished by insertion of a marker of known dimensions into the radiograph in plane with the patient, affording quantitative analysis of many variables such as bone displacement, vascular canal diameter, and bone thickness (Linford et al. 1993, Craig et al. 2001, Rocha et al. 2004, Raub et al. 1989). Standardized radiographic measurements have been shown to aid in morphometric analyses of the distal limb of the horse, including changes in bone size due to injury and remodeling (Raub et al. 1989), third phalanx positioning due to laminitis (Parks and O’Grady 2003) and hoof trimming (Kummer et al. 2006).

More complex calibration of digital radiographs has allowed for quantitative measurement of radiographic opacity or OD. In all photo-film techniques, OD is defined as the percentage of light transmitted through a given thickness and density of material dependent on the mass absorption coefficient of the material (Meakim et al. 1981). In 
radiography, an aluminum (Al) wedge of increasing thickness and uniform density is commonly included in a radiographic study as a comparison for OD, affording determination of bone $\mathrm{OD}$ in terms of $\mathrm{mm} \mathrm{Al}$ or radiographic bone $\mathrm{Al}$ equivalents (Meakim et al. 1981, Inoue et al. 2006, Kolbeck et al. 1999). This method is most readily applied in a research setting as each radiograph must be taken with exactly the same technique (exposure setting and focal distance). Additionally, OD is measured at regions of interest as determined by the researcher. With this system OD cannot quantitatively be compared between studies due to varying radiographic techniques.

Bone OD has been shown to be a reliable assessment of BMD when verified using DEXA, and is successful in detecting bone strength (Nielsen et al. 2007) and osteoporotic changes due to rheumatoid arthritis and osteoporosis in humans (Nagamine et al. 2000, Glüer et al. 1994), regenerative bone growth in the pig tibia (Kolbeck et al. 1999), and exercise-induced bone remodeling in the third metacarpal of young horses (Raub et al. 1989, Riggs and Boyde 1999, Jeffcott et al. 1988). BMD has been correlated with breaking load, revealing that mineral content may be an indicator of breaking strength (Nunamaker et al. 1990, Järvinen et al. 1998, Bell et al. 1967). Mineral content has also been shown to highly correlate with the elastic modulus and ultimate breaking strength in a given area of bone (Schryver 1978). However, no methods have reported quantitative assessment of bone OD, standardized for use with different digital radiology systems and exposure settings (Nagamine et al. 2000). 


\subsection{Justification for Work}

Despite the many studies that have been conducted to determine risk factors associated with stress fractures in athletes and soldiers, there exists relatively little insight into the prevention of these performance related injuries (Myburgh et al. 1990, Giladi et al. 1985). Musculoskeletal injuries occur in 50\% of soldiers in Iraq and Afghanistan and the military spends over 1.5 billion dollars annually treating and managing these injuries (USDA 2001). So common and costly are these injuries that the American Academy of Orthopedic Surgeons has provided guidelines for future research. Fundamental aspects of these recommendations include the development of a large animal model of bone injury (Pollak and Calhoun 2006). Using common digital radiography, quantitative measurements of bone quality would be valuable in a wide range of applications in the medical, military and veterinary fields by evaluation of bone integrity, fracture risk and results of performance training (Heggie et al. 2001). DR is commonly used to detect fractures in large animals and the third metacarpal bone of the horse represents an ideal model of bone fracture due to the high frequency of performance related injury. This will allow assessment of variables that indicate stress fracture risk in vivo, utilizing currently existing and practical technology.

Microfractures are known to weaken the bone, eventually leading to catastrophic failure (Schaffler et al. 1989). However, if damage can be diagnosed and allowed to repair, catastrophic failure may be delayed or prevented (Martin and Burr 1982). Among the identified risk factors of stress fracture development, decreased BMD has been correlated with stress fractures in military and civilian studies, especially in women (Lauder et al. 2000, Giladi et al. 1985, Cranney et al. 2007, Beck et al. 2001). DEXA is 
the standard technology used to diagnose osteoporosis in humans by determination of BMD at specific sites such as the second metacarpal bone, lateral spine or the femoral neck (Szulc 2006). BMD is considered low in each of these sites when compared to a national average, however, as DEXA is not standardized, BMD is dependent on the site scanned and not completely comparable between DEXA machines (Tabensky et al. 1996). Further, comparison of BMD scans to population average BMD for specific sites is not available or practical to the veterinary clinician. Unlike DEXA, DR has the advantage for veterinary clinicians of being extremely portable, relatively inexpensive, and practical in a field setting. Despite the many methods used today to evaluate bone morphology, none are used at near the frequency as DR in qualifying fractures. DR provides the clinician with portable rapid image acquisition, diagnosis, and images that can easily be stored or transferred for off-site review. However, due to the lack of standardization of digital radiographic images, an image cannot entirely be compared to another taken under different conditions such as exposure settings, positioning, and equipment. Development of a quantitative measurement for radiographic bone density using standard radiographs will be valuable to the veterinarian in assessing bone integrity, fracture risk and results of performance training (Heggie et al. 2001).

Many methods have successfully generated basic dimensional measurements from a radiograph by scaling the image to an object of known size in the radiograph, allowing for reproducible radiographic measurements equivalent to actual size (Kummer et al. 2004, Rocha et al. 2004, White et al. 2008). While simple measurements of dimension have been standardized, more complex variables such as bone density have not. Few research studies have reported quantitative assessment of bone OD by inclusion of an Al 
wedge standard, but none are practical in a non-research, clinical setting. Some authors have attempted to eliminate the confounding factor of bone size by measurement of limb circumference (Raub et al. 1989), however, there are no methods available that allow calibration for quantification of OD with different DR systems and exposure settings (Nagamine et al. 2000).

Therefore, we will develop a method to calibrate radiographs such that bone OD determined from radiographs taken under different circumstances can be directly compared among veterinary, medical, and military institutions. This will allow the clinician to compare radiographs from different patients or overtime, regardless of radiographic technique and X-ray machine. The information gained with this investigation will allow more accurate radiographic assessment of performance related injuries, including the ability to accurately interpret radiographs by a specialist thousands of miles away. We believe this will allow a more accurate prediction of bone density and hence, likelihood for stress fracture development. 


\section{INTRODUCTION}

In the first study, a novel morphometric measurement was generated to evaluate the volume of the solar aspect of the distal phalanx in the horse via radiography. Recent advances in standardized digital radiology and software development have supported accurate, quantitative, measurements of the equine digit. Furthermore, these measurements may improve treatment of distal limb lameness by providing the veterinarian with quantitative radiographic assessments of the equine digit (Rocha et al. 2004, Kummer et al. 2004, Hunt 2002, Parks and O'Grady 2003). Our objectives were to describe a novel measurement of the solar, concave aspect of the distal phalanx, termed the Palmar-Metric (PM), via simple radiographic calibration and demonstrate the manner in which the PM changes with age.

The second study contained three parts. In the first part, a quantitative measurement for radiographic bone density was developed that accurately evaluates the radiographic opacity of bone, termed the brightness/darkness index (BDI), under different exposure conditions. This method will be valuable to the veterinarian in assessing bone integrity, fracture risk and results of performance training when using a common digital radiography system (Heggie et al. 2001). By creating a standardized curve for the BDI of the bone as determined from the $\mathrm{BDI}$ along an $\mathrm{Al}$ wedge standard, and characterizing BDI as a smooth, continuous function dependent on intensity and exposure time, we can account for changes in radiographic density due to changes in exposure, affording brightness calibration of any radiograph.

In the second part, we described new analysis methods to reduce the confounding

effect of bone mass attenuation by quantification of bone $\mathrm{OD}\left(\mathrm{g} / \mathrm{cm}^{2}\right)$. In the third part, 
error in bone OD due to effects of soft tissue, bone marrow, radiographic positioning and user error was assessed. Bone OD is a better assessment of bone density than BDI, as the bone/Al mass attenuation coefficient ratio has been shown to change with radiographic exposure (Berger et al. 2000). We hypothesize that bone OD can be determined from a digital radiograph with inclusion of an Al wedge of known thickness and density and known bone/Al mass attenuation coefficient ratio (Curry et al. 1990, Carter et al. 1992). 


\section{SIMPLE RADIOGRAPHIC CALIBRATION}

\subsection{Materials and Methods}

This is one of two studies presented examining standardized digital radiographic measurements of the distal limb of the horse. This study concentrated on a novel radiographic volumetric measurement of the concave, solar aspect of the distal phalanx, termed the PM, and examined how the PM correlated with age in the horse.

\subsection{PM Quantification}

A method to determine the PM from any standard lateral medial (LM) radiograph was developed to evaluate the solar concavity of the distal phalanx. From a digital radiograph, a line we term the palmar curve was traced from the tip of the distal phalanx along the most palmar aspect of the radio-dense line to the proximal palmar aspect of the articular margin of the distal phalanx (Figure 4A,B). The PM was calculated by creating a coordinate system within the radiograph based on the palmar curve and position of the distal phalanx (Figure 4C). A reference rectangle was then constructed and the area within the rectangle defined above and below the palmar curve. The PM was expressed as a percentage of the area under the palmar curve relative to the area of the reference rectangle (Figure 4D).

\subsection{Calibration of the PM}

To confirm the predictability of solar cup volume from the PM, 65 distal phalanx cadaver bones from horses of varying age and breed were radiographed. Each cadaver bone was placed on a standardized hoof block (EponaTech), containing Al 

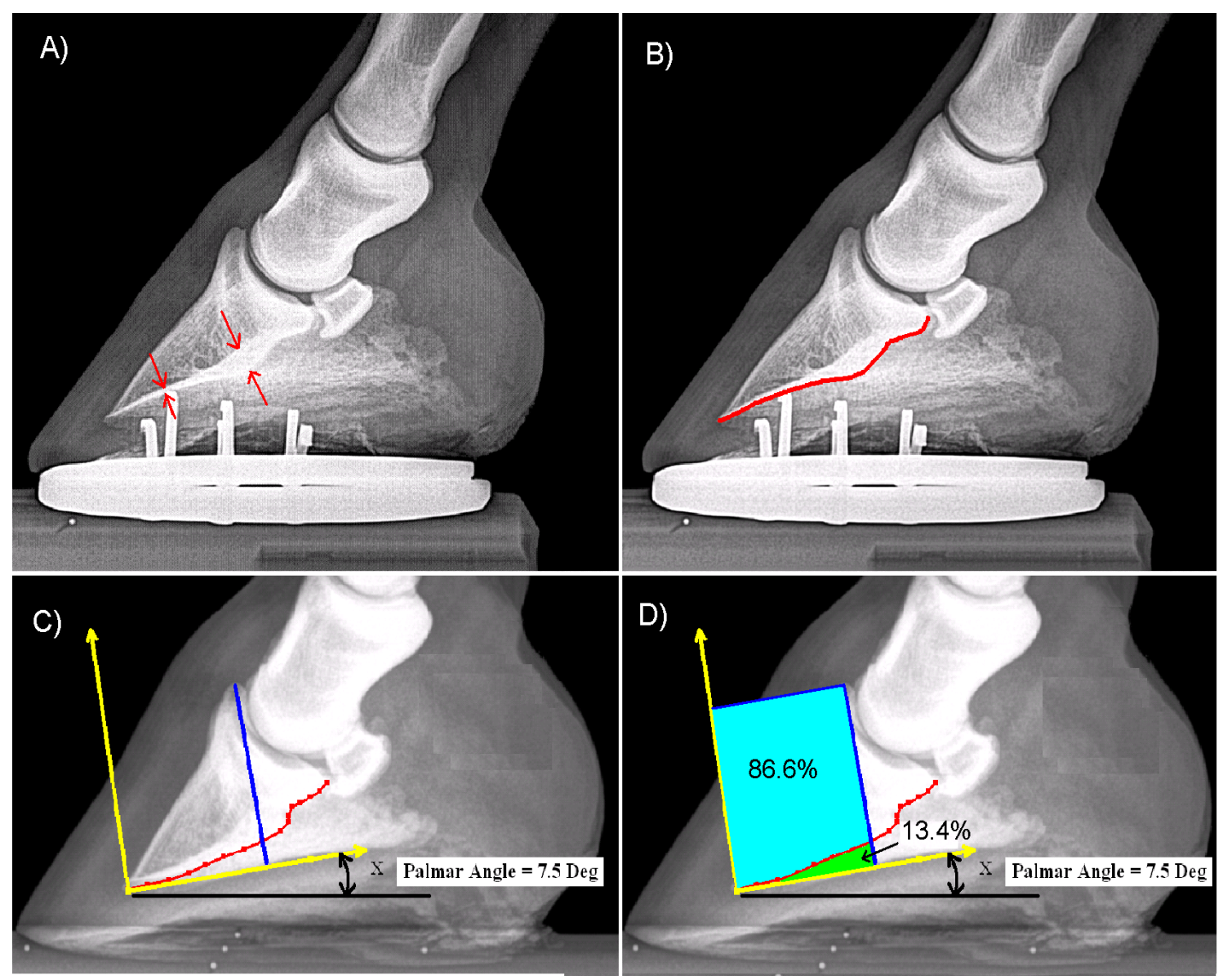

Figure 4. Determination of the PM. (A) The radio-dense line along the midline of the distal phalanx on LM radiograph indicated by red arrows. (B) The palmar curve traced with Metron on LM radiograph. (C) A coordinate system set at the tip of the distal phalanx using a line along the palmar angle and a vertical line through the extensor process. (D) The PM determined from the percent area of the reference rectangle under the palmar curve. 
markers of known length to scale the image. High quality digital LM radiographs were taken of the 65 cadaver bones and hoof block (Figure 5). The PM was determined using the method described above (Figure 6). Radiographs were taken at $65 \mathrm{kV}, 0.06$ seconds and $15 \mathrm{~mA}$ with a focal distance of 26 inches.

For each bone, physical volume of the solar concavity was measured using modeling putty by filling the solar aspect of the distal phalanx. The distal phalanx with putty was pressed onto a hoof block and excess putty was removed. The putty was cut lateral to medial at the position of the orthogonal projection of the extensor process when viewed from above (Figure 7A). The putty dorsal to this cut was removed and discarded. The remaining putty was removed and its volume was measured via water displacement (Figure 7B,C).

Additionally, third phalanx lateral toe length and lateral height were determined from digital radiographs of the 65 cadaver bones (Figure 8). Lateral height was determined as the length perpendicular to the most palmar aspect of the solar surface and intersecting the most proximal point of the extensor process. Toe length was measured from the palmar tip of lateral height to the tip of the third phalanx. Lateral toe length and height were evaluated to determine if they were significant predictors for solar cup volume.

Radiographs were taken with a portable X-ray system (Min X-ray HF80) and digital X-ray plate (Thales FS23, Vetel Diagnostics). Digital images were imported into the software program Metron-DVM (EponaTech). 


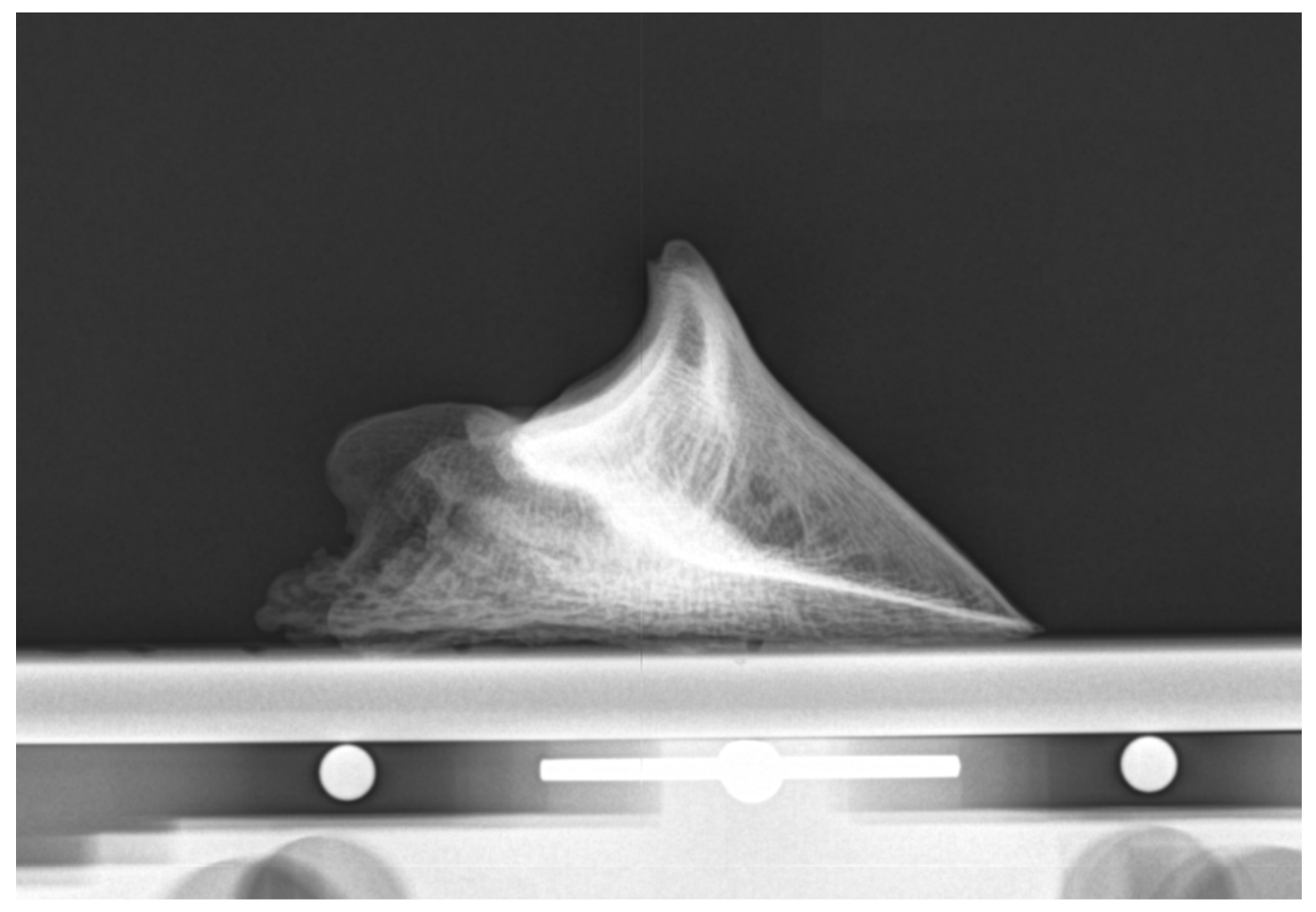

Figure 5. High quality digital lateral medial radiograph of a third phalanx cadaver bone on a standardized hoof block of known dimensions. 


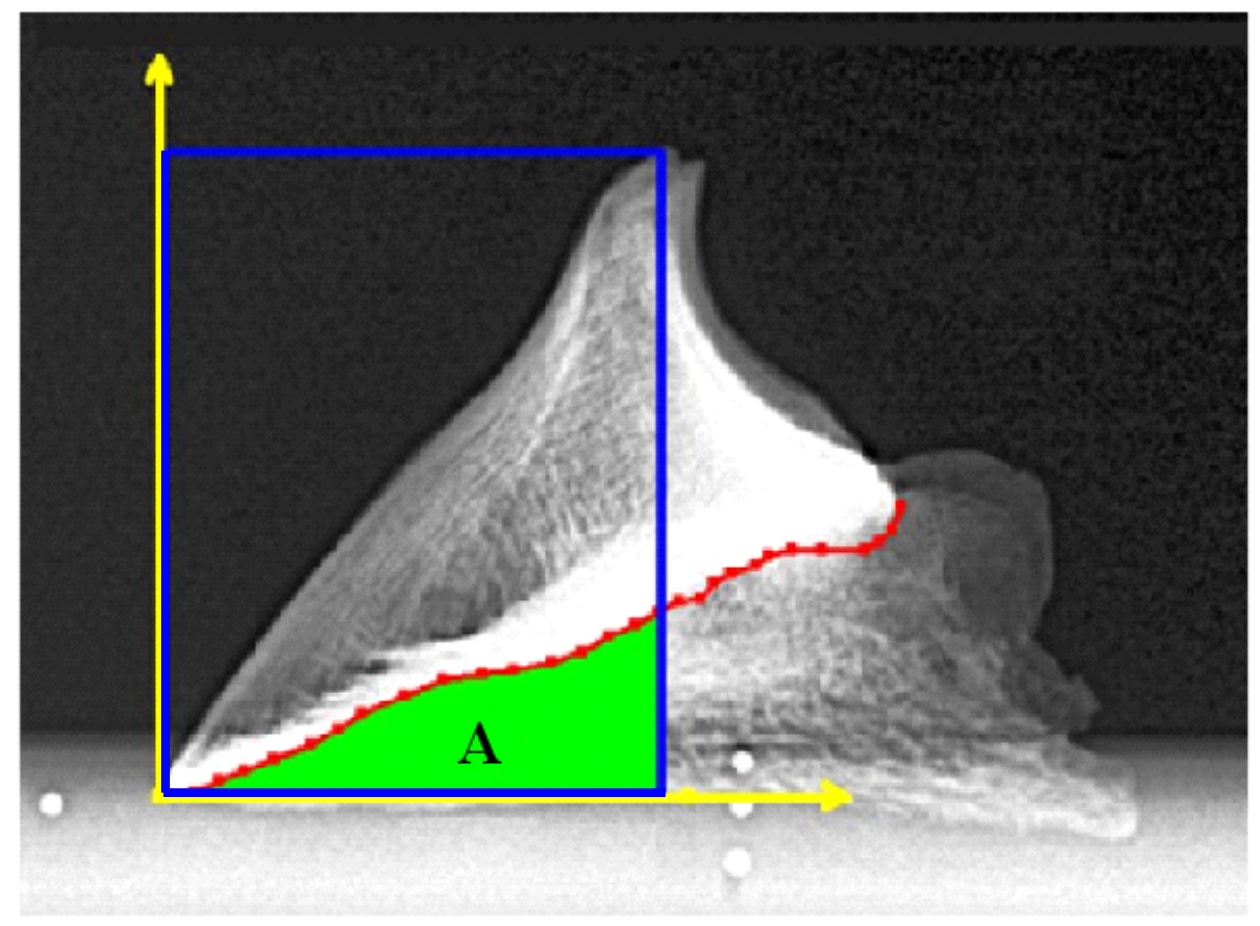

Figure 6. Measurement of the PM represented as the percent area (green) under the palmar curve (red) as compared to the reference rectangle (blue), determined from a lateral medial radiograph of a third phalanx cadaver bone. 

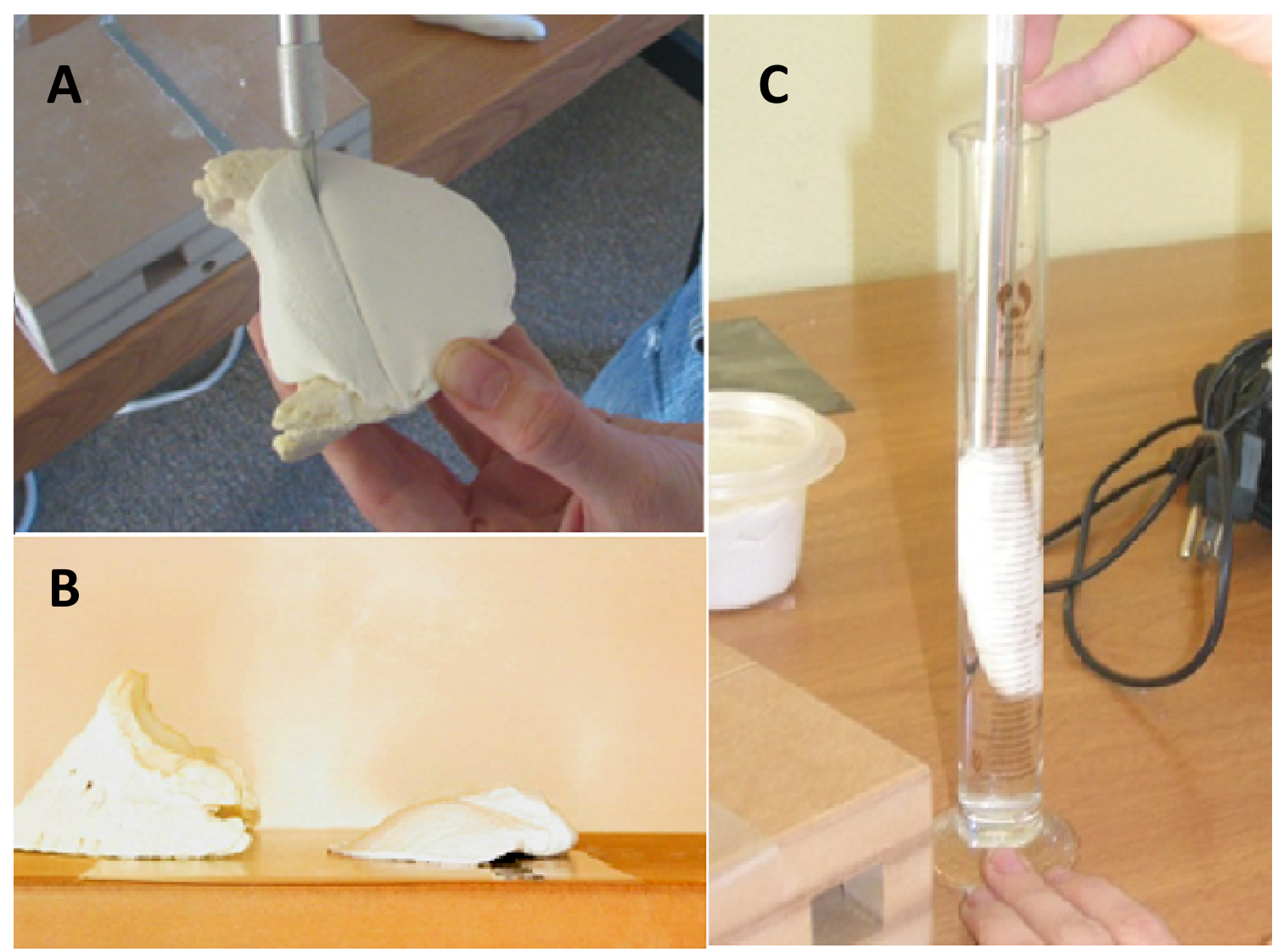

Figure 7. The solar cup volume of the distal phalanx was measured using modeling putty. The putty was cut lateral to medial at the position of the orthogonal projection of the extensor process when viewed from proximal to distal (A). The putty dorsal to this cut was removed and discarded. The remaining putty was removed (B) and its volume (cc) was measured via water displacement (C). 


\section{Height $=1.75$ in}

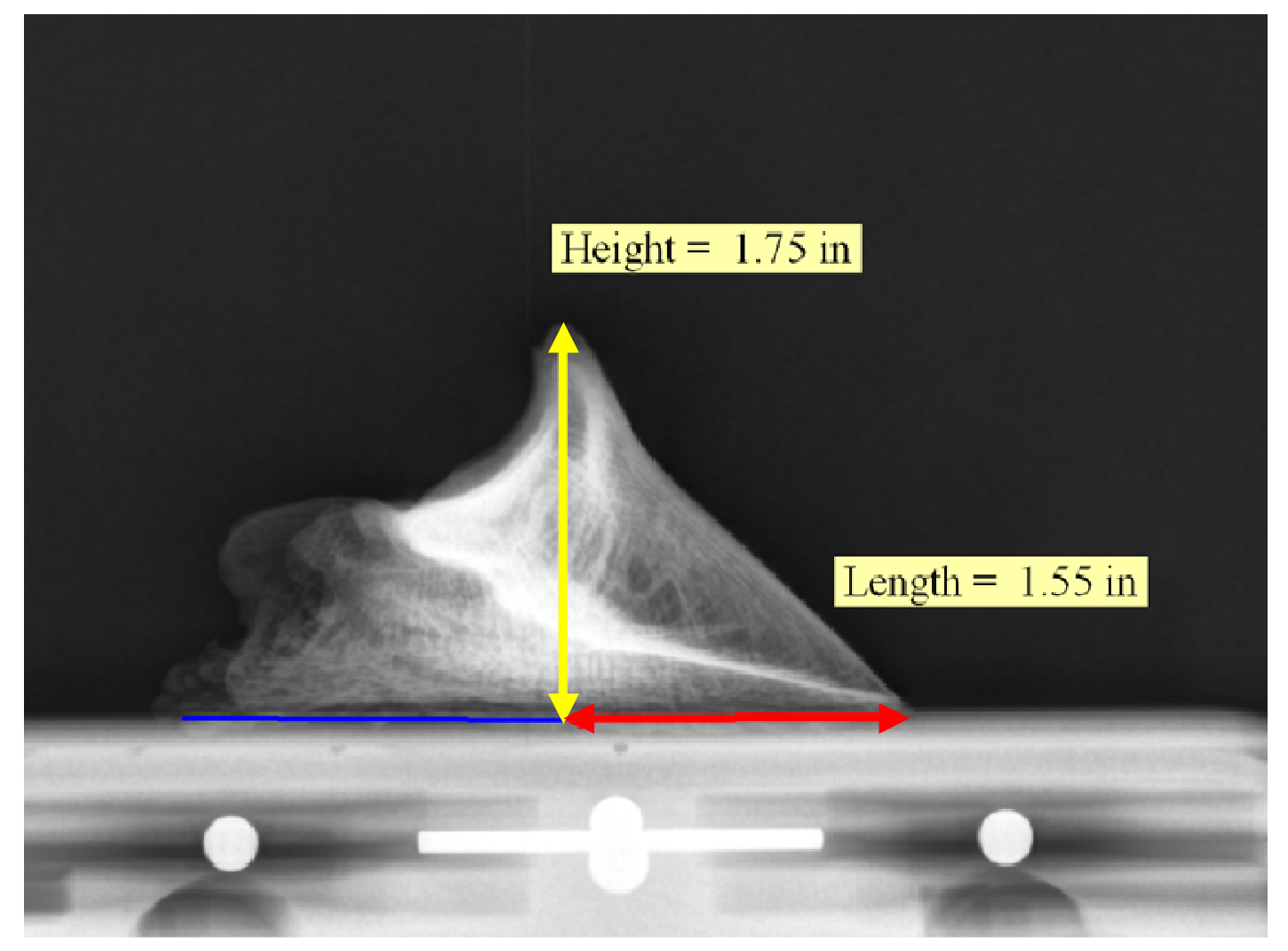

Figure 8. Measurements made from a lateral medial radiograph of a third phalanx cadaver bone. Lateral height (yellow) was determined as the length perpendicular to the solar surface (blue) and intersecting the most proximal point of the extensor process. Toe length (red) was measured from the perpendicular intersection of lateral height and solar surface to the tip of the third phalanx. 


\subsection{PM and Age}

Subsequently, three independent users determined the PM from 544 high quality LM digital radiographs of the front feet of horses (Figure 9). Radiographs were taken with the inclusion of a standardized hoof block, and were obtained from various veterinary clinics and farms for horses of known age and breed. Of the 544 radiographs, 438 (219 pairs) were right and left front feet pairs, resulting in a total of 325 horses radiographed. The average age of the 325 horses was $8.8 \pm 5.1$ years.

Radiographs were taken with various digital systems, at unknown exposure and focal distance, depending on the veterinarian's discretion. Digital images were imported into the software program Metron-DVM (EponaTech).

\subsection{PM Precision}

Changes in PM with radiographic positioning along three directional axes and with rotation around each axis were assessed. The PM was determined from a third phalanx cadaver bone that was displaced from normal up to $9 \mathrm{~cm}$ in all directions along a 3D coordinate system. Additionally, the cadaver bone was rotated from normal along all three directions of rotation, up to 12 degrees from normal (Figure 10). Level of precision errors (SD) and coefficient of variation (CV) was assessed by measuring the PM by four different users, as described by Glüer et al. (1995). Each user independently determined the PM for 50 different standard LM distal limb radiographs, duplicating the measurement after a two week time interval. For comparison, one user was considered an expert. 


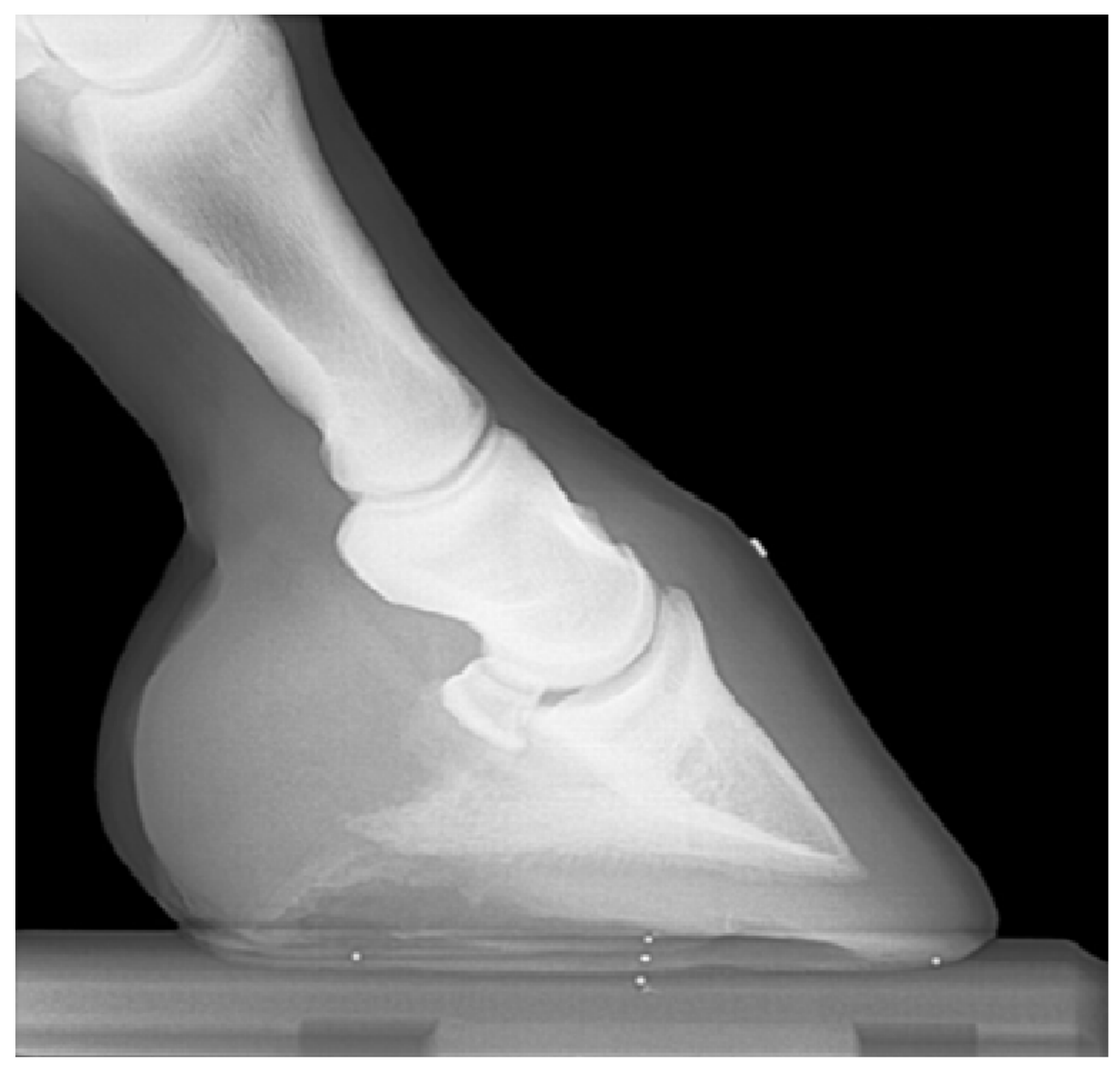

Figure 9. Standard high quality lateral medial radiograph of the distal limb of the horse on a standardized hoof block containing Al markers of known dimensions. 


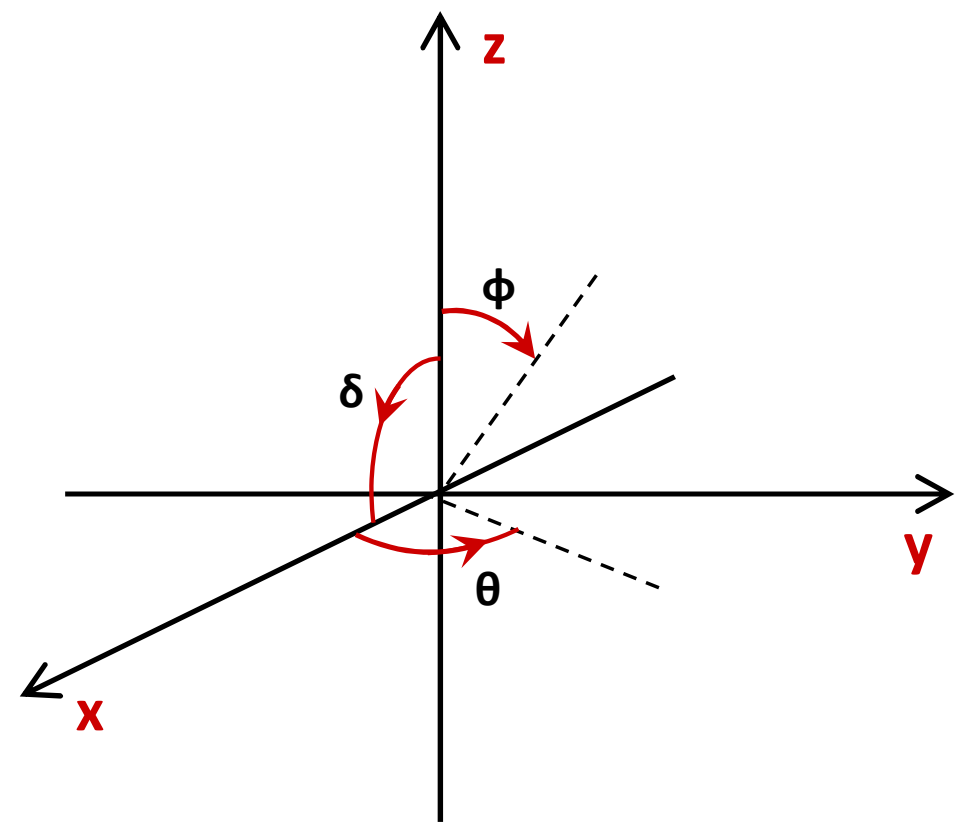

Figure 10. Coordinates for radiographic rotational and positional errors, with angle $\varphi$ representing a rotation about the $\mathrm{x}$-axis, angle $\delta$ representing a rotation about the $y$-axis, and angle $\theta$ representing a rotation about the $\mathrm{z}$-axis. The digital sensor plate was positioned in the $y, z$-plane. 


\subsection{Statistical Analysis}

Linear regression was used to assess the relationship between PM and solar cup volume for the 65 cadaver bones. Of the 544 LM radiographs, 219 left and right pairs were analyzed for differences between left and right PM versus age by comparing slopes using a two sample paired $t$-test. Linear correlation was used to assess the relationship of age, lateral height, toe length and radiographic positioning on PM. All statistical tests were performed using Minitab and were based on a 2-sided null hypothesis of no difference and a level of significance set at 0.05 .

\subsection{Results}

Calibration of the PM was performed via determination of solar cup volume and PM for 65 distal phalanx cadaver bones. Solar cup volume is shown to be a statistically significant predictor of the PM $(t(63)=26.64, p<0.001$, Figure 11). Furthermore, 91.9 $\%$ of the variability in the PM is explained by the regression relationship between PM and solar cup volume $\left(r^{2}=0.9185\right)$. PM increases as lateral height increases $\left(r^{2}=0.668\right.$, $t(63)=11.07, p<0.001)$ and toe length increases $\left(r^{2}=0.684, t(63)=11.483, p<0.001\right)$. Both lateral height and toe length are significant predictors of PM, however, less variability is explained with height or toe length (Figure 12).

From 544 distal limb radiographs, the PM was determined for each age group dependent on left or right front foot (Table 1). Mean $\mathrm{PM} \pm \mathrm{SD}$ and mean age \pm SD from all radiographs in the study was $7.55 \pm 2.70 \%$ and $8.83 \pm 5.13$ years. The slopes of the 


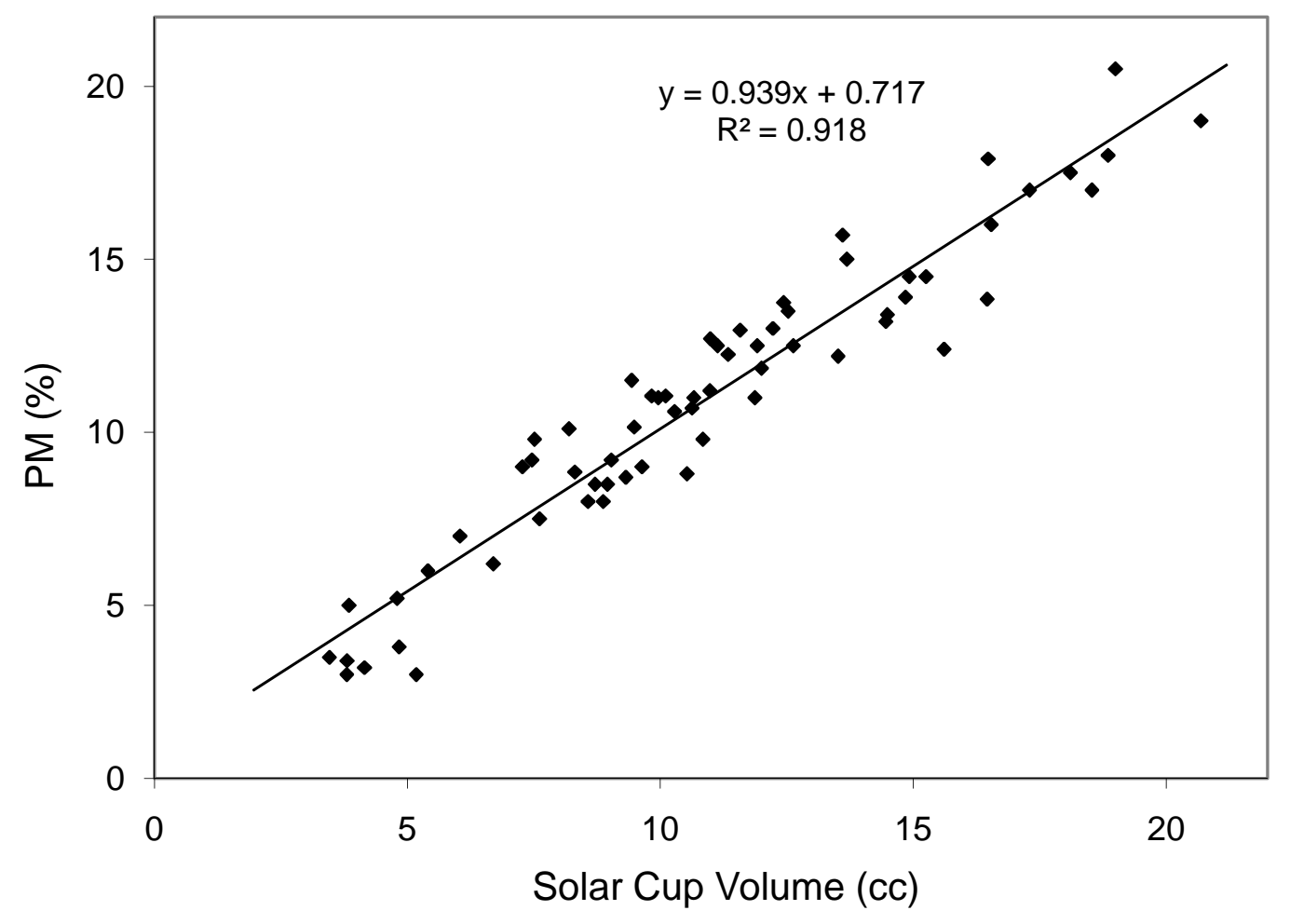

Figure 11. Experimentally measured solar cup volume versus PM, determined from standard lateral medial radiographs of 65 distal phalanx cadaver bones $(t(63)=24.32, p<$ $\left.0.001, r^{2}=0.918\right)$. 

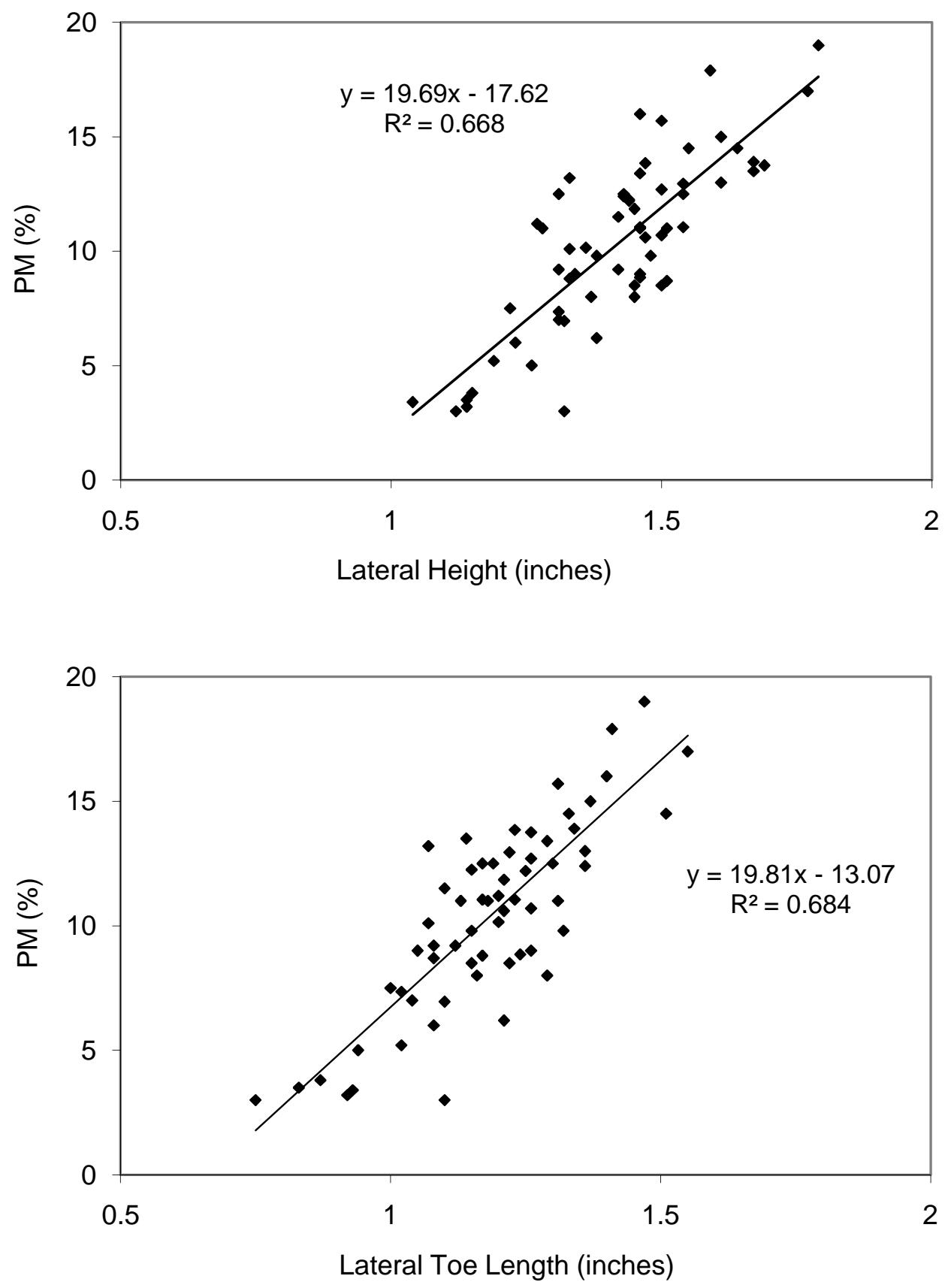

Figure 12. PM versus third phalanx lateral height (top) and toe length (bottom), determined from lateral medial radiographs of 65 third phalanx cadaver bones $(p<0.001)$ 


\begin{tabular}{|c|c|c|c|c|}
\hline \multirow[b]{2}{*}{ Age (years) } & \multirow[b]{2}{*}{$N$} & \multicolumn{3}{|c|}{ Mean Palmar-Metric $\pm S D(\%)$} \\
\hline & & Left $(N=219)$ & Right $(N=219)$ & Averaged $(N=438)$ \\
\hline 1 & 3 & $8.18 \pm 0.78$ & $9.53 \pm 0.59$ & $8.76 \pm 1.44$ \\
\hline 2 & 12 & $8.94 \pm 0.67$ & $9.41 \pm 0.54$ & $9.15 \pm 2.56$ \\
\hline 3 & 21 & $9.74 \pm 0.51$ & $10.12 \pm 0.40$ & $9.94 \pm 2.33$ \\
\hline 4 & 14 & $8.71 \pm 0.53$ & $8.85 \pm 0.59$ & $8.77 \pm 2.40$ \\
\hline 5 & 18 & $9.35 \pm 0.62$ & $8.85 \pm 0.45$ & $9.10 \pm 2.41$ \\
\hline 6 & 14 & $8.50 \pm 0.46$ & $9.29 \pm 0.51$ & $8.86 \pm 2.10$ \\
\hline 7 & 17 & $7.49 \pm 0.50$ & $7.33 \pm 0.43$ & $7.42 \pm 2.21$ \\
\hline 8 & 13 & $6.15 \pm 0.66$ & $6.55 \pm 0.51$ & $6.36 \pm 2.37$ \\
\hline 9 & 12 & $7.25 \pm 0.34$ & $8.22 \pm 0.38$ & $7.78 \pm 1.47$ \\
\hline 10 & 14 & $6.76 \pm 0.51$ & $6.96 \pm 0.48$ & $6.85 \pm 2.09$ \\
\hline 11 & 13 & $6.75 \pm 0.63$ & $7.29 \pm 0.59$ & $7.04 \pm 2.50$ \\
\hline 12 & 12 & $6.70 \pm 0.68$ & $6.77 \pm 0.57$ & $6.74 \pm 2.45$ \\
\hline 13 & 8 & $6.60 \pm 0.64$ & $6.54 \pm 0.65$ & $6.57 \pm 2.07$ \\
\hline 14 & 11 & $6.57 \pm 0.66$ & $6.48 \pm 0.65$ & $6.53 \pm 2.13$ \\
\hline 15 & 5 & $4.73 \pm 0.70$ & $5.18 \pm 0.16$ & $4.93 \pm 1.26$ \\
\hline 16 & 13 & $5.00 \pm 0.66$ & $5.60 \pm 0.87$ & $5.30 \pm 2.75$ \\
\hline 17 & 7 & $7.28 \pm 0.49$ & $6.99 \pm 0.68$ & $7.14 \pm 1.64$ \\
\hline 18 & 4 & $4.41 \pm 0.96$ & $3.06 \pm 0.60$ & $3.81 \pm 1.82$ \\
\hline 20 & 3 & $4.04 \pm 0.66$ & $3.95 \pm 1.22$ & $4.01 \pm 1.59$ \\
\hline 21 & 2 & $3.99 \pm 0.70$ & $4.73 \pm 1.80$ & $4.24 \pm 1.62$ \\
\hline 22 & 1 & 3.22 & 3.70 & $3.46 \pm 0.34$ \\
\hline 23 & 1 & 4.21 & 4.58 & $4.39 \pm 0.26$ \\
\hline 26 & 1 & 3.68 & 5.15 & $4.42 \pm 1.04$ \\
\hline
\end{tabular}

Table 1. Mean PM and standard deviation $(S D)$ by age for the left and right front feet and the left and right front feet average for 219 horses of various breed. There were no significant difference in PM between left and right front feet $(p>0.05)$ as determined with a two sample $t$-test. 
regression lines for PM and age for left $(-0.27 \pm 0.03 \%$ per year $)$ and right $(-0.29 \pm 0.03$ $\%$ per year) front feet were not significantly different from each other $(t(217)=-0.676, p$ $=0.75$, Figure 13). The PM for left and right front feet was averaged to obtain one PM value for each horse. There was strong evidence that the age of the horse was a significant predictor for PM, and decreased at a rate of $0.28 \pm 0.02 \%$ per year $\left(r^{2}=0.33\right.$, $t(217)=-10.4, p<0.001$, Figure 14).

Error in PM due to radiographic positioning was assessed in three linear and three rotational directions. There was no statistical radiographic positioning error in PM associated with the three linear directions and the three directions of rotation up to an 11 degree rotation from normal $(p>0.05$, Table 2$)$. Determination of the PM varied by user and ranged from CV $0.67-23.2 \%$ and SD $0.05-1.35$ (Table 3). For all users, SD was determined to be 1.13 and $\mathrm{CV}$ was $12.14 \%$. 


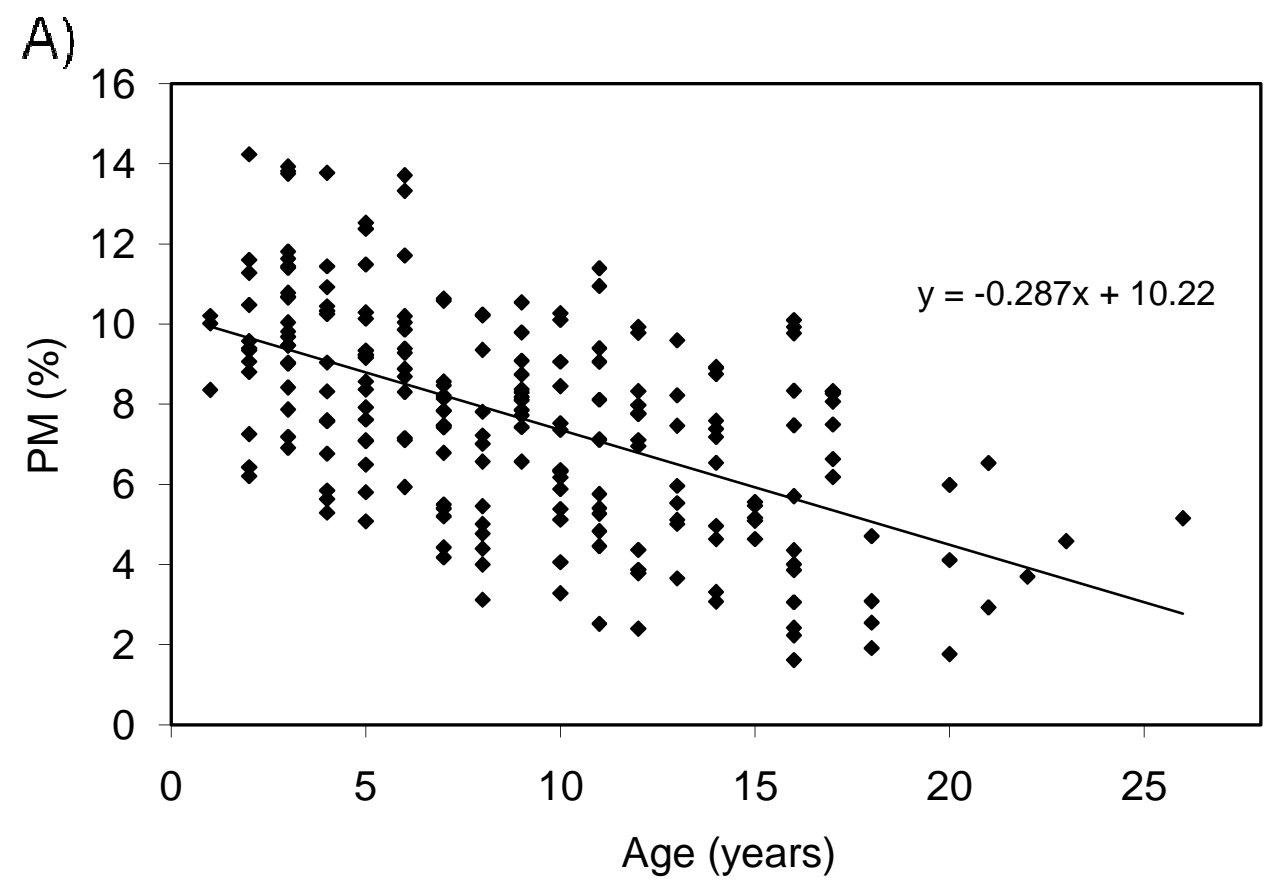

B)

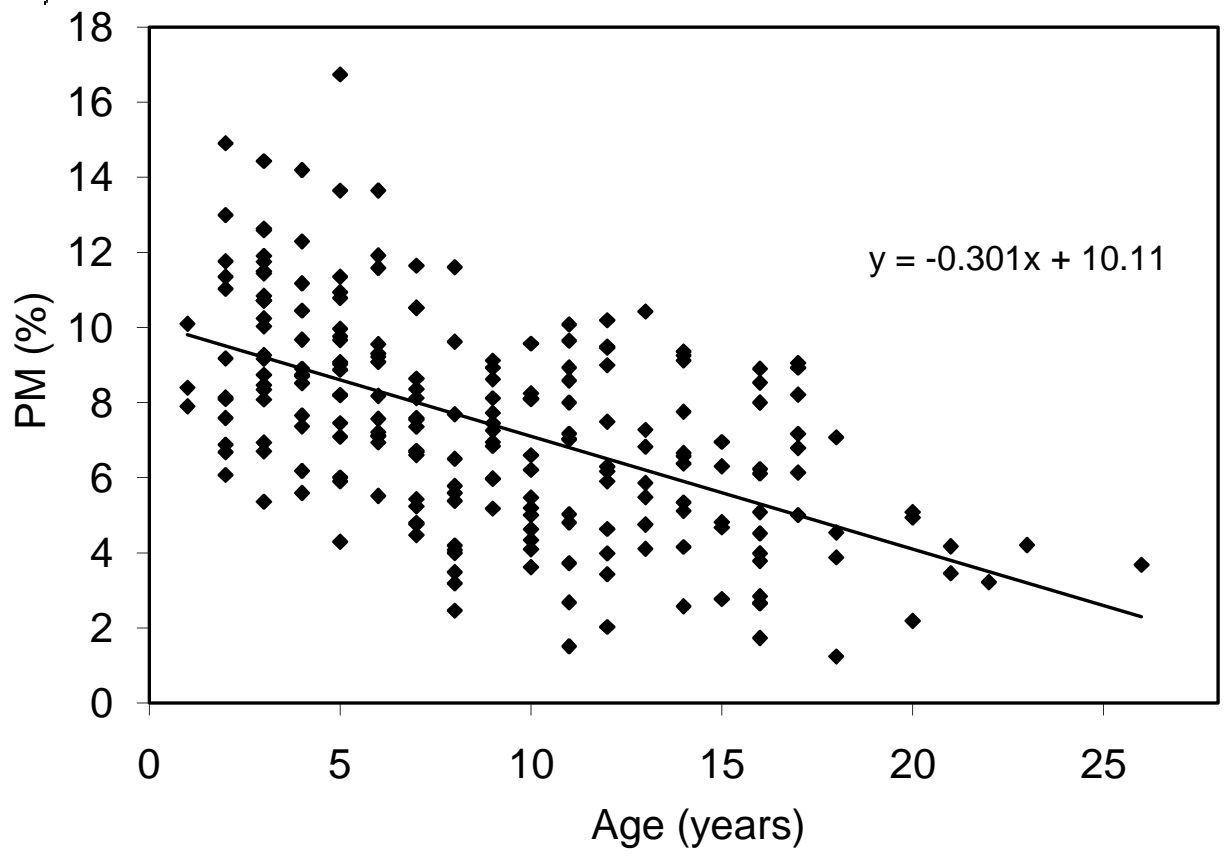

Figure 13. PM versus age for 219 left $(\mathrm{A}, t(217)=-9.78, p<0.001)$ and 219 right $(\mathrm{B}$, $t(217)=-9.85, p<0.001)$ front feet of various breed horses. The slopes of the two regression lines do not differ significantly $(t(217)=-0.676, p=0.75)$. 

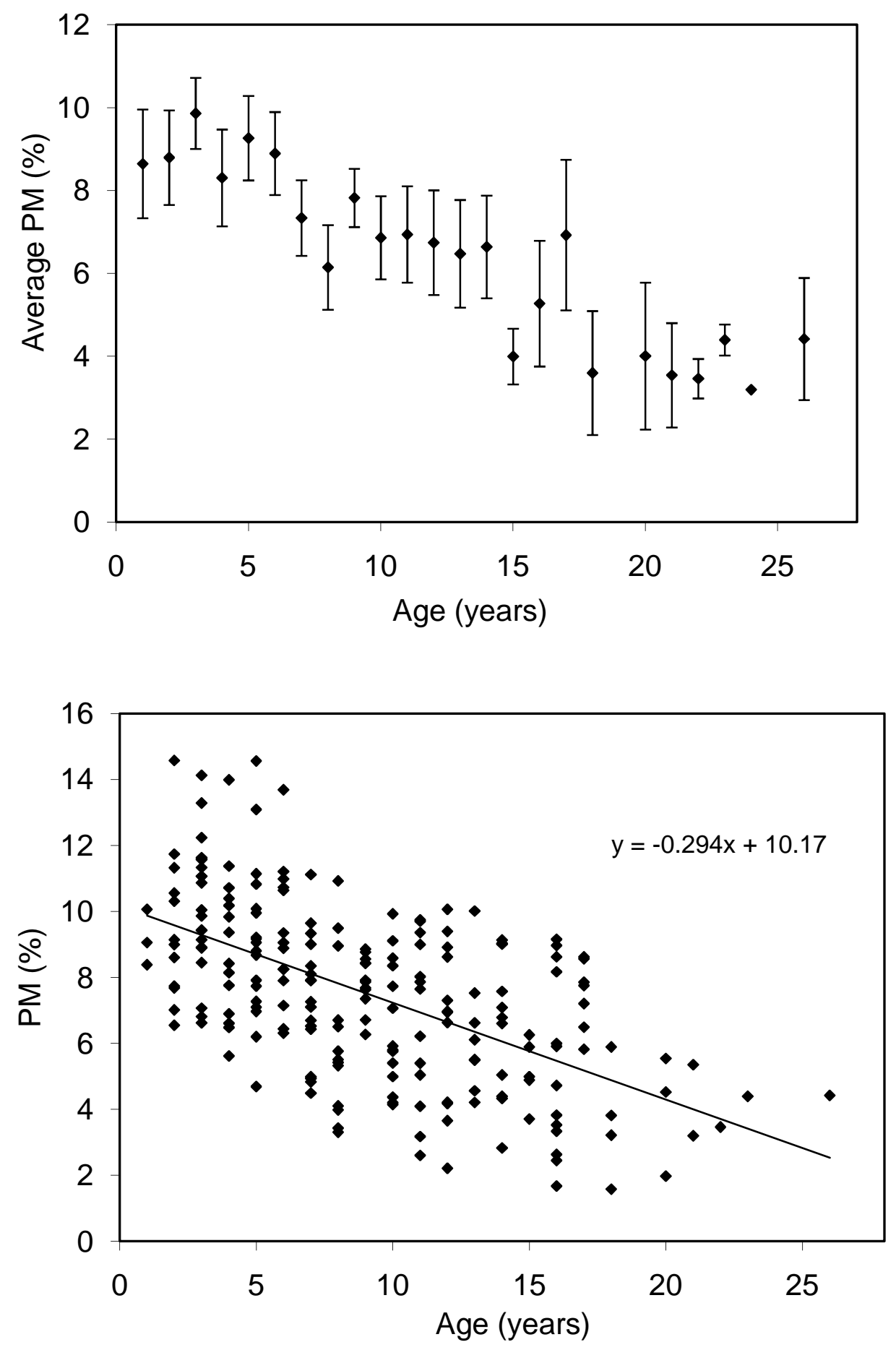

Figure 14. Average PM (top) and PM (bottom) versus age for 219 horses of various breeds. PM decreased at a rate of $0.294 \%$ per year $(t(217)=-10.4, p<0.001)$. 


\begin{tabular}{lccc}
\hline Direction & $d f$ & $P M \pm S D$ & $p$ \\
\hline $\mathrm{x}$ & 12 & $11.24 \pm 0.27$ & 0.301 \\
$\mathrm{y}$ & 12 & $11.13 \pm 0.27$ & 0.901 \\
$\mathrm{z}$ & 27 & $10.70 \pm 0.89$ & 0.100 \\
$\varphi$ & 18 & $10.82 \pm 0.39$ & 0.891 \\
$\delta$ & 30 & $10.60 \pm 0.05$ & 0.095 \\
$\rho$ & 21 & $11.07 \pm 0.36$ & 0.203 \\
\hline
\end{tabular}

Table 2. PM and standard deviation $(S D)$ dependent on radiographic positioning in three linear directions $(\mathrm{x}, \mathrm{y}$, and $\mathrm{z})$ and three directions of rotation $(\varphi, \delta$, and $\rho)$. Significant $P$ values indicate that the mean PM is different from the PM measured at zero displacement from normal. 


\begin{tabular}{lccc}
\hline User & $d f$ & $S D$ & $C V(\%)$ \\
\hline 1 & 50 & 1.23 & 22.62 \\
2 & 50 & 0.79 & 11.07 \\
3 & 50 & 1.35 & 23.20 \\
4 & 50 & 0.05 & 0.67 \\
All & 350 & 1.13 & 21.97 \\
\hline
\end{tabular}

Table 3. PM levels of precision errors $(S D)$ and coefficients of variation $(C V)$ determined for two repeat observations of 50 lateral medial radiographs of the distal phalanx. User 4 is considered an expert. 


\section{Complex Radiographic Calibration}

\subsection{Materials and Methods}

This is the second study examining standardized radiographic measurements in the distal limb of the horse. This study contained three parts: the first part concentrated on calibration of BDI in the third metacarpal of the horse over different exposure ranges, the second part concentrated on measurement of bone OD via digital radiographs, and the third part concentrated on error associated with the measurement of bone OD due to effects of soft tissue, radiographic positioning and user error.

\subsection{Determining BDI}

BDI was evaluated in the same manner in all instances. First, digital radiographs were imported into the software program Metron-DVM (EponaTech). To determine BDI a unit-less value was assigned to each 16 bit pixel on a greyscale from 0 to 65,535 , with zero being completely black and 65,000 being completely white. A predetermined area or region of interest was generated by forming a rectangle using the software program Metron-DVM. The BDI for the area is determined by averaging the greyscale value of each pixel in the area, using Excel (Microsoft). In determining BDI pixels with BDI equal to the BDI of the background were not included.

\subsection{Radiographic Method}

Each radiograph contained an Auto-Scaler (EponaTech) and Al wedge. The Al wedge was machined from type $6061 \mathrm{Al}$ and was $20.20 \mathrm{~cm}$ in length, $2.54 \mathrm{~cm}$ in width and increased linearly from 0.20 to $31.80 \mathrm{~mm}$ in thickness, with a constant density of 
$2.70 \mathrm{~g} / \mathrm{cm}^{3}$. The Auto-Scaler contained metal markers that standardized the dimensions of the radiograph when imported into Metron. All radiographs were taken with a portable Xray system (Min X-ray HF80 or HF100+) and X-ray sensor (Canon CXDI 60G, Vetel Diagnostics).

\subsection{BDI at Varying Radiographic Exposures}

As the BDI of a region of interest decreases with increasing X-ray exposure, the nature of this effect on both cortical bone and an $\mathrm{Al}$ standard needed to be evaluated to correctly assess cortical bone BDI at varying radiographic exposure settings. A third metacarpal equine cadaver bone was placed on a wooden block with Al wedge and AutoScaler. The cadaver bone was positioned perpendicular to the ground in the center of the line of exposure with the Al wedge and Auto-Scaler positioned on either side. The bone was placed to produce a standard dorsal palmar (DP) radiograph (Figure 15). The focal distance was 26 inches, with the plane of interest containing the cadaver bone, Al wedge, and Auto-Scaler positioned against the face of the sensor. Radiographs were taken at all available combinations of pre-set exposure intensities ranging from 55 to $80 \mathrm{kV}$ with 5 $\mathrm{kV}$ intervals, and exposure times from 0.02 to 0.14 seconds every 0.02 seconds. All radiographs were taken at $15 \mathrm{~mA}$, the only setting available for the $\mathrm{X}$-ray source.

The BDI of the Al wedge and of the cadaver bone was measured on each radiograph. The Al BDI was measured by creating a rectangle encompassing the entire wedge. The bone BDI was determined from a region of interest with a width larger than the cross-sectional width of the bone perpendicular to the sagittal plane, and a height 


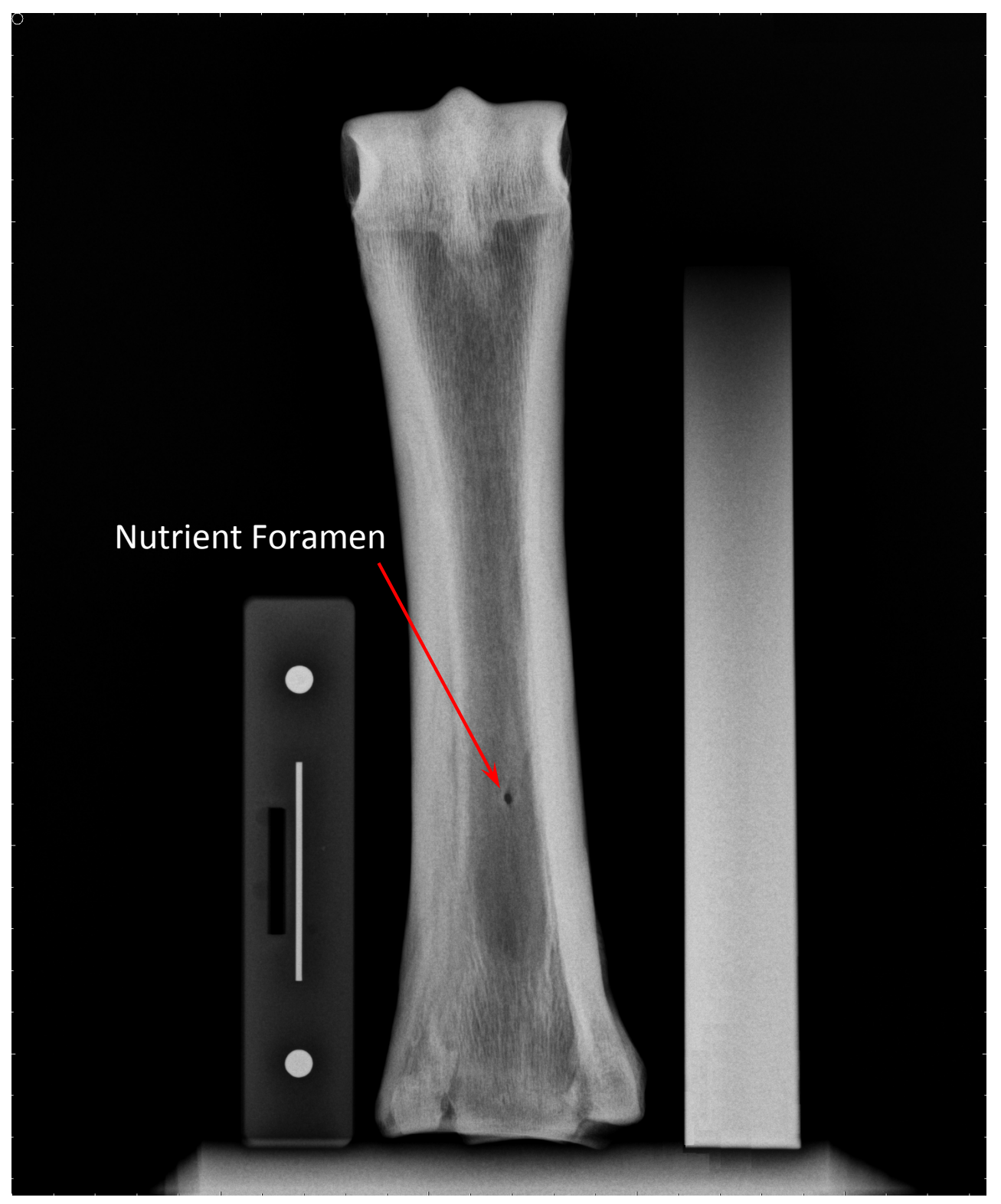

Figure 15. Dorsal palmar positioning of a third metacarpal equine cadaver bone on a wooden block with Auto-Scaler (left) of known dimensions and Al wedge (right) of known thickness and density. The nutrient foramen (red arrow) can be seen as a dark spot on the diaphysis. 
equal to the diameter of the nutrient foramen (NF) (Figure 16). The NF was used as a marker so that the measurement of bone BDI was always for the same region of interest to ensure that changes in BDI were solely due to effects of radiographic exposure. $\mathrm{Al}$ BDI and bone BDI were evaluated for dependency on exposure intensity and exposure time. Al BDI was compared to bone BDI for each combination of X-ray intensities and exposure times to ensure Al BDI correlated linearly with that of bone. We expect a smooth linear correlation of bone BDI to $\mathrm{Al} \mathrm{BDI}$ over a range of exposures to ensure that $\mathrm{X}$-rays interact the same with $\mathrm{Al}$ and bone, and that the interaction was some function of exposure that was easily standardized. This allowed for BDI calibration of radiographs taken at varying exposure intensity and exposure time using an Al wedge standard.

\subsection{Calibration of BDI}

For subsequent radiographs, the $\mathrm{Al}$ wedge was used to standardize the BDI of a given image in units of $\mathrm{mm} \mathrm{Al}$. Each radiograph was standardized by creating a standard curve unique to that image. The standard curve was obtained by measuring average BDI horizontally across the $\mathrm{Al}$ wedge (or for one thickness of $\mathrm{Al}$ ) and plotting the BDI versus the length along the midline of the wedge (Figure 17). As the thickness of Al increased linearly from 0 to $31.80 \mathrm{~mm}$, we expected $\mathrm{Al} \mathrm{BDI}$ to increase in a determinable manner. From this relationship, thickness of $\mathrm{Al}$ could be determined from a measured BDI value. To test if this was accurate for any exposure, radiographs were obtained of the Al wedge and an $\mathrm{Al}$ step-wedge. The $\mathrm{Al}$ step-wedge was made from $6061 \mathrm{Al}$ alloy, was a constant $2.70 \mathrm{~g} / \mathrm{cm}^{3}$, and contained 16 steps of known increasing thickness (Figure 18). 


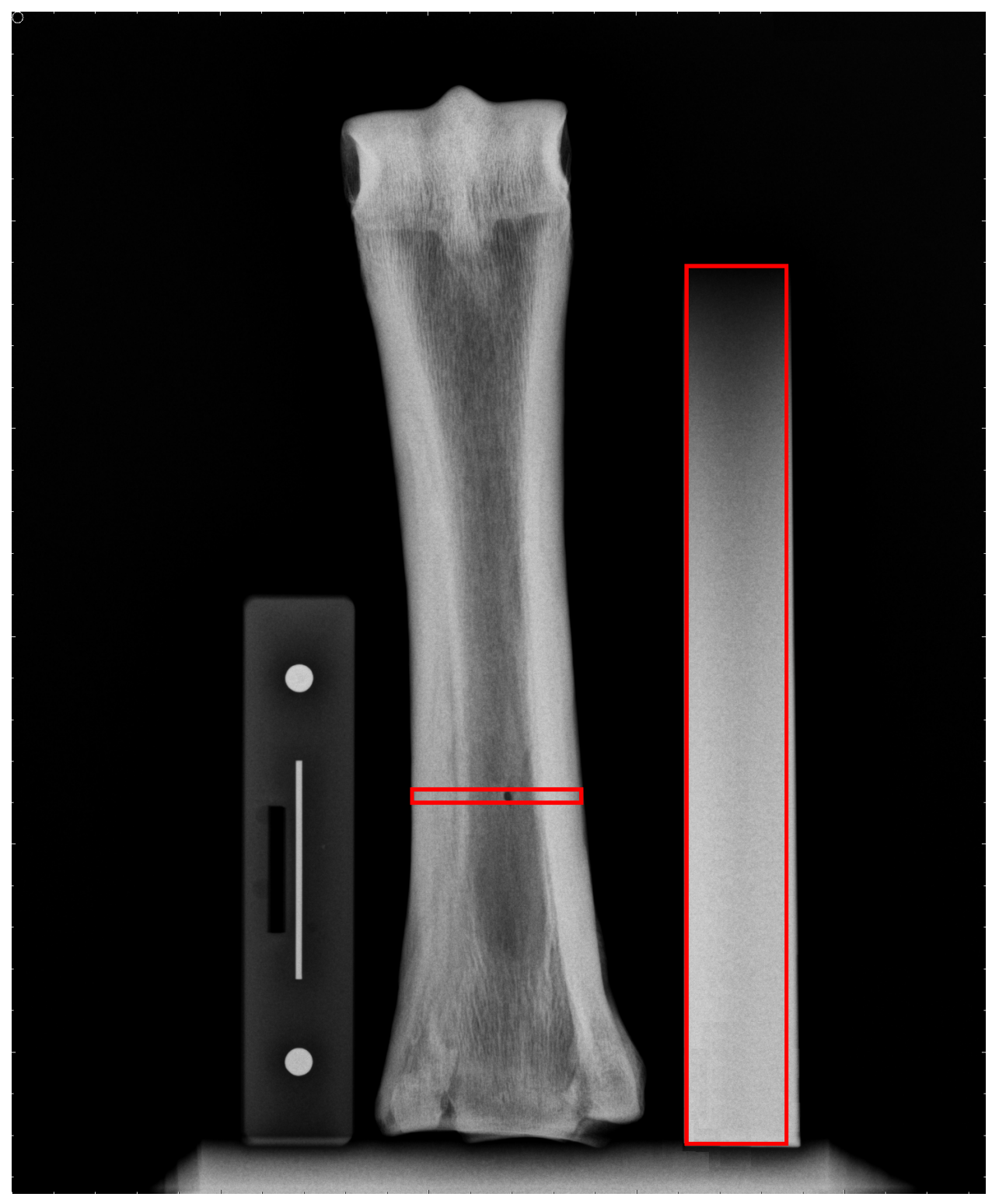

Figure 16. Selection of regions of interest (red) for measuring bone BDI at the nutrient foramen and $\mathrm{Al} \mathrm{BDI}$ from an $\mathrm{Al}$ wedge, determined from a dorsal palmar radiograph of a third metacarpal cadaver bone. 


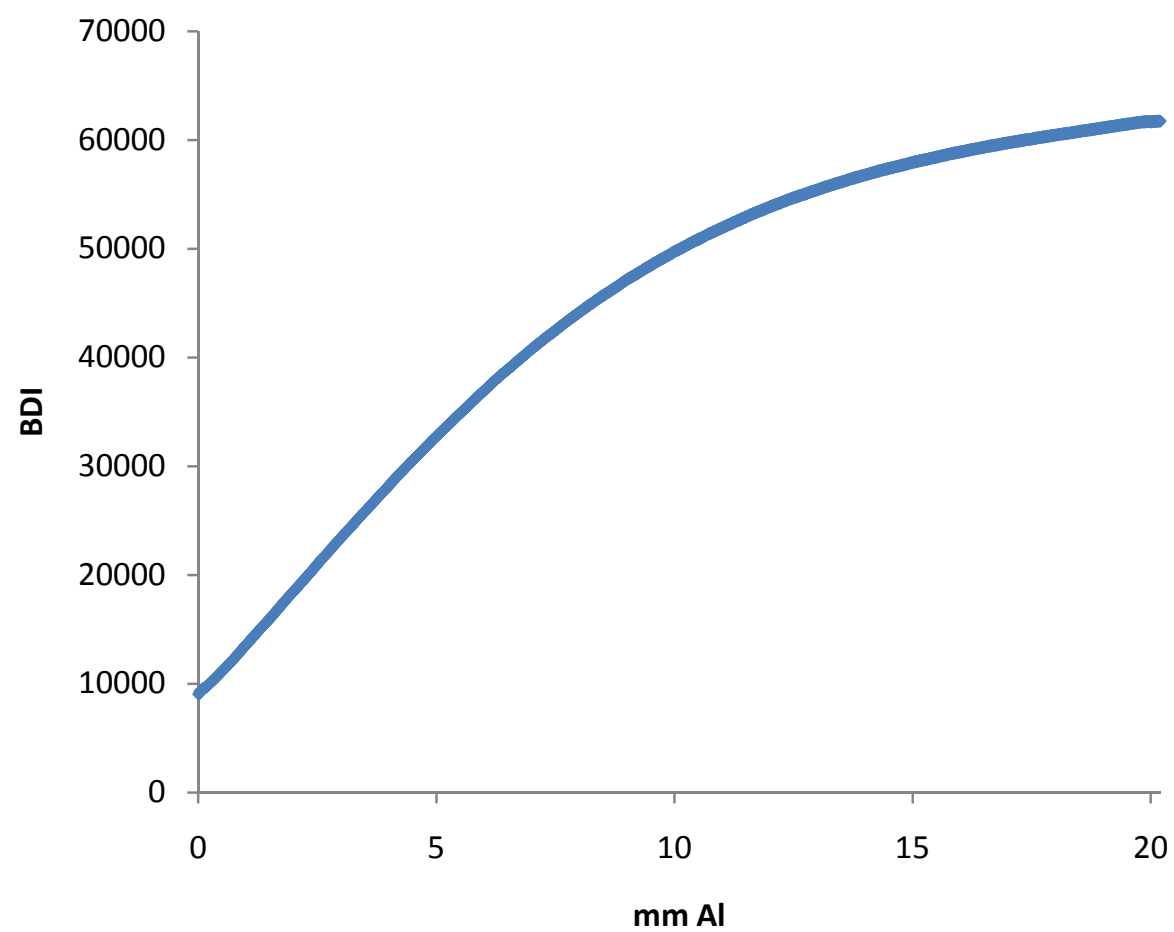

Figure 17. Standard curve of $\mathrm{BDI}$ versus thickness of $\mathrm{Al}(\mathrm{mm} \mathrm{Al})$ for a radiograph of an $\mathrm{Al}$ wedge taken at $60 \mathrm{kV}, 0.06$ seconds and $15 \mathrm{~mA}$. 


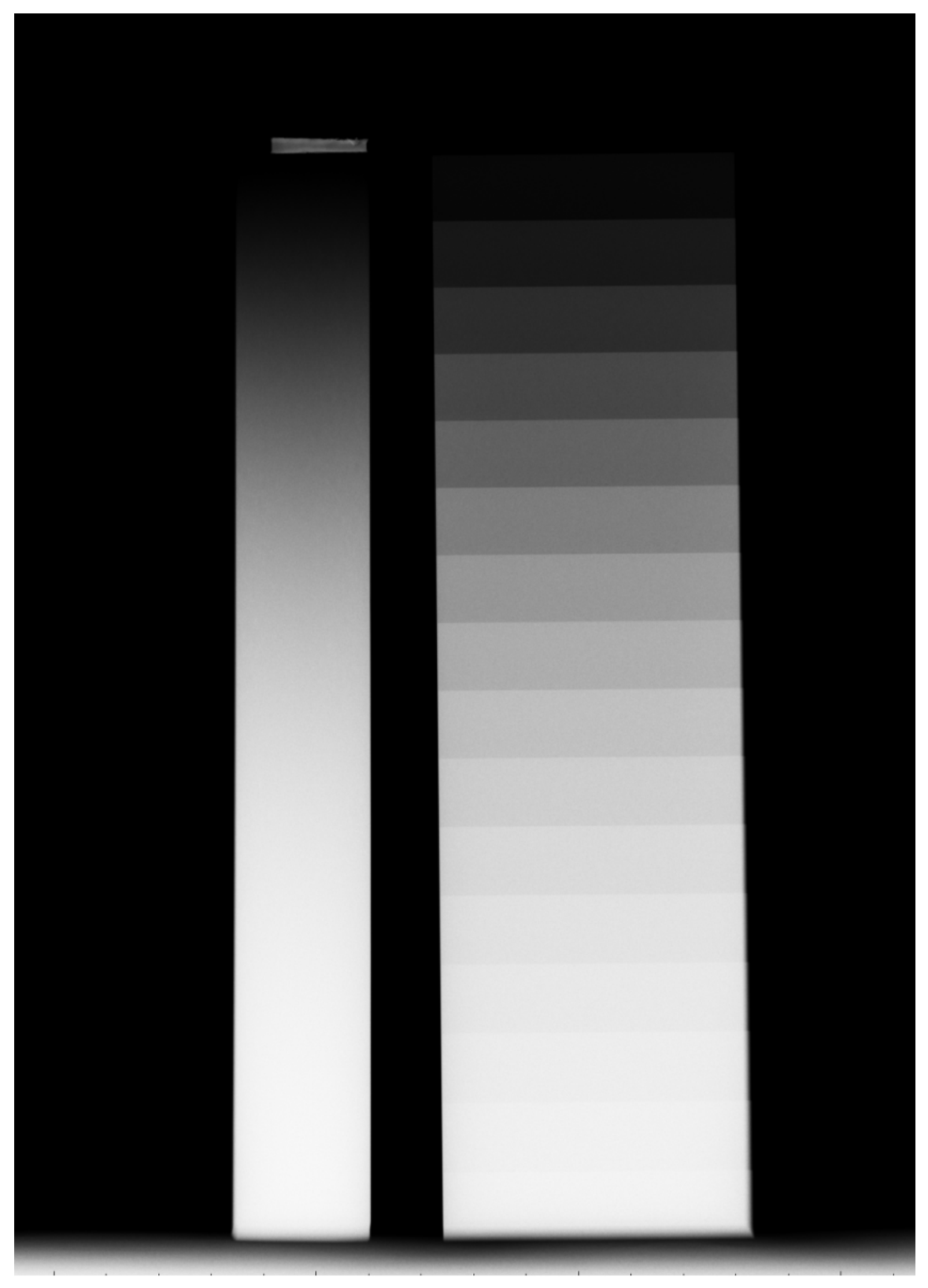

Figure 18. Radiograph of Al wedge (left) and Al step-wedge (right), taken at $60 \mathrm{kV}, 0.06$ seconds and $15 \mathrm{~mA}$. Radiographic opacity visibly correlates with the thickness of $\mathrm{Al}$, with darker areas being thinner than brighter areas. 
Radiographs were taken in combinations from 40 to $90 \mathrm{kV}$ and 0.04 to 0.08 seconds at a focal distance of 26 inches. Radiographs were standardized using the Al wedge standard curve. The thickness of each step of the Al step-wedge was measured with 6 inch digital calipers (Fisher Scientific) with $0.01 \mathrm{~mm}$ accuracy. Additionally, step thickness was measured from a standardized radiograph in terms of mm Al. A marker was placed at the end of the Al wedge to ensure the full length was used to create an accurate standard curve. The step thickness was measured using a region of interest that was centered horizontally on the step and 9 pixels wide (Figure 19). The region of interest excluded the edges of the step where BDI was most likely to fluctuate due to edge affects.

\subsection{Quantification of Optical Density}

Measurement of BDI or mm Al is generally only used for research as its value is dependent on the grayscale chosen by the individual and the attenuation properties of the material being measured. OD is preferred to BDI as an indicator of bone mineral density as confirmed by DEXA, and is commonly used in human medicine (Nagamine et al. 2000). In determining OD, the Beer-Lambert law applies to all photo-film techniques:

$$
I=I_{o} e^{-\mu t}
$$

Where $I=$ transmitted beam intensity, $I_{o}=$ incident beam intensity, $\mu=$ linear attenuation coefficient, and $t=$ thickness of the material (Curry et al. 1990).

The equation can be rewritten as:

$$
I=I_{o} e^{-\mu \rho t / \rho}=I_{o} e^{-\mu_{m} \rho t},
$$

where $\mu_{m}=\frac{\mu}{\rho}=$ mass attenuation coefficient. The value of the mass attenuation 


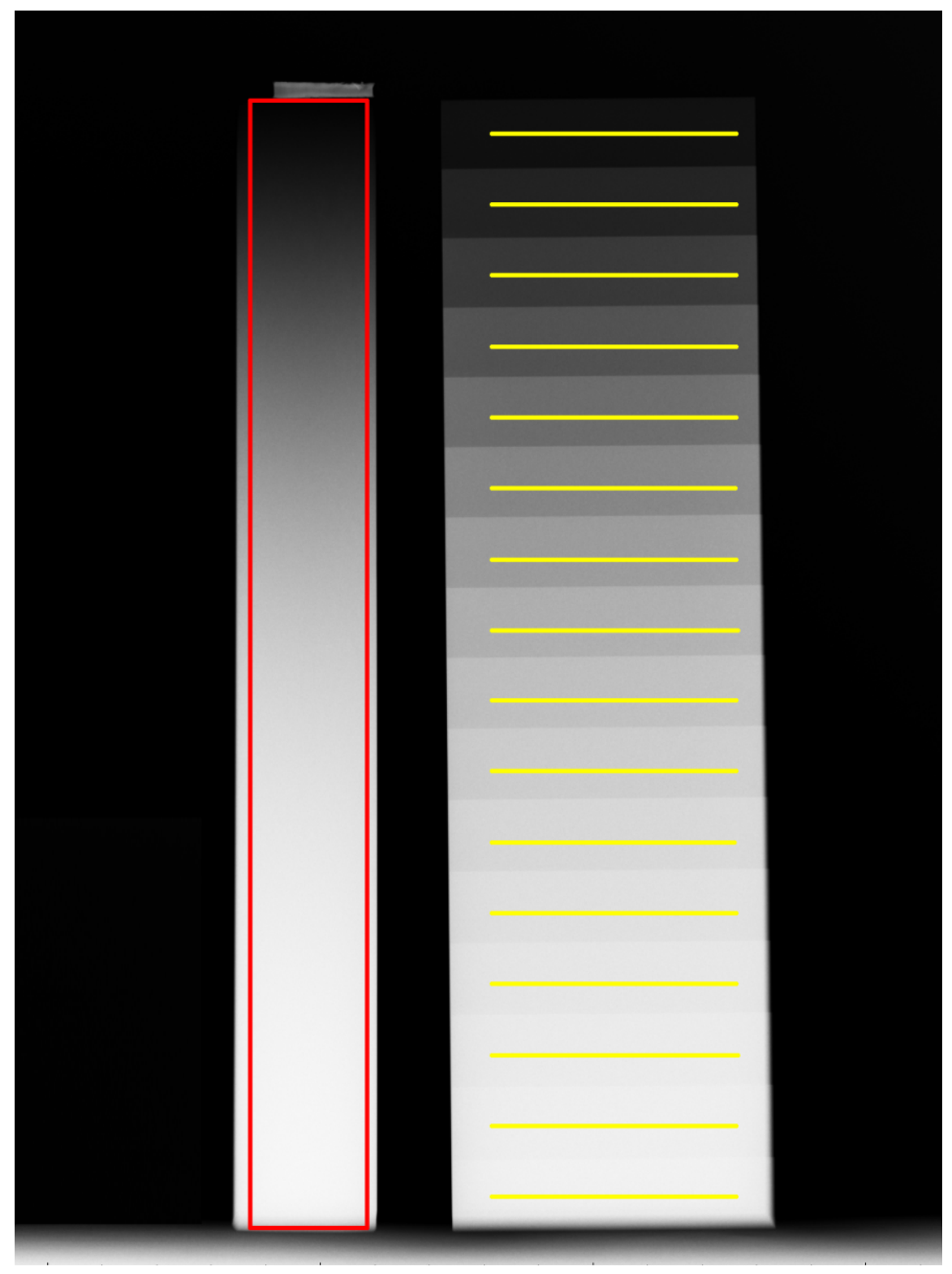

Figure 19. Region of interest selection for $\mathrm{Al}$ wedge (red box), and 16 regions of interest (yellow lines) corresponding with each step of the Al step-wedge, determined from a radiograph taken at $60 \mathrm{kV}, 0.06$ seconds and $15 \mathrm{~mA}$. 
coefficient is dependent upon attenuation of an X-ray through matter, and is affected by several different mechanisms such as energy of the incident X-rays, the attenuator's atomic mass number, Rayleigh or coherent scattering, Compton or incoherent scattering, photoelectric absorption, and electron/positron pair production. The value of the mass attenuation coefficient is independent of the density of the attenuator (Curry et al. 1990). In medically relevant exposure ranges of 50 to $90 \mathrm{kV}$, the effects of coherent scatter and pair production are relatively insignificant as the average atomic numbers of cortical bone (13.7) and Al (13) are low (Graham and Cloke 1982, Hubbell and Seltzer 2004). Although the mass attenuation coefficients vary significantly over this range, the mass attenuation coefficient ratio is relatively constant at $0.886 \pm 0.026$ (Figure 20) (Hubbell and Seltzer 2004).

Radiographic density or OD, commonly referred to as luminosity or opacity of the bone sampled, is defined as:

$$
O D=\log \frac{I}{I_{o}}=-\mu_{m} \rho t
$$

And OD of Al, for example, would be:

$$
O D_{A l}=-\left(\mu_{m} \rho t\right)_{A l}
$$

Comparing optical densities of $\mathrm{Al}$ and bone, we set $O D_{A l}$ equal to $O D_{B}$ :

$$
\begin{gathered}
\left(\mu_{m} \rho t\right)_{A l}=\left(\mu_{m} \rho t\right)_{B} \\
\rho_{B}=\left(\mu_{m A l} / \mu_{m B}\right) \cdot\left(t_{A l} / t_{B}\right) \cdot \rho_{A l}
\end{gathered}
$$

The relationship shown in Equation (2) can be experimentally utilized to determine true bone density from a radiographic image (Curry et al. 1990). However, cortical bone thickness is generally unknown in situ and difficult to quantify and commonly density and thickness of the bone are quantified together and known as areal 


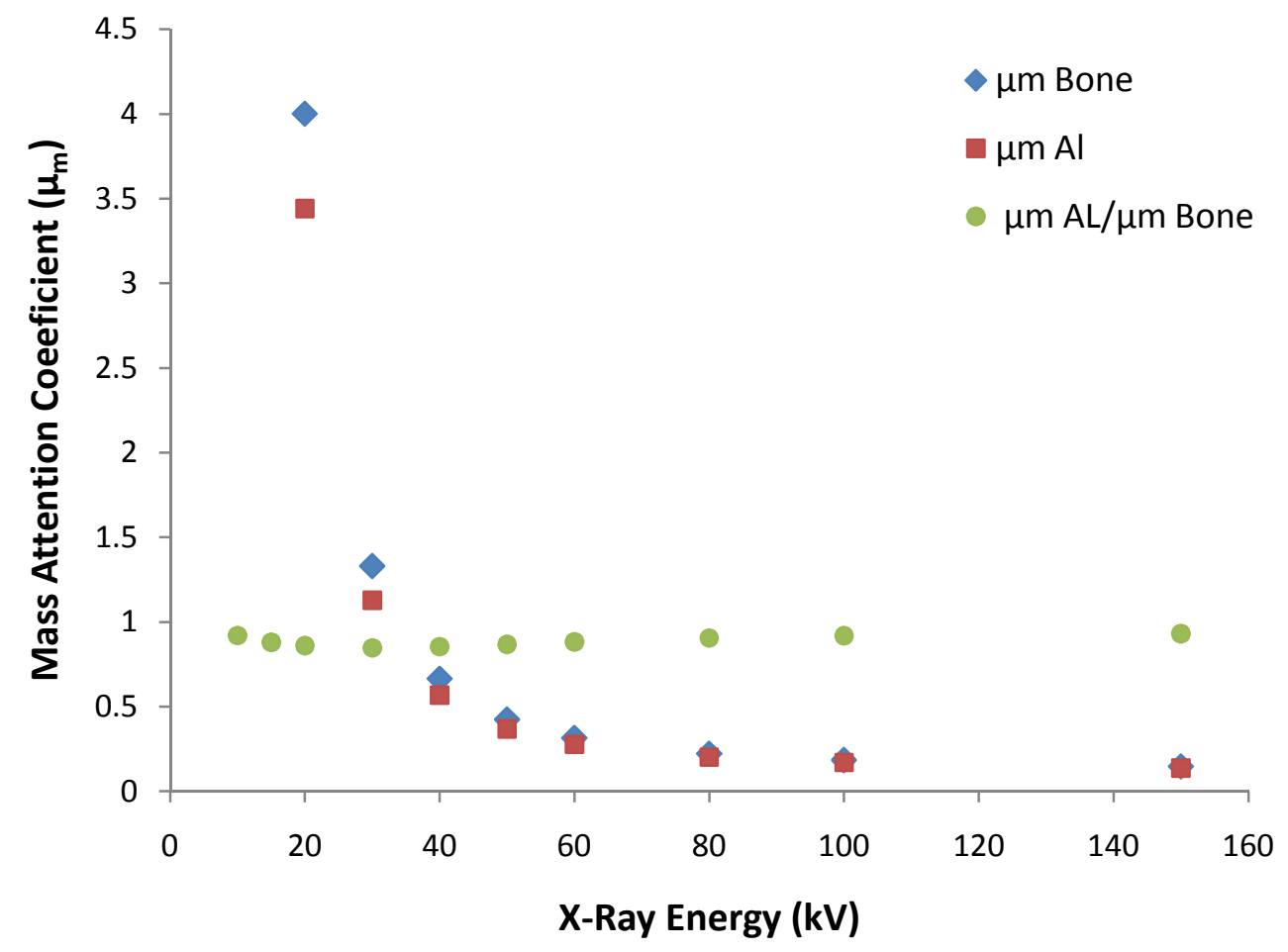

Figure 20. Mass attenuation coefficients for cortical bone (blue) and $\mathrm{Al}$ (red). The mass attenuation coefficient ratio (green) is relatively constant at $0.886 \pm 0.026$ (Hubbell and Seltzer 2004). 
bone density, which is proportional to OD. For example, two materials such as bone and Al of known density and thickness are radiographed. The point at which the radiograph exhibits equal BDI for both materials, the mass attenuation ratio for the materials can be calculated using Equation 3 (Carricart-Ganivet and Barnes 2007, Chalker et al. 1985). By determining the mass attenuation coefficient ratio for cortical bone and $\mathrm{Al}$ using an $\mathrm{Al}$ wedge of known areal density, bone density can be quantified from a standardized digital radiograph.

In determining the mass attenuation coefficient ratio, a cortical bone step-wedge was created of known density and increasing thickness. Cortical bone was obtained from a third metacarpal equine cadaver bone in the mid-diaphysis region. The cortical bone was cut into slices using a diamond blade tile saw. The average dimension of each slice was $15.28 \pm 3.3 \mathrm{~mm}$ square and $4.23 \pm 1.0 \mathrm{~mm}$ thick. A bone step-wedge was created by stacking each bone slice in increasing thickness from the one slice up to 6 slices thick, consecutively from Row 1 to Row 10 . Scotch tape was used on the sides of the bone slices to hold them in place, forming a total of ten steps of increasing thickness. The thickness and volume corresponding with each bone step was determined using 6 inch digital calipers (Fisher Scientific) with $0.01 \mathrm{~mm}$ accuracy. Weight was measured using a digital balance (Accu-224, Fisher Scientific) with $0.1 \mathrm{mg}$ accuracy. The density for each bone step was determined by dividing weight by volume for each step. Slices were stored at $5^{\circ} \mathrm{C}$ and kept hydrated in a saline solution.

Standard digital radiographs were taken of the bone wedge and Al wedge (Figure 21). The bone step-wedge was positioned to intersect the center of the line of exposure, 


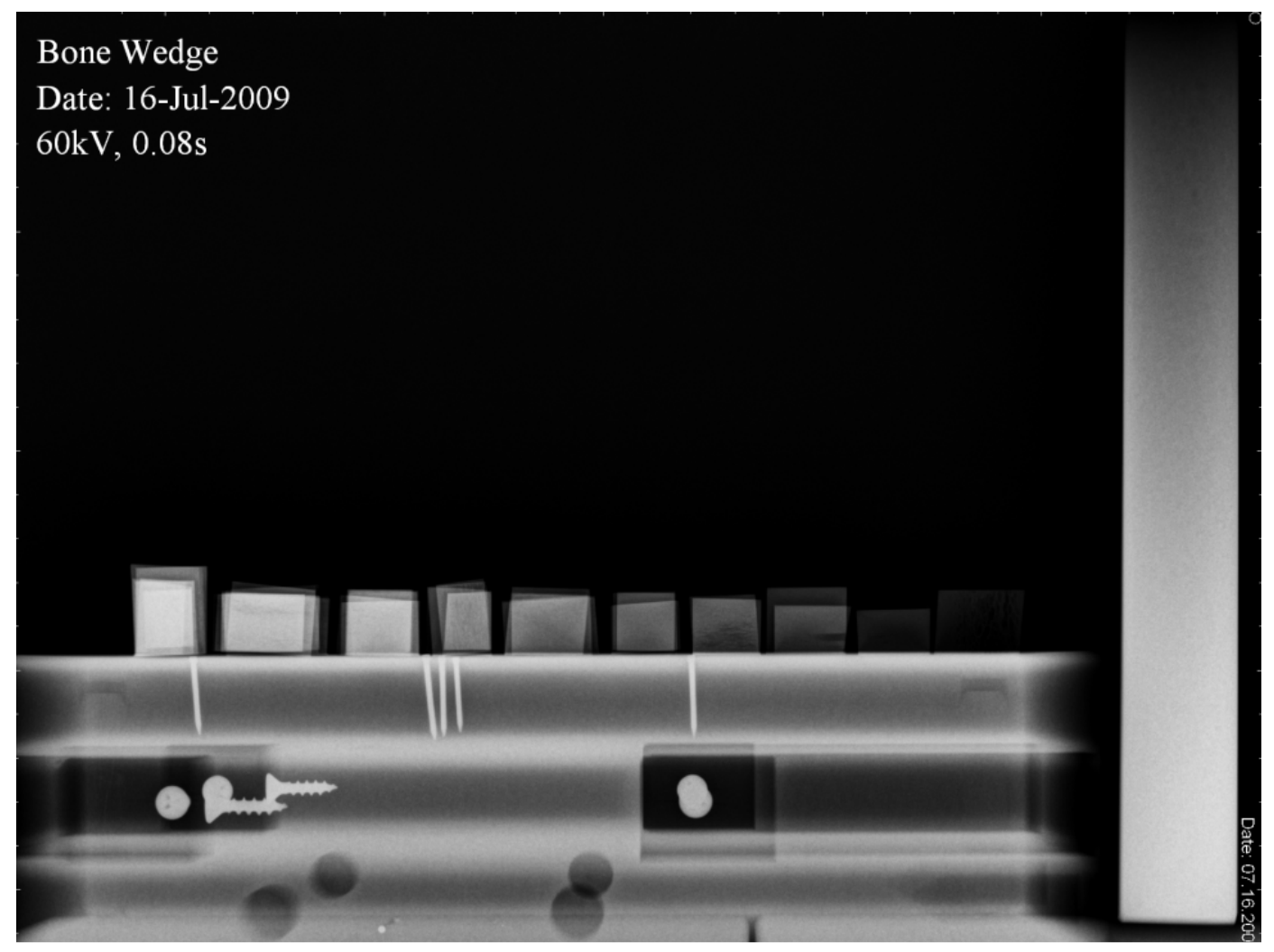

Figure 21: Bone wedge (center) made of 10 cortical bone steps of decreasing thickness (left to right) on a standardized hoof block and $\mathrm{Al}$ wedge (right), from a digital radiograph taken at $60 \mathrm{kV}, 0.08$ seconds and $15 \mathrm{~mA}$. 
with the Al wedge on one side. BDI was determined for each step of bone and for the standard curve obtained from the Al wedge (Figure 22). Standardized curves were created for bone BDI versus bone areal density, and Al BDI versus Al areal density. Where $\mathrm{Al} \mathrm{BDI}$ was equal to bone $\mathrm{BDI}$, the correlation between bone and $\mathrm{Al}$ areal density could be determined, and therefore the mass attenuation coefficient ratio. Radiographs were taken with a focal distance of 26 inches, with the plane of interest containing the bone wedge and the $\mathrm{Al}$ wedge positioned against the face of the sensor. Radiographs were taken at $60 \mathrm{kV}, 15 \mathrm{~mA}$ and 0.08 seconds.

To test if bone OD was an accurate predictor of bone areal density for any exposure, further evaluation of the bone step-wedge was performed while varying $\mathrm{kV}$. Radiographs were obtained of the bone step-wedge and Al wedge using methods described in the previous experiment. Radiographs were taken from 40 to $90 \mathrm{kV}, 0.06$ seconds and $15 \mathrm{~mA}$ at a focal distance of 26 inches. Bone OD was measured and compared to the areal density for each cortical bone step.

\subsection{Error Associated with Optical Bone Density}

To assess the effect of soft tissue and marrow on the quantification of bone OD, standard DP and LM radiographs were taken of a distal cadaver limb with soft tissue and marrow, and without soft tissue, and without soft tissue and bone marrow present. Ends of the cadaver limb containing the third metacarpal epiphyses were cut off using a band saw to make soft tissue easier to remove. Soft tissue including skin, muscle, tendons and adipose tissue was removed using a scalpel blade. Bone marrow was removed by 


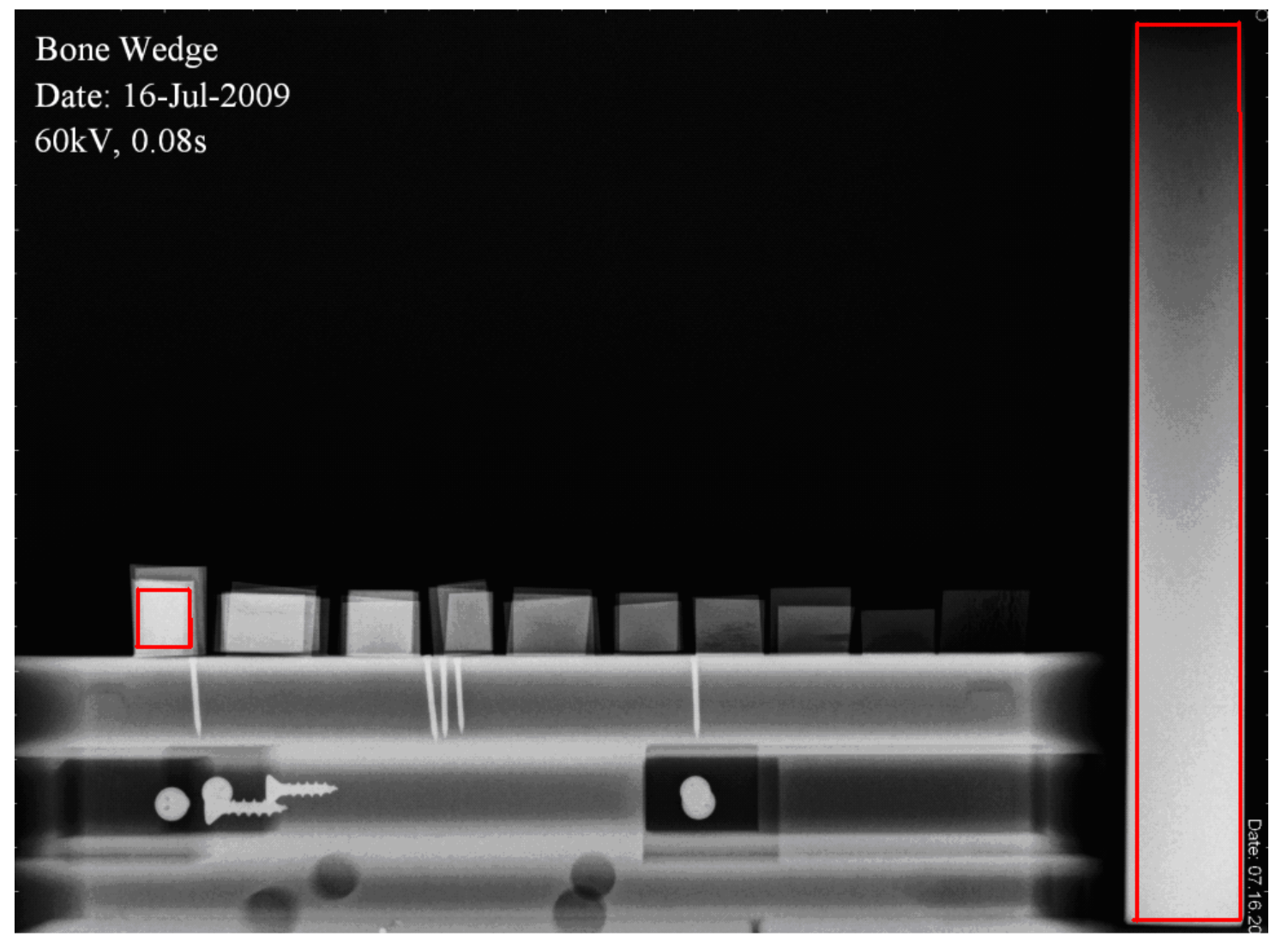

Figure 22. Selection of the regions of interest (red) for measuring Al BDI (right) and bone BDI (left) from the tenth and thickest step of the bone wedge, determined from a digital radiograph taken at taken at $60 \mathrm{kV}, 0.08$ seconds and $15 \mathrm{~mA}$. 


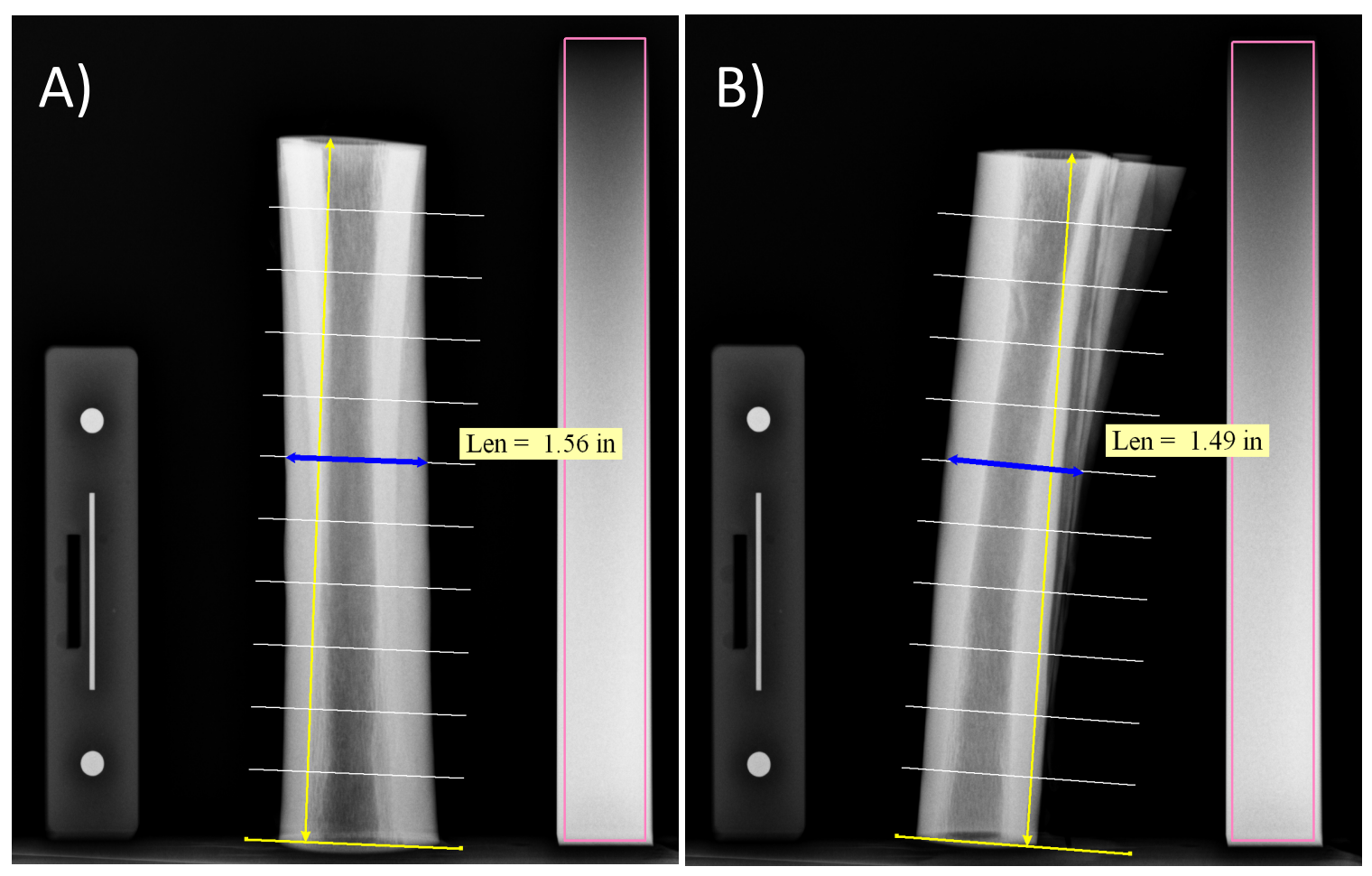

Figure 23. Selection of 10 regions of interest (white lines) along a third metacarpal cadaver bone without soft tissue and bone marrow from a dorsal palmar (A) and lateral medial radiograph (B). The diameter of the bone was measured at each region of interest for both views. Both images contain an Auto-Scaler (left) and Al wedge (right). 
scraping out the medullary cavity with a metal spoon. For all radiographs, bone OD was measured at 10 different regions of interest spaced equally proximal to distal along the midline of the third metacarpal (Figure 23). Each region of interest was equal to the diameter of the bone in width, and 9 pixels in height. Bone OD was analyzed for differences in each region of interest dependent on radiographic view (DP and LM) and presence of soft tissue and bone marrow. Additionally, the diameter of the third metacarpal bone at each of the regions of interest was measured on both LM and DP views to determine bone density. Bone density was determined by dividing OD from one view by the diameter measured from the opposite view for each region of interest. Radiographs were taken with a focal distance of 26 inches and exposure settings of 65 $\mathrm{kV}, 0.06$ seconds and $15 \mathrm{~mA}$.

Error in bone OD due to radiographic positioning was further investigated in a single region of interest at the mid-diaphysis of a third metacarpal cadaver limb. The region of interest was limited to a known area of cortical bone on the lateral wall in a DP view (Figure 24). Bone OD was determined for this region while varying the angle between the X-ray source and limb in two rotational planes: one proximal to distal and the second lateral to medial. Angles varied from 5 - 32 degrees proximal to distal, and from 10 - 30 degrees lateral to medial, with 0 degrees being normal. Radiographs were taken $66 \mathrm{kV}, 0.06$ seconds and $15 \mathrm{~mA}$ with a focal distance of 26 inches.

Levels of precision errors (SD) and coefficients of variation (CV) were assessed by measuring bone OD from 40 different LM radiographs by three different users (Glüer et al. 1995). 


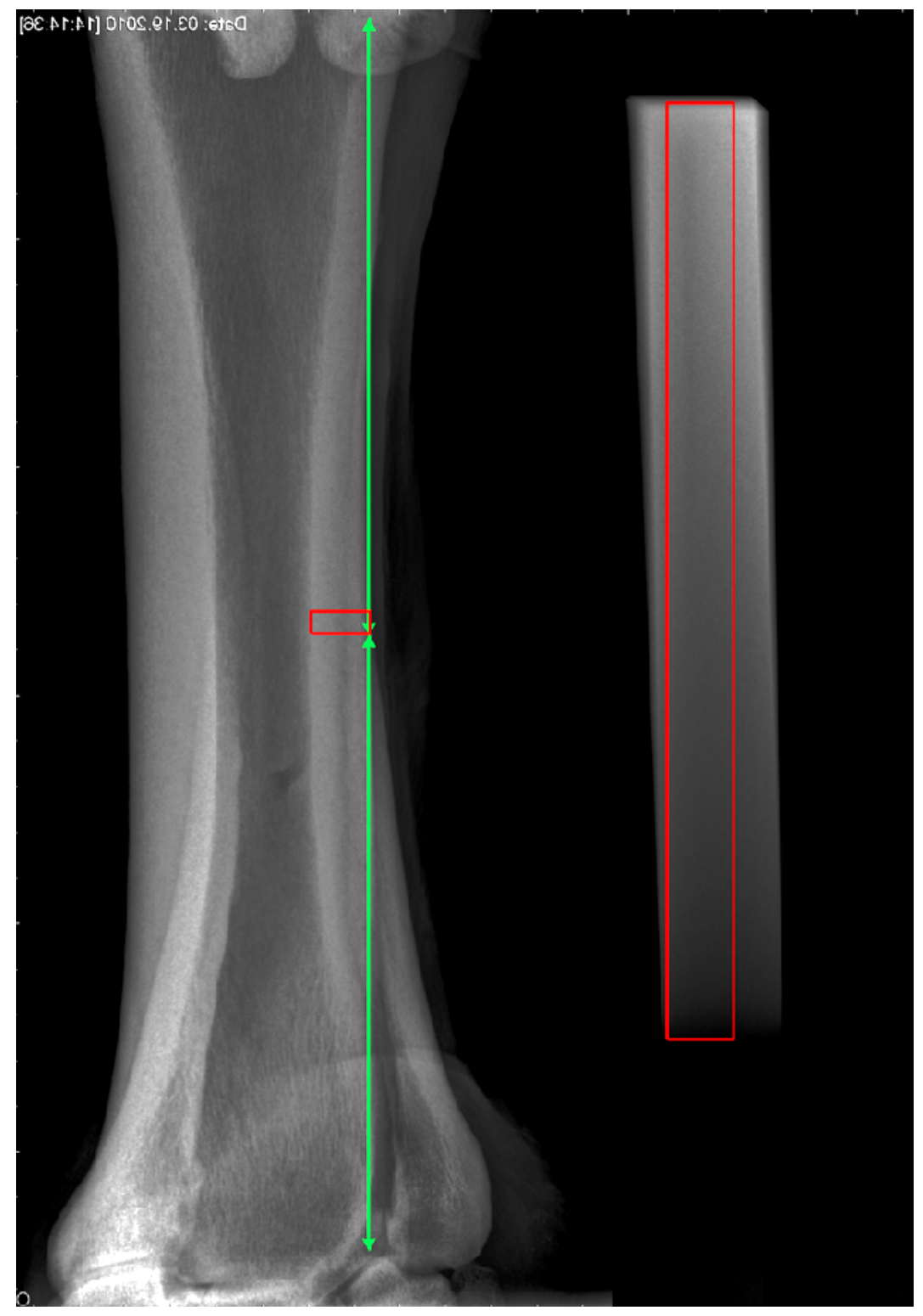

Figure 24. Selection of regions of interest (red) for the Al wedge (right) and cortical bone (left) positioned at the mid-diaphysis in the lateral cortical region of the third metacarpal bone, determined from a dorsal palmar radiograph taken at $60 \mathrm{kV}, 0.06$ seconds and 15 $\mathrm{mA}$. The X-ray source was placed at 30 degrees rotation from a standard dorsal palmar view. 


\subsection{Statistical Analysis}

Regression analyses were performed using the least squares method. Slope of the regression lines were shown to be different from zero determined by a Student's $t$-test. Multi-variable analysis was done for BDI versus exposure intensity and time using an ANOVA and associated $F$-test. All statistical tests were performed using Minitab and were based on a 2-sided null hypothesis of no difference and a level of significance set at 0.05 .

\subsection{Results}

While standardizing BDI, bone BDI decreased with increasing exposure intensity and exposure time. From 0.02 to 0.14 seconds and 55 to $80 \mathrm{kV}$, bone BDI ranges from 13,747 to 49,851 (Table 4A). Similarly, Al BDI decreased with increasing exposure intensity and exposure time, ranging from 21,388 to 54,328 (Table 4B). BDI correlated linearly with exposure intensity and exposure time for $\mathrm{Al}\left(r^{2}=0.8594, F(2,39)=119.2, p\right.$ $<0.001)$ and bone $\left(r^{2}=0.9126, F(2,39)=203.7, p<0.001\right)$ (Figure 25). For each combination of intensity and exposure time, Al BDI showed a linear correlation with bone BDI $\left(r^{2}=0.9599, F(1,40)=957.3, p<0.001\right)$. As Al BDI increased per unit, there was an increase in bone BDI of $1.12 \pm 0.04$ (Figure 26).

When checking for BDI standardization over a range of exposures, we determined the thickness of steps from an $\mathrm{Al}$ step-wedge when using a standard curve from the $\mathrm{Al}$ wedge (Table 5). The radiographic measurement of $\mathrm{mm} \mathrm{Al}$ was a significant predictor of the Al step-wedge thickness $\left(r^{2}=0.992, F(1,249)=31,790, p<0.001\right.$, Figure 27). Additionally, there was no significant evidence that mm Al was not equal to the step- 

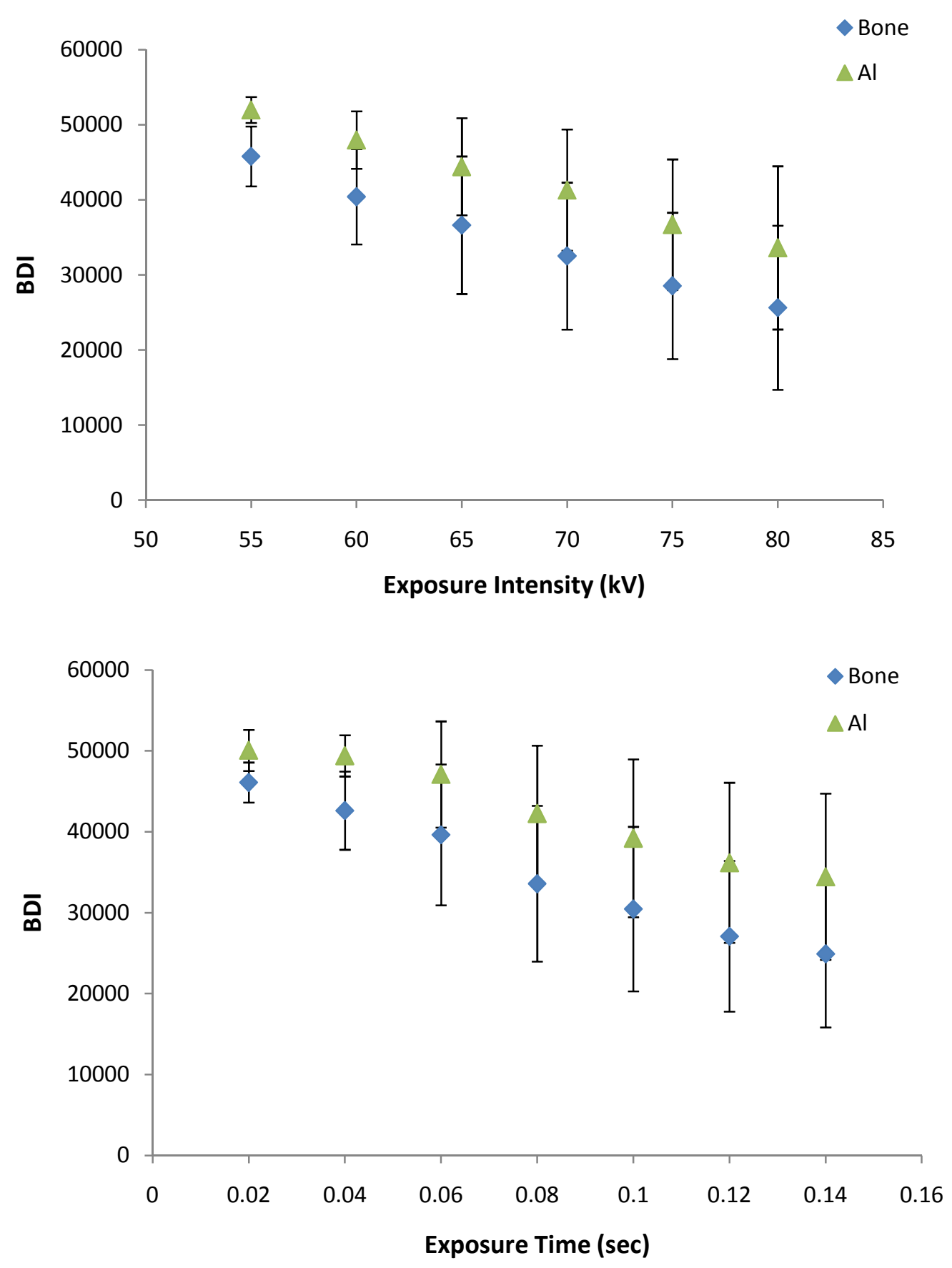

Figure 25. BDI versus exposure intensity (top) and exposure time (bottom) determined from a dorsal palmar radiograph of a third metacarpal cadaver bone and $\mathrm{Al}$ wedge taken at varying exposure $(p<0.001)$. 


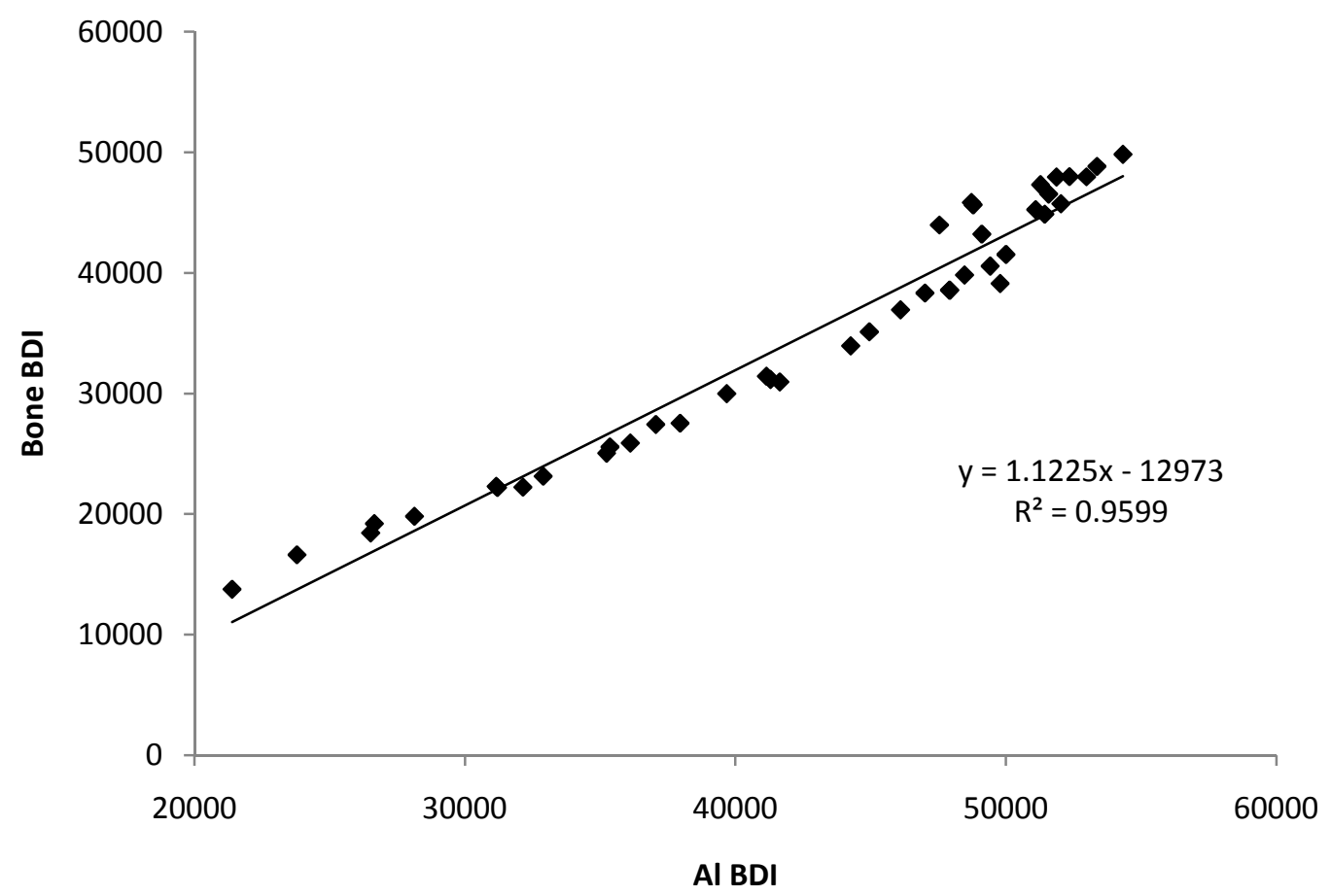

Figure 26. Linear correlation of BDI of a third metacarpal cadaver bone versus Al BDI at varying exposure intensities $(55-80 \mathrm{kV})$ and exposure times $(0.02-.014 \mathrm{~s})(p<0.001)$. 


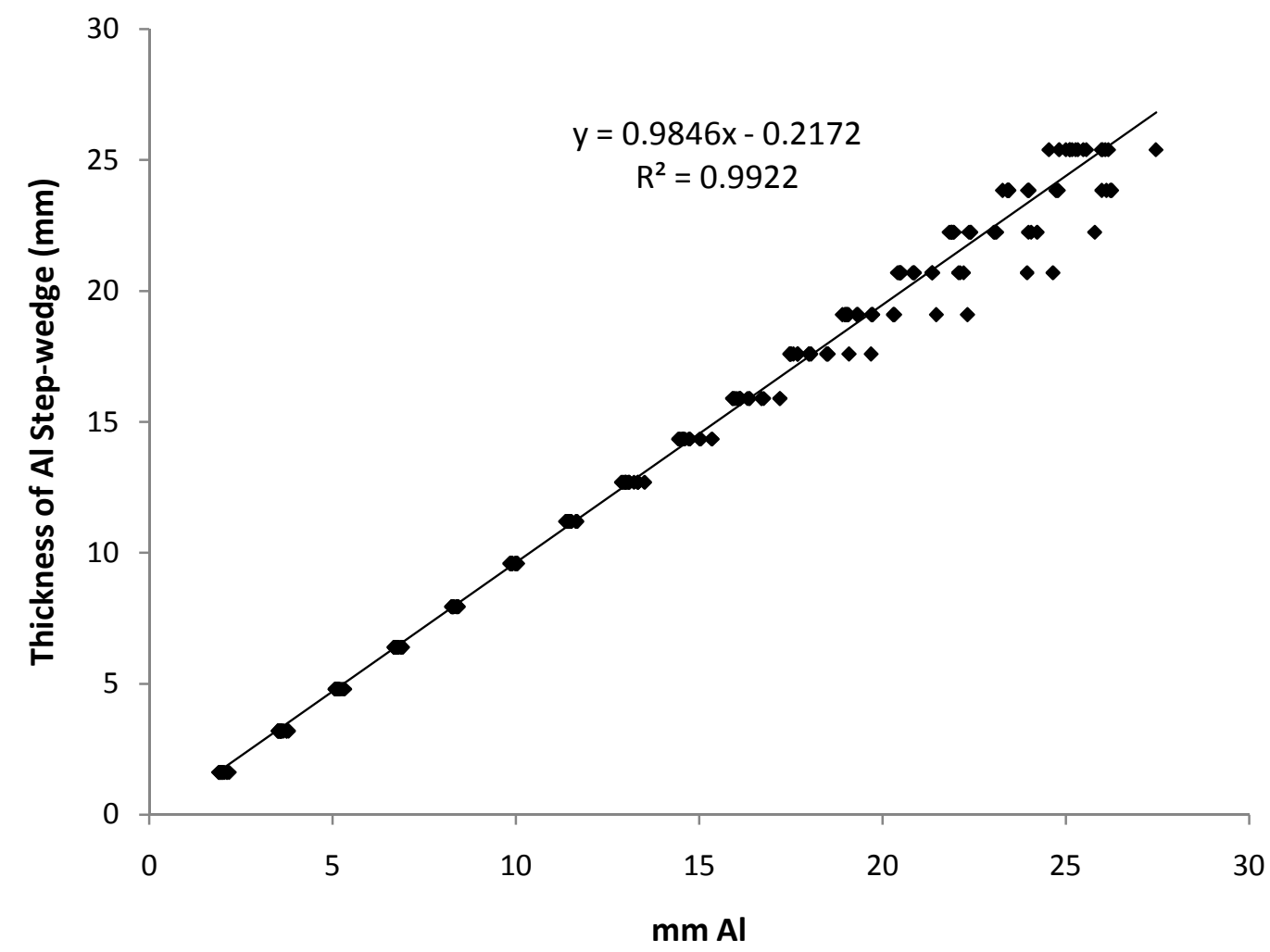

Figure 27. Regression of $\mathrm{mm} \mathrm{Al} \mathrm{measured} \mathrm{from} \mathrm{a} \mathrm{radiograph} \mathrm{versus} \mathrm{thickness} \mathrm{of} \mathrm{Al}$ determined with calipers for 16 steps of an $\mathrm{Al}$ step-wedge. Greater variance is seen at steps thicker than $12 \mathrm{~mm}(p<0.001)$. 


\begin{tabular}{|c|c|c|c|c|c|c|c|}
\hline A) & \multicolumn{2}{|c|}{ Exposure Time (sec) } & \multirow[b]{2}{*}{0.06} & \multirow[b]{2}{*}{0.08} & \multirow[b]{2}{*}{0.1} & \multirow[b]{2}{*}{0.12} & \multirow[b]{2}{*}{0.14} \\
\hline & 0.02 & 0.04 & & & & & \\
\hline 55 & 49851.20 & 47324.93 & 48851.92 & 47979.78 & 45745.73 & 41531.48 & 39134.09 \\
\hline 60 & 45854.03 & 48001.42 & 44886.04 & 40580.10 & 38567.94 & 33940.24 & 30970.81 \\
\hline 65 & 45657.83 & 45258.55 & 46563.14 & 35112.90 & 31168.28 & 27543.62 & 25046.51 \\
\hline 70 & 47970.69 & 39823.54 & 38583.39 & 29976.86 & 25877.64 & 23134.80 & 22218.42 \\
\hline 75 & 43981.89 & 38335.79 & 31419.15 & 25567.06 & 22194.23 & 19800.11 & 18432.86 \\
\hline 80 & 43221.42 & 36932.82 & 27441.96 & 22277.3 & 19188.45 & 16605.65 & 13747.36 \\
\hline
\end{tabular}

\begin{tabular}{|c|c|c|c|c|c|c|c|}
\hline \multirow[t]{2}{*}{ B) } & \multicolumn{2}{|c|}{ Exposure Time (sec) } & \multirow[b]{2}{*}{0.06} & \multirow[b]{2}{*}{0.08} & \multirow[b]{2}{*}{0.1} & \multirow[b]{2}{*}{0.12} & \multirow[b]{2}{*}{0.14} \\
\hline & 0.02 & 0.04 & & & & & \\
\hline 55 & 54328.01 & 51278.43 & 53365.63 & 52982.59 & 52035.74 & 50003.53 & 49789.47 \\
\hline 60 & 48724.45 & 52346.50 & 51439.42 & 49420.01 & 47922.23 & 44261.64 & 41638.44 \\
\hline 65 & 48790.40 & 51097.91 & 51579.49 & 44946.46 & 41295.99 & 37956.83 & 35236.51 \\
\hline 70 & 51871.32 & 48464.33 & 47919.15 & 39674.84 & 36117.23 & 32890.75 & 32145.65 \\
\hline 75 & 47540.82 & 47008.81 & 41149.23 & 35358.32 & 31197.42 & 28125.15 & 26515.69 \\
\hline 80 & 49108.10 & 46107.06 & 37058.30 & 31152.24 & 26649.52 & 23781.63 & 21387.57 \\
\hline
\end{tabular}

Table 4. BDI at the nutrient foramen (A) and Al wedge (B) determined from a dorsal palmar radiograph of a third metacarpal at varying exposure intensities $(55-80 \mathrm{kV})$ and exposure times $(0.02-0.14$ seconds $)$. 


\begin{tabular}{lcccccccc}
\hline & \multicolumn{7}{c}{ mm Al at Varying $k V$} & \\
\cline { 2 - 7 } & 50 & 60 & 70 & 80 & 90 & Average $\pm S D$ & & \\
\hline 1 & 1.90 & 1.91 & 1.99 & 2.01 & 2.14 & $1.99 \pm 0.10$ & 1.62 & 22.9 \\
2 & 3.58 & 3.52 & 3.59 & 3.61 & 3.77 & $3.61 \pm 0.09$ & 3.20 & 12.9 \\
3 & 5.16 & 5.07 & 5.15 & 5.15 & 5.28 & $5.16 \pm 0.08$ & 4.80 & 7.6 \\
4 & 6.79 & 6.68 & 6.73 & 6.73 & 6.88 & $6.76 \pm 0.08$ & 6.40 & 5.6 \\
5 & 8.39 & 8.27 & 8.28 & 8.28 & 8.42 & $8.33 \pm 0.07$ & 7.95 & 4.7 \\
6 & 10.04 & 9.90 & 9.87 & 9.85 & 9.99 & $9.93 \pm 0.08$ & 9.60 & 3.4 \\
7 & 11.66 & 11.49 & 11.43 & 11.38 & 11.47 & $11.48 \pm 0.10$ & 11.20 & 2.5 \\
8 & 13.33 & 13.08 & 12.99 & 12.91 & 13.00 & $13.06 \pm 0.16$ & 12.70 & 2.8 \\
9 & 15.03 & 14.74 & 14.58 & 14.46 & 14.55 & $14.67 \pm 0.22$ & 14.35 & 2.2 \\
10 & 16.72 & 16.35 & 16.12 & 15.95 & 16.01 & $16.23 \pm 0.32$ & 15.90 & 2.1 \\
11 & 18.50 & 18.01 & 17.69 & 17.49 & 17.52 & $17.84 \pm 0.42$ & 17.60 & 1.4 \\
12 & 20.31 & 19.72 & 19.32 & 19.00 & 19.00 & $19.47 \pm 0.56$ & 19.10 & 1.9 \\
13 & 22.14 & 21.36 & 20.85 & 20.47 & 20.47 & $21.06 \pm 0.70$ & 20.70 & 1.7 \\
14 & 24.09 & 23.07 & 22.39 & 21.92 & 21.86 & $22.67 \pm 0.93$ & 22.25 & 1.9 \\
15 & 26.10 & 24.76 & 23.98 & 23.44 & 23.36 & $24.33 \pm 1.14$ & 23.85 & 2.0 \\
16 & 26.81 & 25.82 & 25.24 & 24.88 & 25.18 & $25.59 \pm 0.76$ & 25.40 & 0.7 \\
\hline
\end{tabular}

Table 5. Thickness of $\mathrm{Al}(\mathrm{mm} \mathrm{Al})$, average thickness of $\mathrm{Al}$ with standard deviation (Average $\pm S D$ ), and actual thickness $(t)$ of $\mathrm{Al}$ determined for 16 steps of an Al stepwedge. Thickness in $\mathrm{mm} \mathrm{Al}$ was measured from digital radiographs taken from 50 to 90 $\mathrm{kV}$ at 0.06 seconds while actual thickness (Actual $t$ ) was measured using digital calipers. Percent error compared actual thickness of the step to radiographic quantification of average $\mathrm{mm} \mathrm{Al}$. 
wedge thickness as the regression slope was not significantly different than $1(t(249)=$ 1.373, $p=0.171$ ). At thicker steps of $\mathrm{Al}$ (steps $10-16$ ) larger variation in $\mathrm{mm} \mathrm{Al}$ was seen.

To determine OD for cortical bone, the relationship between OD and BDI was quantified. Bone BDI was shown to increase linearly with increasing areal bone density and therefore bone OD $\left(r^{2}=0.9716, F(1,1193)=40,850, p<0.001\right.$, Figure 28). From Row 1 to Row 10 of the bone wedge, the BDI ranged from $3,648 \pm 723$ to $54,151 \pm 691$ (Table 6). Similarly, Al BDI increased with increasing Al areal density and, therefore, Al $\mathrm{OD}$, ranging from a BDI of 0 to 53,810 with a constant density of $2.70 \mathrm{~g} / \mathrm{cm}^{3}$. Al thickness increased linearly along the length of the Al wedge from 0 to $4.26 \mathrm{~cm}$ before the slope of the standard curve began to decrease resulting in a nonlinear correlation with $\mathrm{Al}$ OD above $4.26 \mathrm{~cm} \mathrm{Al} \mathrm{thick} \mathrm{(Figure} \mathrm{29).} \mathrm{For} \mathrm{thicknesses} \mathrm{under} 4.26 \mathrm{~cm} \mathrm{Al}$ a linear approximation could be made, allowing determination of the mass attenuation coefficient ratio from a single variant $\left(r^{2}=0.9973, F(1,631)=232,800, p<0.001\right.$, Figure 30). In addition, the ratio of the mass attenuation coefficients could be solved for by comparing $\mathrm{Al} \mathrm{OD}$ to that of bone when $\mathrm{Al} \mathrm{BDI}$ equals bone BDI, utilizing Equation 3. The mass attenuation coefficient ratio $\left(\mu_{m A l} / \mu_{m B}\right)$ was estimated using regression equations from Figures 27 and 29. At the point where BDI was equal for both materials $\mu_{m A l} / \mu_{m B}$ was determined to be $0.9042(p<0.001)$ (Appendix A). This allowed for determination of bone OD in terms of $\mathrm{g} / \mathrm{cm}^{2}$.

When checking for OD standardization, bone OD determined from radiographs of the bone wedge was compared to bone areal density determined using a scale and calipers. Bone areal density correlated linearly with bone OD determined from 


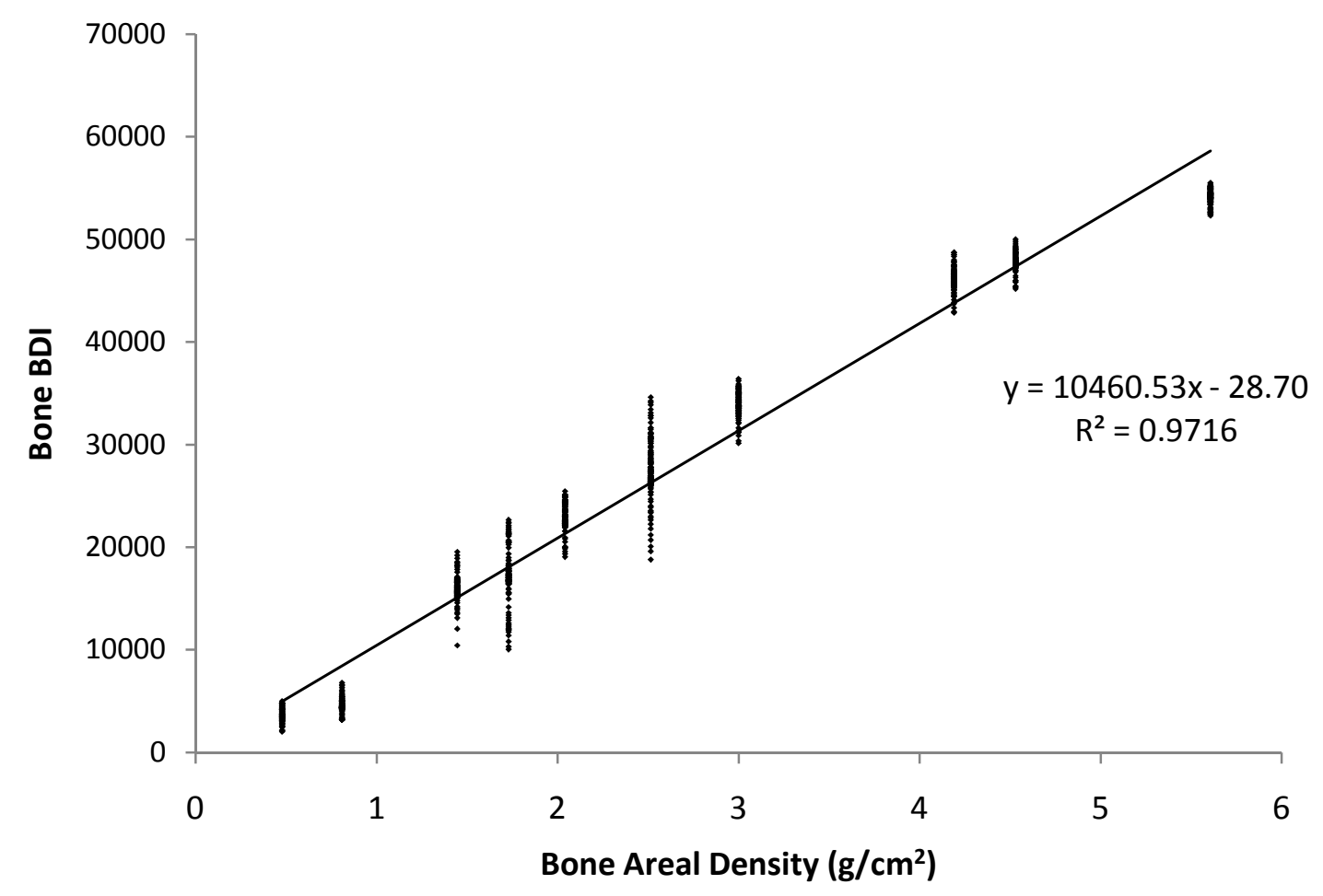

Figure 28. Bone BDI determined from a radiograph of the bone step-wedge versus bone areal density measured with digital scale and calipers $(p<0.001)$. 


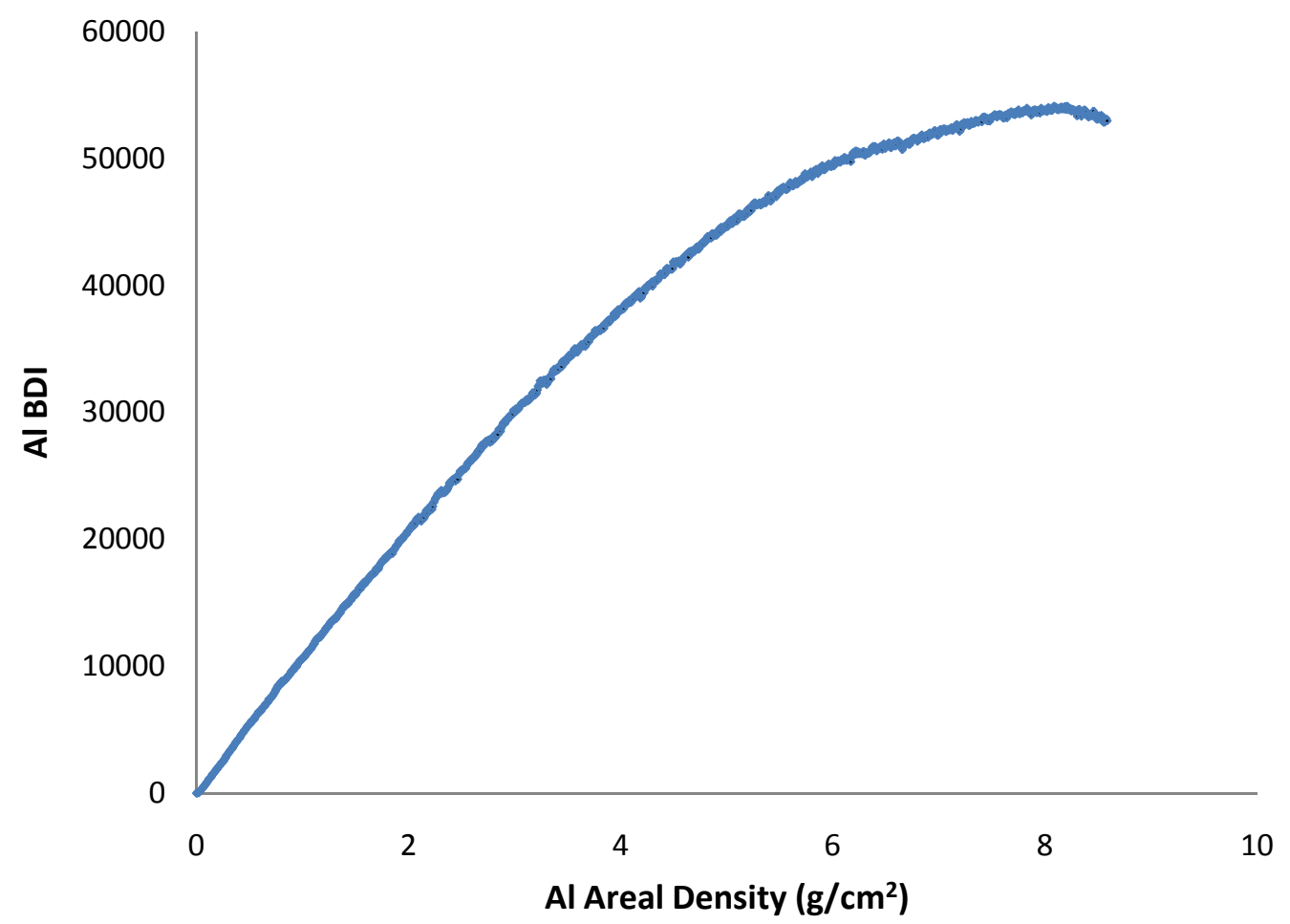

Figure 29. Al BDI versus $\mathrm{Al}$ areal density for the length of the $\mathrm{Al}$ wedge. With areal density greater than $4 \mathrm{~g} / \mathrm{cm}^{2}$ there is a visible decrease in slope of the standard curve. 


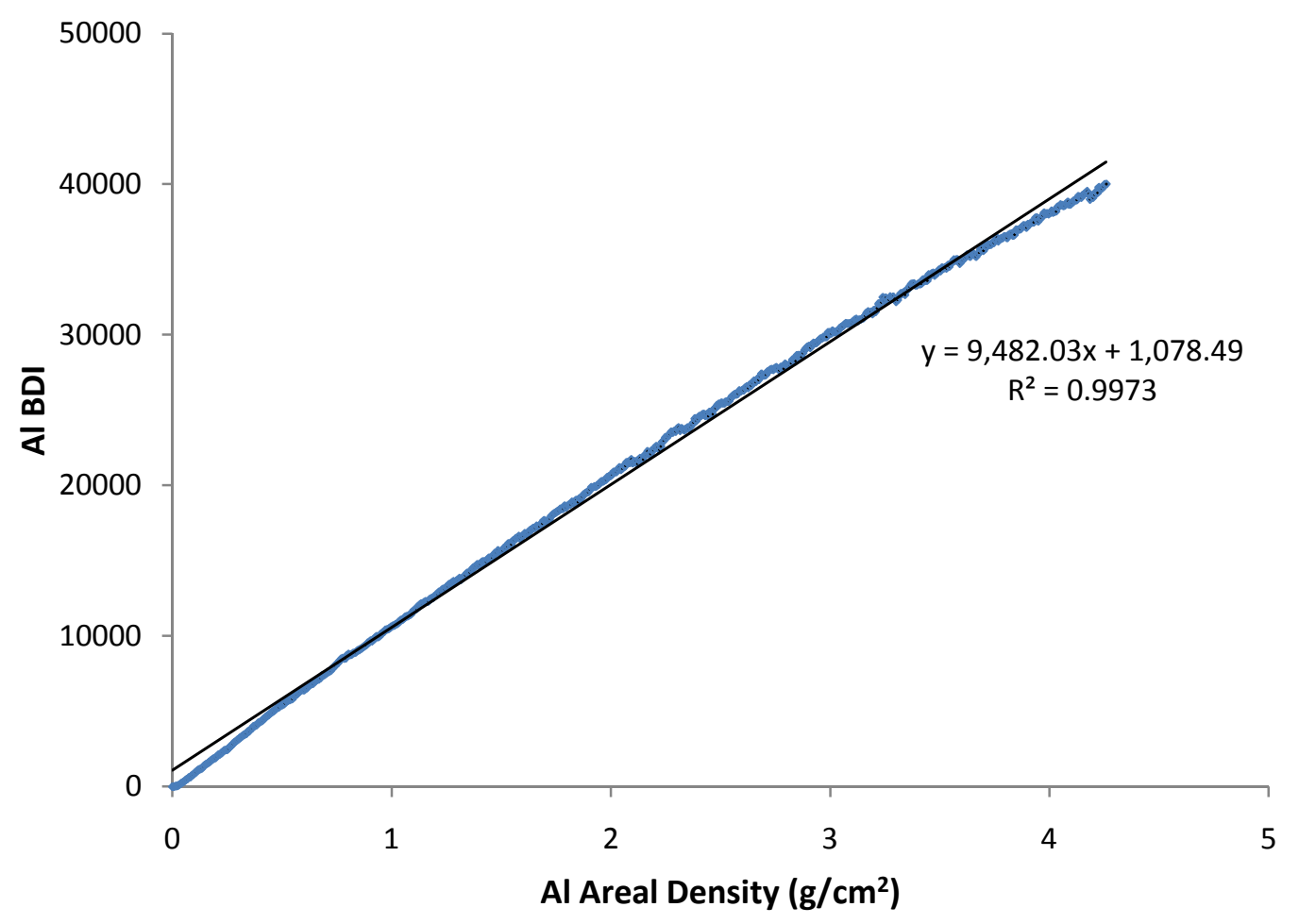

Figure 30. Al BDI versus $\mathrm{Al}$ areal density determined for the linear region $(0-40,000$ $\mathrm{BDI})$ of the $\mathrm{Al}$ wedge standard curve from a radiograph taken at $66 \mathrm{kV}, 0.08$ seconds and $15 \mathrm{~mA}(p<0.001)$. 


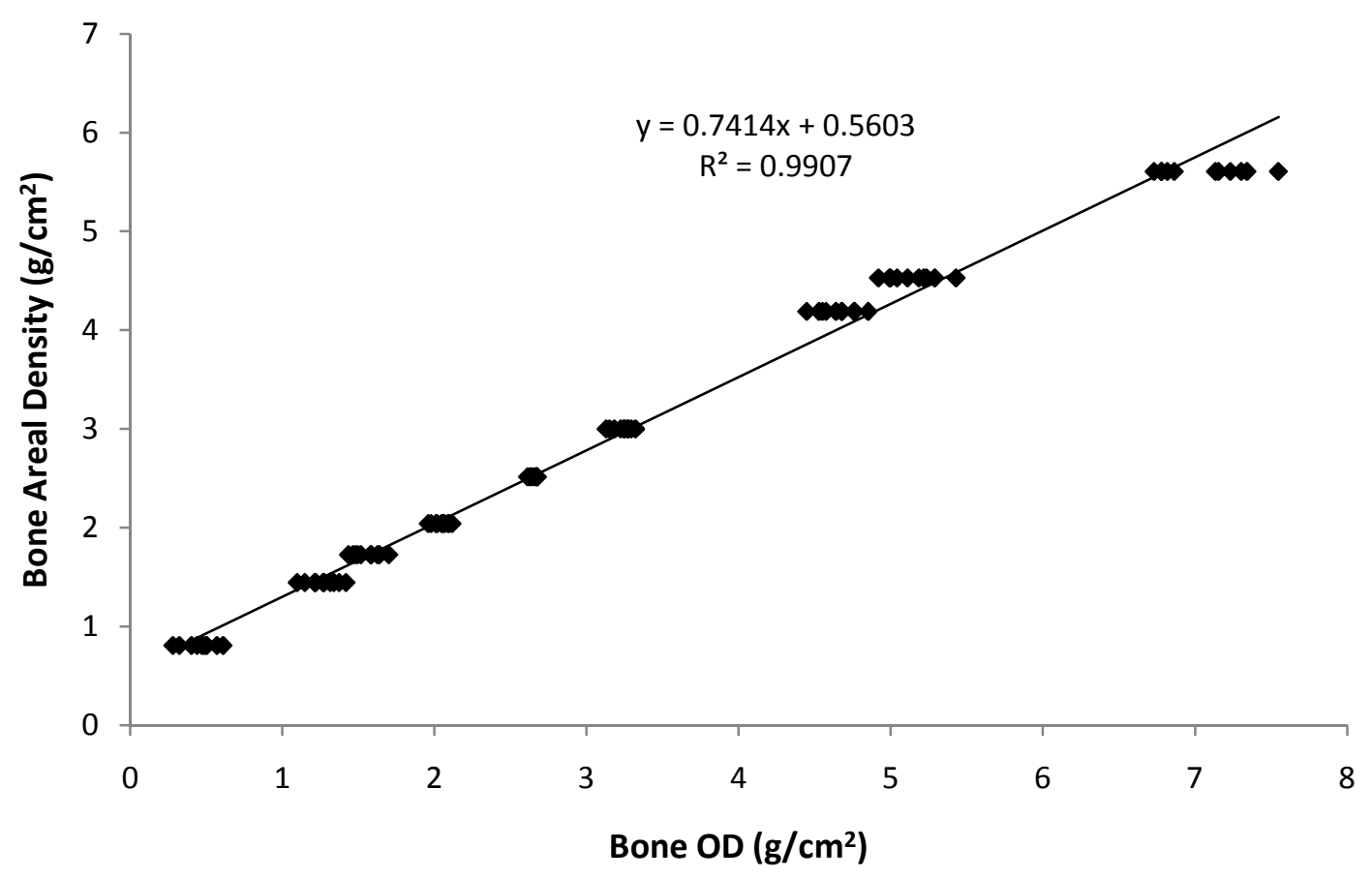

Figure 31. Regression of areal bone density versus bone OD determined from radiographs of a cortical bone wedge at 40 to $90 \mathrm{kV}$. 


\begin{tabular}{lcccc}
\hline Step & Bone BDI $\pm S D$ & $t(\mathrm{~cm})$ & $D\left(\mathrm{~g} / \mathrm{cm}^{3}\right)$ & $D * t\left(\mathrm{~g} / \mathrm{cm}^{2}\right)$ \\
\hline 1 & $3,648 \pm 723$ & 0.271 & 1.76 & 0.48 \\
2 & $4,591 \pm 757$ & 0.400 & 2.02 & 0.81 \\
3 & $15,962 \pm 129$ & 0.754 & 1.92 & 1.45 \\
4 & $17,187 \pm 268$ & 0.929 & 1.86 & 1.79 \\
5 & $22,964 \pm 133$ & 1.047 & 1.95 & 2.04 \\
6 & $27,536 \pm 280$ & 1.325 & 1.90 & 2.50 \\
7 & $33,969 \pm 127$ & 1.601 & 1.87 & 3.00 \\
8 & $46,201 \pm 115$ & 2.140 & 1.96 & 4.12 \\
9 & $47,870 \pm 952$ & 2.498 & 1.81 & 4.53 \\
10 & $54,151 \pm 691$ & 3.004 & 1.87 & 5.61 \\
\hline
\end{tabular}

Table 6: BDI and standard deviation (SD), thickness $(t)$, density $(D)$ and areal bone density $\left(D^{*} t\right)$ determined for ten steps of the cortical bone step-wedge. BDI was measured from a digital radiograph taken at $60 \mathrm{kV}, 0.08$ seconds and $15 \mathrm{~mA}$. Thickness was determined using digital calipers, and density was determined from weight $(g)$ using a digital balance divided by volume $\left(\mathrm{cm}^{3}\right)$ determined using digital calipers. 


\section{Appendix A}

\section{Equation 3:}

$$
\begin{gathered}
\rho_{B} t_{B}=\left(\mu_{m A l} / \mu_{m B}\right) \cdot \rho_{A l} t_{A l} \\
\left(\mu_{m A l} / \mu_{m B}\right)=\rho_{B} t_{B} / \rho_{A l} t_{A l}
\end{gathered}
$$

Regression equations:

$$
\begin{aligned}
& B D I_{\text {bone }}=0.105 \cdot \rho_{B} t_{B}-0.023 \\
& B D I_{A l}=0.095 \cdot \rho_{A l} t_{A l}+0.108
\end{aligned}
$$

Solving for $\mu_{m A l} / \mu_{m B}$ :

$$
\begin{aligned}
& 0.105 \cdot \rho_{B} t_{B}-0.023=0.095 \cdot \rho_{A l} t_{A l}+0.108 \\
& \rho_{B} t_{B} / \rho_{A l} t_{A l}=\left(\mu_{m A l} / \mu_{m B}\right)=0.904
\end{aligned}
$$


radiographs taken from 40 to $90 \mathrm{kV}$, resulting in a 0.741 increase in areal density per unit increase in bone OD $\left(r^{2}=0.9907, F(1,89)=184.7, p<0.001\right.$, Figure 31). Using the regression equation from Figure 31, bone areal density can be determined using the predictor variable bone OD accurate greater than $93 \%$ for exposure intensities of 50 - 90 $\mathrm{kV}$ (Table 7).

In measuring $\mathrm{OD}$, errors associated with effects of radiographic positioning were evaluated. To assess error in OD due to positioning, bone OD was measured in the cortical region of the mid-diaphysis of a third metacarpal cadaver limb. At zero degrees lateral to medial rotation, OD was determined to be $5.70 \pm 0.02 \mathrm{~g} / \mathrm{cm}^{2}$. From $10-30$ degrees of rotation in the lateral to medial direction average OD was $5.33 \pm 0.24 \mathrm{~g} / \mathrm{cm}^{2}$. Error in OD was greater than $10 \%$ with lateral to medial rotation greater than 18 degrees, and less than 3\% with rotation under 5 degrees (Table 8). From 5 - 32 degrees of rotation in the proximal to distal direction the average OD was $5.17 \pm 0.20 \mathrm{~g} / \mathrm{cm}^{2}$, measured on a slightly different region of cortical bone as part of the third metacarpal was cut off the radiograph. Error in OD was less than $10 \%$ with proximal to distal rotation under 30 degrees, and less than $3 \%$ with rotation under 5 degrees (Table 9).

Error in OD associated with effects of bone marrow and soft tissue were also analyzed. OD was determined for 10 regions of interest dependent on radiographic view (DP and LM) for three conditions: with soft tissue and marrow, after removal of soft tissue, and after removal of soft tissue and marrow (Figure 32). Additionally, the diameter of the third metacarpal bone at each of the regions of interest was measured on both views to determine bone density $\left(\mathrm{g} / \mathrm{cm}^{3}\right)$ (Figure 33, Table 10). The slopes of the 

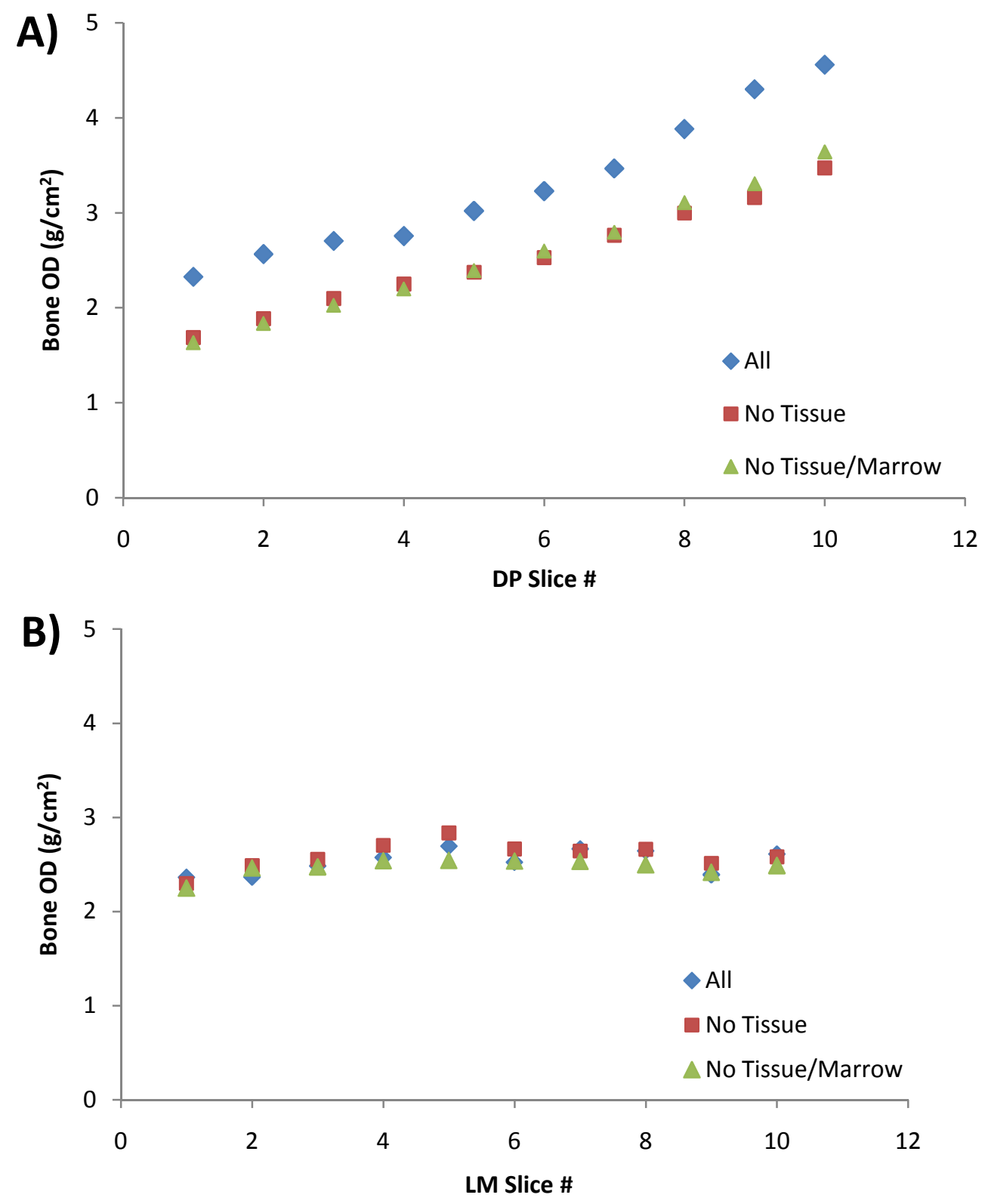

Figure 32. Bone OD versus 10 regions of interest (slice \#) of known thickness determined from a dorsal palmar (A) and lateral medial (B) radiograph of a third metacarpal cadaver limb (A) and LM view (B). Bone OD was measured with soft tissue and marrow (blue), after the removal of soft tissue (red) and after the removal of soft tissue and marrow (green). 

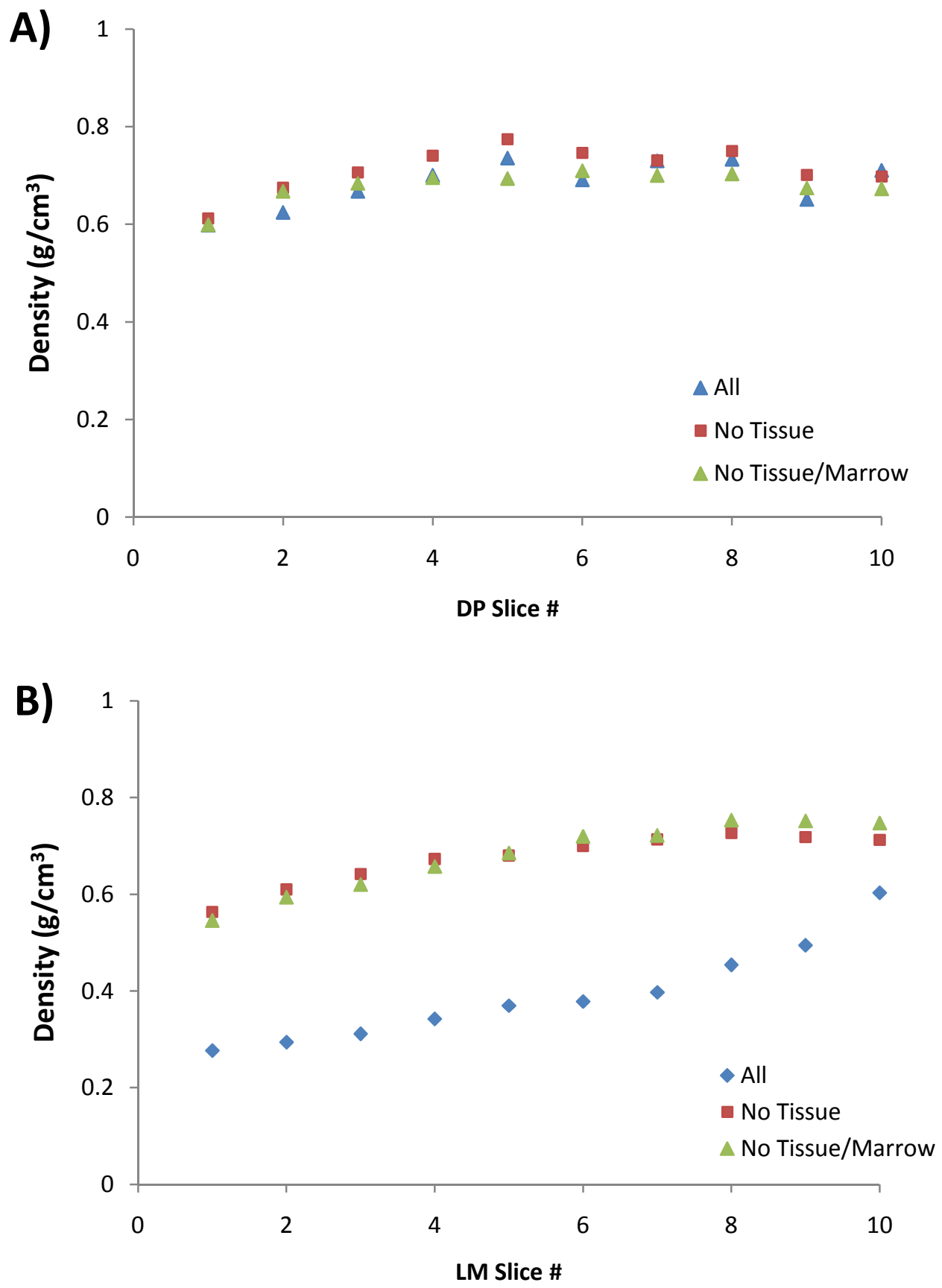

Figure 33. Bone density versus 10 regions of interest (slice \#) of known thickness determined from a dorsal palmar (A) and lateral medial (B) radiograph of a third metacarpal cadaver limb (A) and LM view (B). Bone density was measured with soft tissue and marrow (blue), after the removal of soft tissue (red) and after the removal of soft tissue and marrow (green). 


\begin{tabular}{llll}
\hline Step & Average Bone OD $\pm S D$ & $D^{*} t\left(\mathrm{~g} / \mathrm{cm}^{2}\right)$ & \% Error \\
\hline 2 & $0.84 \pm 0.08$ & 0.808 & 4.3 \\
3 & $1.44 \pm 0.08$ & 1.445 & 0.1 \\
4 & $1.65 \pm 0.07$ & 1.729 & 4.3 \\
5 & $2.02 \pm 0.04$ & 2.040 & 1.2 \\
6 & $2.46 \pm 0.02$ & 2.514 & 2.0 \\
7 & $2.89 \pm 0.05$ & 2.999 & 3.6 \\
8 & $3.93 \pm 0.10$ & 4.189 & 6.2 \\
9 & $4.29 \pm 0.12$ & 4.530 & 5.2 \\
10 & $5.73 \pm 0.22$ & 5.606 & 2.2 \\
\hline
\end{tabular}

Table 7. Average bone OD and standard deviation $(S D)$ and bone areal density $(D * t)$ for the ten steps of the bone step-wedge, determined from radiographs taken from $50-90$ $\mathrm{kV}$. Percent error compared bone areal density for the step to radiographic quantification of bone OD. Step 1 is not included as it was too thin to determine bone OD from the radiographs. 


\begin{tabular}{lcr}
\hline Rotation $\left(^{\circ}\right)$ & $O D \pm S D\left(\mathrm{~g} / \mathrm{cm}^{2}\right)$ & $\%$ Error \\
\hline 0.0 & $5.70 \pm 0.02$ & 0.00 \\
10.0 & $5.55 \pm 0.07$ & 2.66 \\
15.0 & $5.29 \pm 0.02$ & 7.16 \\
18.0 & $5.27 \pm 0.07$ & 7.49 \\
22.0 & $5.10 \pm 0.09$ & 10.60 \\
29.0 & $5.08 \pm 0.08$ & 10.87 \\
\hline
\end{tabular}

Table 8. OD and standard deviation $(S D)$ of the lateral cortical region of the middiaphysis determined from radiographs of the third metacarpal cadaver limb measured with lateral medial rotation. Error was determined as compared to 0 degrees rotation. 


\begin{tabular}{lcr}
\hline Rotation $\left(^{\circ}\right)$ & $O D \pm S D\left(\mathrm{~g} / \mathrm{cm}^{2}\right)$ & $\%$ Error \\
\hline 0.0 & $4.98 \pm 0.02$ & 0.00 \\
5.0 & $5.01 \pm 0.05$ & 0.69 \\
15.0 & $5.09 \pm 0.05$ & 2.25 \\
20.0 & $5.27 \pm 0.06$ & 5.86 \\
30.0 & $5.49 \pm 0.03$ & 10.17 \\
\hline
\end{tabular}

Table 9. OD and standard deviation (SD) for the lateral cortical region of a radiograph of a third metacarpal cadaver limb measured with dorsal palmar rotation. Percent error was determined as compared to 0 degrees rotation. 
A)

\begin{tabular}{cccccccccc}
\hline & \multicolumn{3}{c}{ All } & \multicolumn{4}{c}{ No Soft Tissue } & \multicolumn{3}{c}{ No Soft Tissue or Marrow } \\
\cline { 2 - 9 } Slice & $\begin{array}{c}\text { OD } \\
\left(\mathrm{g} / \mathrm{cm}^{2}\right)\end{array}$ & $t(\mathrm{~mm})$ & $\begin{array}{c}D \\
\left(\mathrm{~g} / \mathrm{cm}^{3}\right)\end{array}$ & $\begin{array}{c}\text { OD } \\
\left(\mathrm{g} / \mathrm{cm}^{2}\right)\end{array}$ & $\begin{array}{c}t \\
(\mathrm{~mm})\end{array}$ & $\begin{array}{c}D \\
\left(\mathrm{~g} / \mathrm{cm}^{3}\right)\end{array}$ & $\begin{array}{c}\text { OD } \\
\left(\mathrm{g} / \mathrm{cm}^{2}\right)\end{array}$ & $\begin{array}{c}t \\
(\mathrm{~mm})\end{array}$ & $\begin{array}{c}D \\
\left(\mathrm{~g} / \mathrm{cm}^{3}\right)\end{array}$ \\
\hline 1 & 2.33 & 4.30 & 0.28 & 1.69 & 3.31 & 0.56 & 1.63 & 3.31 & 0.55 \\
2 & 2.56 & 4.54 & 0.29 & 1.89 & 3.42 & 0.61 & 1.84 & 3.42 & 0.59 \\
3 & 2.70 & 4.48 & 0.31 & 2.10 & 3.62 & 0.64 & 2.03 & 3.62 & 0.62 \\
4 & 2.75 & 4.35 & 0.34 & 2.25 & 3.70 & 0.67 & 2.20 & 3.70 & 0.66 \\
5 & 3.02 & 4.54 & 0.37 & 2.37 & 3.86 & 0.68 & 2.39 & 3.86 & 0.69 \\
6 & 3.23 & 5.17 & 0.38 & 2.53 & 4.00 & 0.70 & 2.60 & 4.00 & 0.72 \\
7 & 3.47 & 5.25 & 0.40 & 2.76 & 4.28 & 0.71 & 2.80 & 4.28 & 0.72 \\
8 & 3.88 & 5.86 & 0.45 & 3.00 & 4.56 & 0.73 & 3.11 & 4.56 & 0.75 \\
9 & 4.30 & 7.31 & 0.49 & 3.16 & 4.87 & 0.72 & 3.31 & 4.87 & 0.75 \\
10 & 4.56 & 7.10 & 0.60 & 3.47 & 5.39 & 0.71 & 3.64 & 5.39 & 0.75 \\
\hline
\end{tabular}

B)

\begin{tabular}{cccccccccc}
\hline & \multicolumn{3}{c}{ All } & \multicolumn{9}{c}{ No Soft Tissue } & \multicolumn{3}{c}{ No Soft Tissue or Marrow } \\
\cline { 2 - 10 } Slice & $\begin{array}{c}\text { OD } \\
\left(\mathrm{g} / \mathrm{cm}^{2}\right)\end{array}$ & $\begin{array}{c}t \\
(\mathrm{~mm})\end{array}$ & $\begin{array}{c}D \\
\left(\mathrm{~g} / \mathrm{cm}^{3}\right)\end{array}$ & $\begin{array}{c}\text { OD } \\
\left(\mathrm{g} / \mathrm{cm}^{2}\right)\end{array}$ & $\begin{array}{c}t \\
(\mathrm{~mm})\end{array}$ & $\begin{array}{c}D \\
\left(\mathrm{~g} / \mathrm{cm}^{3}\right)\end{array}$ & $\begin{array}{c}\text { OD } \\
\left(\mathrm{g} / \mathrm{cm}^{2}\right)\end{array}$ & $\begin{array}{c}t \\
(\mathrm{~mm})\end{array}$ & $\begin{array}{c}D \\
\left(\mathrm{~g} / \mathrm{cm}^{3}\right)\end{array}$ \\
\hline 1 & 2.36 & 9.46 & 0.60 & 2.30 & 4.15 & 0.61 & 2.25 & 4.15 & 0.60 \\
2 & 2.37 & 8.91 & 0.62 & 2.49 & 4.08 & 0.67 & 2.46 & 4.08 & 0.67 \\
3 & 2.48 & 8.83 & 0.67 & 2.55 & 4.00 & 0.71 & 2.47 & 4.00 & 0.68 \\
4 & 2.57 & 8.32 & 0.70 & 2.70 & 4.04 & 0.74 & 2.54 & 4.04 & 0.70 \\
5 & 2.70 & 8.07 & 0.74 & 2.84 & 4.05 & 0.77 & 2.54 & 4.05 & 0.69 \\
6 & 2.52 & 7.39 & 0.69 & 2.66 & 3.95 & 0.75 & 2.54 & 3.95 & 0.71 \\
7 & 2.67 & 7.43 & 0.73 & 2.64 & 4.00 & 0.73 & 2.53 & 4.00 & 0.70 \\
8 & 2.64 & 6.44 & 0.73 & 2.66 & 3.92 & 0.75 & 2.50 & 3.92 & 0.70 \\
9 & 2.39 & 5.35 & 0.65 & 2.51 & 3.96 & 0.70 & 2.42 & 3.96 & 0.67 \\
10 & 2.61 & 4.79 & 0.71 & 2.58 & 4.09 & 0.70 & 2.49 & 4.09 & 0.67 \\
\hline
\end{tabular}

Table 10. OD and diameter thickness $(t)$ for 10 regions of interest (slice) determined from a radiograph of a third metacarpal cadaver limb with soft tissue and marrow ( $A l l)$, without soft tissue, and without soft tissue and marrow. Density $(D)$ for each slice was determined by dividing OD by thickness. For each case, OD was measured from the lateral medial view while thickness was measured from the dorsal palmar view (A) or OD was measured from the dorsal palmar view while thickness was measured from the lateral medial view (B). 
regression lines for OD and bone density associated with no soft tissue and no marrow were not significantly different from each other in both the LM and DP views $(p>0.05)$. The slopes of the regression lines for OD associated with soft tissue were significantly different from the other conditions of no soft tissue and no soft tissue and marrow, but only in the DP view $(p<0.001$, Table 11). The slopes of the regression lines for bone density associated with soft tissue were significantly different from the other conditions of no soft tissue and no soft tissue and marrow, but only in the LM view $(p<0.001$, Table 11).

Error in OD associated with user error was determined for three different users that evaluated 40 radiographs of third metacarpal bone over a two week interval. Determination of OD varied by user and ranged from CV $1.51-4.01 \%$ and SD $0.05-$ 0.13 (Table 12). 


\begin{tabular}{lcccc}
\hline \multirow{2}{*}{ Sample } & \multicolumn{2}{c}{$O D \pm S D\left(\mathrm{~g} / \mathrm{cm}^{2}\right)$} & \multicolumn{2}{c}{ Density $\pm S D\left(\mathrm{~g} / \mathrm{cm}^{3}\right)$} \\
\cline { 2 - 5 } & $L M$ & $D P$ & $L M$ & $D P$ \\
\hline All & $2.53 \pm 0.13^{*}$ & $3.28 \pm 0.76$ & $0.39 \pm 0.10$ & $0.68 \pm 0.05^{\dagger}$ \\
No Soft Tissue & $2.59 \pm 0.15^{*}$ & $2.52 \pm 0.57^{*}$ & $0.67 \pm 0.05^{\dagger}$ & $0.71 \pm 0.05^{\dagger}$ \\
No Soft Tissue/Marrow & $2.47 \pm 0.09^{*}$ & $2.55 \pm 0.66^{*}$ & $0.68 \pm 0.07^{\dagger}$ & $0.68 \pm 0.03^{\dagger}$ \\
\hline
\end{tabular}

${ }^{*, \dagger}$ no significant difference between values $(P>0.05)$

Table 11. Average OD and bone density and standard deviation $(S D)$ from lateral medial and dorsal palmar radiographs of a third metacarpal cadaver limb with soft tissue and marrow (All), without soft tissue (No Soft Tissue) and without soft tissue and bone marrow (No Soft Tissue/Marrow). 


\begin{tabular}{lccc}
\hline User & $d f$ & $S D$ & $C V(\%)$ \\
\hline 1 & 40 & 0.10 & 3.28 \\
2 & 40 & 0.13 & 4.01 \\
3 & 40 & 0.05 & 1.51 \\
All & 280 & 0.11 & 3.46 \\
\hline
\end{tabular}

Table 12. Levels of precision errors $(S D)$ and coefficients of variation $(C V)$ for OD determined from three different users and all users together. Error in OD was determined for three different users that evaluated 40 radiographs over a two week interval. 


\section{DISCUSSION}

Digital radiographic standardization allows quantitative evaluation of bone structure and quality. Objective measurements from radiographs may improve treatment of equine limb lameness by providing the veterinarian with multiple quantitative radiographic assessments of the equine skeleton (Rocha et al. 2004, Kummer et al. 2004, Hunt 2002, Parks and O'Grady 2003). In the first study, a novel morphometric measurement was generated via simple radiographic calibration to evaluate the volume of the solar aspect of the distal phalanx in the horse. While form and function of the distal phalanx has been described, to our knowledge the PM is the only quantitative, radiographic assessment of the solar, concave aspect of the distal phalanx (Parks and O'Grady 2003, Smallwood and Holladay 1987). The PM is a significant predictor of solar cup volume $(t(63)=26.64, p<0.001$, Figure 11), better than common morphometric measurements of lateral toe length $\left(r^{2}=0.684, t(63)=11.483, p<0.001\right)$ and lateral height of the distal phalanx $\left(r^{2}=0.668, t(63)=11.07, p<0.001\right)$ (Figure 12). As the PM is a unit-less while solar cup volume is not, we are assuming in this study that the 65 cadaver bones are of similar size and that changes in solar cup volume are due to a decrease in the PM, not simply a smaller third phalanx bone. The PM is independent of radiographic exposure and positioning, but may be dependent on radiographic positioning greater than an 11 degree rotational displacement $(p>0.05$, Table 2). Further, error in determining the PM is significantly affected by experience of the user, as seen in User 4 in Table 3, as the measurement is dependent on the user tracing a radio-dense curve, a highly subjective assessment. 
Because the PM is a ratio, it is not dependent on size of the distal phalanx and can be assessed independent of breed related differences in foot size. The PM ranged from $1.24-16.74 \%$ and was shown to be negatively correlated with age (Figures 13, 14). Therefore, young horses have a significantly greater PM than older horses in this study. Additionally, the PM for left and right front feet were not significantly different at any age class in our study $(t(217)=-0.676, p=0.75$, Figure 13). Measurement of the PM may afford the veterinarian a quantitative technique to assess the presence of significant unilateral foot pathology that would result in differences between the left and right PM for an individual horse. As the age-related, gradual demineralization of bones is a well studied phenomenon, especially in osteoporosis in humans, we believe that in horses the decreased depth of the solar concavity over time is due to gradual demineralization of the third phalanx along the solar margin. Because the distal phalanx is so variable in morphology, especially along the solar margin, it is not an ideal model for radiographic determination of osteoporotic changes.

In the second study, the more complex variable of bone density was standardized using digital radiographs. Bone density measurement to assess bone strength is a commonly accepted concept in human medicine but not normally used in veterinary medicine, mostly due to the impractical use and expense of large machinery for the traveling professional (Tabensky et al. 1996, Leichter et al. 1982). Veterinary clinicians routinely utilize radiographs to assess bone health and diagnose abnormalities such as fractures and osteoarthritis, subjectively and qualitatively assessing the opacity or optical density of areas of interest. A tool to quantitatively evaluate bone strength or density in regions of interest from radiographic images would be invaluable. Therefore, we 
developed a method based on standardized digital radiographs that affords the veterinary professional accurate and repeatable measurement of areal bone density.

As the third metacarpal in the mid-diaphysis region is composed of uniformly dense cortical bone and very trabecular bone and soft tissue, it is an ideal choice to investigate the parameters associated with radiographic determination of bone density. In this study, we showed that the attenuation of X-rays through bone and $\mathrm{Al}$ occurs in a smooth, linear fashion in response to exposure settings and properties of the material itself (Figure 25, 26, Table 4). Over the range of clinically relevant exposures, the BDI of an object of known density and thickness such as an $\mathrm{Al}$ wedge is a significant predictor of bone BDI of unknown density and thickness $\left(r^{2}=0.9599, F(1,40)=957.3, p<0.001\right.$, Figure 26). BDI is determined using a standard curve from an $\mathrm{Al}$ wedge, where BDI is a function of thickness or mm Al. For regions of interest thicker than $\sim 12 \mathrm{~mm} \mathrm{Al}$, there is greater variability from the actual thickness of the region of interest (Figure 27). This is due the non-linear portion of the Al wedge standard curve; as the slope decreases with thickness of Al, there is a less distinguishable difference in BDI (Figure 29). In checking the accuracy of $\mathrm{mm} \mathrm{Al}$ determination using the standard curve, $\mathrm{mm} \mathrm{Al}$ from the standard curve was a significant predictor of the Al step-wedge thickness, measured using digital calipers $\left(r^{2}=0.992, F(1,249)=31,790, p<0.001\right.$, Figure 27). Additionally, there was no significant evidence that $\mathrm{mm} \mathrm{Al}$ was not equal to the actual thickness of the $\mathrm{Al}$ stepwedge as the regression slope was not significantly different from $1(t(249)=1.373, p=$ 0.171). These results indicate that calibration of BDI with an $\mathrm{Al}$ wedge standard curve allows for accurate assessment of the thickness of bone or $\mathrm{Al}$ in units of $\mathrm{mm} \mathrm{Al} \mathrm{for}$ medically relevant ranges of exposure. 
In determining bone OD, a bone step-wedge of known density and thickness was created (Table 6). BDI was shown to be a significant predictor of areal density in both Al $\left(r^{2}=0.9973, F(1,631)=232,800, p<0.001\right.$, Figure 30) and bone $\left(r^{2}=0.9716, F(1,1193)\right.$ $=40,850, p<0.001$, Figure 28). Further, our goal was to determine bone OD in terms of $\mathrm{g} / \mathrm{cm}^{2}$ with known values for the mass attenuation coefficient ratio, density and thickness of Al. The ratio of the mass attenuation coefficients was solved for by comparing Al OD to that of bone when $\mathrm{Al} \mathrm{BDI}$ equals bone $\mathrm{BDI}$, utilizing Equation 3. The mass attenuation coefficient ratio $\left(\mu_{m A l} / \mu_{m B}\right)$ was estimated using regression equations from Figures 27 and 29. At the point where BDI was equal for both materials, $\mu_{m A l} / \mu_{m B}$ was determined to be $0.9042(p<0.001)$ (Appendix A). Our experimental value for the mass attenuation coefficient ratio was is $2.41 \%$ different from the published value of $0.8825 \mathrm{~cm}^{2} / \mathrm{g}$ at 60 $\mathrm{kV}$. Between the medically relevant energies of the incident X-rays $(40-100 \mathrm{kV})$, the mass attenuation coefficient ratio of $\mathrm{Al}$ and cortical bone is relatively constant at $0.886 \pm$ 0.026 (Figure 20) (Hubbell and Seltzer 2004). Further evaluation of the bone step-wedge was performed to test if bone OD was an accurate predictor of bone areal density for any exposure. We hypothesized that filters associated with the digital sensor software (Canon) where applied differently depending on exposure. Although the filtering is inherent in the digital image uptake, it was turned off as much as possible. Further, there may be error in bone $\mathrm{OD}$ associated with the non-linear portion of the $\mathrm{Al}$ wedge standard curve. Subsequently, correction was necessary to ensure that bone OD was an accurate predictor of bone areal density from 50 to $90 \mathrm{kV}$. The relationship of bone areal density versus bone OD was characterized from radiographs of the bone step-wedge using linear regression $\left(r^{2}=0.9907, F(1,89)=184.7, p<0.001\right.$, Figure 31). After correcting bone OD 
using the regression equation, bone areal density could be determined from a radiograph with less than a $7 \%$ error (Table 7). This method permits accurate evaluation of BDI and, therefore, bone OD independent of the exposure setting.

We performed this study using the third metacarpal equine bone, eliminating confounding factors due to marrow and soft tissue. In vivo, soft tissue and marrow would be expected to have substantial effects on density measurements due to X-ray beam attenuation, magnification and photon absorption, making it difficult to determine both bone thickness and the OD or density of cortical bone alone. However, the contribution of density, mass attenuation, and thickness from marrow and soft tissue on OD are known to be significantly less than that of cortical bone. Comparing the effect of density and mass attenuation on BDI reveals the contribution of soft tissue to be relatively minimal, as the density of soft tissue is $0.55 \mathrm{~g} / \mathrm{cm}^{3}$ compared to $1.92 \mathrm{~g} / \mathrm{cm}^{3}$ in cortical bone and the mass attenuation coefficient of soft tissue is $0.2048 \mathrm{~cm}^{3} / \mathrm{g}$ compared to $0.3148 \mathrm{~cm}^{3} / \mathrm{g}$ in cortical bone measured at $60 \mathrm{kV}$ (Berger et al. 2000, Hubbell and Seltzer 2004). Therefore, we expected cortical bone to have the largest effect on OD and density measurement. OD was determined for 10 regions of interest proximal to distal along the mid-diaphysis of the third metacarpal view of the distal limb dependent on radiographic view (DP and LM) and presence of soft tissue and marrow (Figure 32). Bone OD determined from the third metacarpal cadaver limb after only soft tissue was removed was not significantly different from bone OD after soft tissue and bone marrow were removed in both the LM and DP views ( $p>0.05$, Figure 32$)$. The slopes of the regression lines for bone OD associated with soft tissue was significantly different from no soft tissue and no soft tissue or marrow, but only in the LM view ( $p<0.001$, Figure 32 , Table 
11). We observed that the presence of both soft tissue and bone marrow significantly affected the measurement of OD when measuring from the DP view. OD measured from the DP view of an intact limb was significantly greater than for the LM view or for any other condition. This is explained by our method of determining OD as an average value for a given region of interest, meaning OD was much greater when the soft tissue was compacted into a smaller region of interest in the DP view. From the LM view, the region of interest encompassed the bone only, and therefore much less soft tissue. From our results, there were no statistically significant effects of soft tissue on OD measurements from the LM view of an intact third metacarpal limb.

Additionally, we hypothesized that true bone density could be determined providing an Al wedge was included in the radiograph and the thickness of bone was known. From the previous study, thickness of the third metacarpal was determined from both the DP and LM view (Table 10). Bone density determined after soft tissue was removed was not significantly different than bone density determined after soft tissue and marrow were removed in both the LM and DP views ( $p>0.05$, Figure 33). The slopes of the regression lines for bone density associated with soft tissue was significantly different from the other conditions, but only in the LM view ( $p<0.001$, Figure 33, Table 11). The average density determined from radiographs for all regions of interest along the third metacarpal was determined to be $0.686 \pm 0.052 \mathrm{~g} / \mathrm{cm}^{3}$. Our experimental value for bone density was closer to the published value for the density of soft tissue of $0.55 \mathrm{~g} / \mathrm{cm}^{3}$ compared to $1.92 \mathrm{~g} / \mathrm{cm}^{3}$ for cortical bone (Berger et al. 2000). Presently, bone density may not be reliably determined with this method due to effects from assorted variables. Error in our measurement of bone density may be due to effects of soft tissue when 
determining OD. Also, use of the third metacarpal diameter for the thickness value of cortical bone may be decreasing our value for bone density, as it is an overestimate of cortical bone thickness by including the thickness of soft tissue. Further, filtering techniques performed by the Canon software apply various complex and non-linear imaging processing algorithms to the image, which may be applied to a single pixel individually, to a pixel depending on neighboring pixels, or even to a pixel depending on non-localized effects from a different region of the image. Overall, determination of bone density from standardized radiographs is a complex task due to effects of soft tissue and the difficulty in determining cortical bone thickness.

Effects on OD determination due to radiographic positioning were also evaluated. We observed less than a $10 \%$ error in OD as long as the user did not exceed 18 degrees of lateral to medial rotation and 30 degrees of proximal to distal rotation (Table 8, 9). Error in OD measurement due to user error was also determined to be low, with a maximum $\mathrm{CV}$ of $4.01 \%$ (Table 12). Although error in the 5\% range is not acceptable for accurate medical diagnosis of decreased bone mineralization in humans, this method allows quantitative comparison of OD from any digital radiograph standardized in this manner.

This method successfully quantified bone OD via measurement of BDI from standardized digital radiographs, allowing for the opacity of radiographs to be truly comparable when taken under different circumstances. This may be useful in evaluation for diseases that weaken bone in certain areas more than others, such as osteoarthritis, or diseases that need to be monitored over time. This may have practical applications in clinical circumstances as OD is dependent only on thickness and density of the material; therefore, a given area of bone with lower OD than another area of bone of similar 
thickness can be concluded to have a lower density. It has been suggested that bone fractures in racehorses are due to areas of weakened bone or fatigue fractures that occur during training (Nunamaker et al. 1990, Warden et al. 2005), and may be evaluated as areas of decreased OD. Further, stress fractures induced by exercise are correlated with decreased BMD (Vinther et al. 2005), and OD may be an accurate predictor of BMD. In young racehorses, the amount of bone remodeling during training could be investigated by comparison of OD for different areas of the remodeling third metacarpal bone in hope of preventing stress fractures, and ultimately, catastrophic fractures. 


\section{REFERENCES}

Arthur's Medical Clipart. March 2009.

<http://www.arthursclipart.org/medical/skeletal/long\%20bone\%20structure.gif>

Beck TJ, Ruff CB, Shaffer RA, et al. Stress fracture in military recruits: gender differences in muscle and bone susceptibility factors. Bone 2001; 27(3):437-44.

Bell GH, Dunbar O, Beck JS, Gibb A. Variations in strength of vertebrae with age and their relation to osteoporosis. Calcif Tissue Res 1967; 1(1):75-86.

Berger MJ, Coursey JS, Zucker MA, Chang J. Stopping power and range tables for electrons, protons, and helium ions. http://physics.nist.gov/physrefdata/star/text/contents.html. 2000.

Beutel J, Kundel HL, Van Metter RL. Handbook of Medical Imaging: Physics and psychophysics. Washington: SPIE, 2000.

Bloomfield SA. Bone, ligament, and tendon. In: Lamb DR, Gisolfi CV, and Nadel E (Eds.) Perspectives in Exercise Science and Sports Medicine. Carmel, IN: Cooper Publishing Group, 1995; 175-235.

Bonnick SL. Bone Densitometry in Clinical Practice. New York: Humana Press, 2010.

Burr DB, Schaffler MB, Yang KH, et al. The effects of altered strain environments on bone tissue kinetics. Bone 1989; 10:215-221.

Carricart-Ganivet JP, Barnes DJ. Densitometry from digitized images of X-radiographs: Methodology for measurement of coral skeletal density. J Exp Mar Biol Ecol 2007; 344(1):67-72.

Carter DR. The relationship between in vivo stresses and conical bone remodeling. Boca Raton, FL: CRC Press, 1982. 
Carter DR. Mechanical loading histories and cortical bone remodeling. Calcif Tissue Int 1984; 36:S19.

Carter DR. Mechanical loading history and skeletal biology. J Biomech 1987; 20:1095.

Carter DR, Bouxsein ML, Marcus R. New approaches for interpreting projected bone densitometry data. J Bone Miner Res 1992; 7(2):137-45

Cavolina J, Evans GL, Harris SA, et al. The effects of orbital spaceflight on bone histomorphometry and messenger ribonucleic acid levels for bone matrix proteins and skeletal signaling peptides in ovariectomized growing rats. Endocrinology 1997; 138:1567-1576.

Chalker B, Barnes D, Isdale P. Calibration of X-ray densitometry for the measurement of coral skeletal density. Coral Reefs (Springer) 1985; 4:95-100.

Chappard C, Laugier P, Fournier B. Assessment of the relationship between broadband ultrasound attenuation and bone mineral density at the calcaneus using BUA imaging and DXA. Osteoporos Int 1997; 7(4):316-22.

Craig J, Craig M, Weltner T. Quantifying conformation of the equine digit from lateromedial radiographs. In: Proceedings Assoc Equine Sports Med 2001; 21:20-25. Cranney A, Jamal SA, Tsang JF, et al. Low Bone Mineral Density and Fracture Burden in Post Menopausal Women. CMAJ 2007; 177(6):575-80.

Curry TS, Murry RC, Dowdey JE, et al. Christensen's Physics of Diagnostic Radiology: 4th Edition. Philadelphia, Pennsylvania: Lippencott Williams \& Wilkins, 1990.

Dackiewicz D, Bergsneider C, Piraino D. Impact of digital radiography on clinical workflow and patient satisfaction. J Digit Imaging 2000 May;13(2 Suppl 1):200-1. 
Daly RM, Saxon L, Turner CH. The relationship between muscle size and bone geometry during growth and in response to exercise. Bone 2004; 34(2):281-7.

Ensminger A. Foods and Nutrition Encyclopedia Vol.1, 2nd edition. Boca Raton, FL: CRC Press, 1994.

Estberg L, Stover SM, Case JT, et al. Case-control study of racing related risk factors for catastrophic injuries of the thoroughbred racehorse. Proc Am Assoc Equine Practnr 1993; 39:129-130.

Estberg L, Stover SM, Gardner IA, et al. Fatal musculoskeletal injuries incurred during racing and training in Thoroughbreds. JAVMA 1996; 208:92-96.

Feldkamp LA, Goldstein SA, Parfitt AM. The direct examination of three-dimensional bone architecture in vitro by computed tomography. J Bone Miner Re. 1989; 4(1):311.

Fink C, Hallscheidt PJ, Noeldge G. Clinical comparative study with a large-area amorphous silicon flat-panel detector: image quality and visibility of anatomic structures on chest radiography. AJR Am J Roentgenol 2002; 178(2):481-6.

Forwood MR, Parker AW. Effects of exercise on bone morphology. Acta Orthop Scand 1986; 57:204.

Frost HM. Skeletal structural adaptations to mechanical usage (SATMU): 2. redefining Wolff's law: The remodeling problem. Anat Rec 1990; 226:414-422.

Garmer M, Hennigs SP, Jager HJ, et al. Digital Radiography Versus Conventional Radiography in Chest Imaging: Diagnostic Performance of a Large-Area Silicon FlatPanel Detector in a Clinical CT-Controlled Study. AJR Am J Roentgenol 2000; 174(1):75-80 . 
Giladi M, Ahronson Z, Stein M, et al. Unusual distribution and onset of stress fractures in soldiers. Clin Orthop 1985; 192:142-6

Glüer CC, Cummings SR, Pressman A. Prediction of hip fractures from pelvic radiographs: the study of osteoporotic fractures. The Study of Osteoporotic Fractures Research Group. J Bone Miner Res 1994; 9(5):671-7.

Goodship AE, Lanyon LE, McFie H. Functional adaptation of bone to increased stress. $\mathbf{J}$ Bone Joint Surg 1979; 61-A:539-546.

Graham DT, Cloke PJ. Principles of radiological physics. London: Elsevier Limited, $1982 ; 292-300$.

Hammett FS. A biochemical study of bone growth. II. Changes in the calcium, magnesium and phosphorus of bone during growth. J Biol Chem 1925; 64:685-692.

Heggie J, Liddel N, Maher K. Applied Imaging Technology. Melbourne : St. Vincent's Hospital, 2001.

Hendee WR, Ritenour ER. Medical Imaging Physics. New York: Wiley-Liss, 2002.

Hirsch FR, Franklin WA, Gazdar AF, et al. Early detection of lung cancer: clinical perspectives of recent advances in biology and radiology. Clin Cancer Res 2001; $7(1): 5-22$.

Hubbell JH, Seltzer SM. Tables of X-Ray Mass Attenuation Coefficients and Mass Energy-Absorption Coefficients (version 1.4). [Online] Available: http://physics.nist.gov/xaamdi [2009, October 12]. Gaithersburg, MD: National Institute of Standards and Technology, 2004. 
Hui SL, Gao S, Zhou XH, et al. Universal standardization of bone density measurements: a method with optimal properties for calibration among several instruments. J Bone Miner Res 1997; 12(9):1463-70.

Hunt RJ. Laminitis in the geriatric horse. Vet Clin Equine 2002; 18:439-452.

Inoue Y, Asai Y, Tomita M, Kuribara K, et al. The effect of milk basic protein supplementation on bone metabolism during training of young thoroughbred racehorses. Equine Vet J Suppl 2006 Aug;(36):654-8.

Järvinen TL, Sievänen H, Kannus P, Järvinen M. Dual-energy X-ray absorptiometry in predicting mechanical characteristics of rat femur. Bone 1998; 22(5):551-8.

Jeffcott LB, Buckingham SH, McCarthey RN. Noninvasive measurement of bone quality in horses and changes associated with exercise. Equine Vet J Suppl 1988; (6):71-9.

Jeffcott LB, Rossdale PD, Freestone J, et al. Digital Radiography: A Predictor of Regenerate Bone Stiffness in Distraction Osteogenesis. Clin Orthop Relat Res 1999; (366):221-8.

Johnson B. A look at racetrack breakdowns - 1991. J Equine Vet Sci 1993; 13:129-132.

Johnson B, Ardans A, Stover SM, et al. California racehorse postmortem program: A 4year overview. Proc Am Assoc Equine Practnr 1994; 40:167-169.

Jones HH, Priest JD, Hayes WC, et al. Humeral hypertrophy in response to exercise. J Bone Joint Surg 1977; 59-A:204-208.

Kolbeck S, Bail H, Weiler A, et al. Digital radiography. A predictor of regenerate bone stiffness in distraction osteogenesis. Clin Orthop Relat Res 1999 Sep; (366):221-8.

Krause GR, Thompson JR. March Fracture of the Tibia. Radiology 1943; 41:580-5. 
Krølner B, Pors Nielsen S. Bone mineral content of the lumbar spine in normal and osteoporotic women: cross-sectional and longitudinal studies. Clin Sci (Lond) 1982 Mar;62(3):329-36.

Kummer M, Lischer C, Ohlerth S, et al. Evaluation of a standardised radiographic technique of the equine hoof. Schweiz Arch Tierheilkd 2004; 146:507-14.

Kummer M, Geyer H, Imboden I, Auer J, Lischer C. The effect of hoof trimming on radiographic measurements of the front feet of normal Warmblood horses. Vet J 2006 Jul;172(1):58-66.

Lanyon LE. Functional strain as a determinant for bone remodeling. Calcif Tissue Int 1984; 36:S56-S61.

Larcos G, Wahner HW. An evaluation of forearm bone mineral measurement with dualenergy X-ray absorptiometry. J Nucl Med 1991 Nov;32(11):2101-6.

Lauder TD, Dixit S, Pezzin LE, Williams MV. The relation between stress fractures and bone mineral density: evidence from active-duty Army women. Arch Phys Med Rehabil 2000; 81(1):73-9.

Leichter I, Weinreb A, Hazan G, et al. The effect of age and sex on bone density, bone mineral content and cortical index. Clin Orthop Relat Res 1981 May;(156):232-9.

Leichter I, Margulies JY, Weinreb A, et al. The relationship between bone density, mineral content, and mechanical strength in the femoral neck. Clin Orthop Relat Res $1982 ; 163: 272-81$.

Lindner A, Dingerkus A. Incidence of training failure among Thoroughbred horses at Cologne, Germany. Prev Vet Med 1993; 16:85-94. 
Linford RL, O'Brien TR, Trout DR. Qualitative and morphometric radiographic findings in the distal phalanx and digital soft tissues of sound thoroughbred racehorses. Am J Vet Res 1993; 54(1):38-51.

MacMahon H, Vyborny CJ, Metz CE, et al. Digital radiography of subtle pulmonary abnormalities: an ROC study of the effect of pixel size on observer performance. Radiology 1986; 158(1):21-6.

Martin RB, Burr DB. A hypothetical mechanism for the stimulation of osteonal remodelling by fatigue damage.J Biomech 1982; 15(3):137-9.

McCarthy RN, Jeffcott LB. Effects of treadmill exercise on cortical bone in the third metacarpus of young horses. Res Vet Sci 1992; 52:28-37.

Meade JB, Cowin SC, Klawitter JJ, et al. Bone remodeling due to continuously applied loads. Calcif Tissue Int 1984; 36:S25-S30.

Meakim DW, Ott EA, Asquith RL, et al. Estimation of mineral content of the equine third metacarpal by radiographic photometry. J Anim Sci 1981; 53:1019-26.

Moris M, Peretz A, Tjeka R. Quantitative ultrasound bone measurements: normal values and comparison with bone mineral density by dual X-ray absorptiometry. Calcif Tissue Int 1995; 57(1):6-10.

Myburgh KH, Hutchins J, Fataar AB, et al. Low bone density is an etiologic factor for stress fractures in athletes. Ann Intern Med 1990; 113(10):754-9.

Nagamine R, Hanada Y, Masakazu K, et al. Quantification of Bone Volume on Radiographs Using NIH Image. Mod Rheumatol 2000; 10:220-225. 
Nielsen BD, Potter GD, Morris EL, et al. Changes in the third metacarpal bone and frequency of bone injuries in young Quarter horses during race training - observations and theoretical considerations. J Equine Vet Sci 1997; 17:541-549.

Nielsen DH, McEvoy FJ, Madsen MT, et al. Relationship Between Bone Strength and Dual-energy X-ray Absorptiometry Measurements In Pigs. J Anim Sci 2007; 85:667672.

Nunamaker DM, Butterweck DM, Provost MT. Fatigue fractures in thoroughbred racehorses: relationships with age, peak bone strain, and training. J Orthop Res 1990; 8:604-11.

Palmar SE. Prevalence of carpal fractures in thoroughbred and standardbred racehorses. J Am Vet Med Assoc 1986; 188:1171-3.

Parks AH, O'Grady SE. Chronic laminitis: current treatment strategies. Vet Clin North Am Equine Pract 2003; 19:393-416.

Pentecost RL, Murray RA, Brindley HH. Fatigue, insufficiency, and pathologic fractures. JAMA 1964; 187:1001-4.

Pollak AN, Calhoun JH. Extremity war injuries: state of the art and future directions. Priorotized future research objectives. J Am Acad Orth Surg. 2006; 14(10 Spec No.):viii-ix.

Porr C, Kronfeld DS, Lawrenc LA, et al. Deconditioning reduces mineral content of the third metacarpal bone in horses. J Anim Sci 1998; 76:1875-1879.

Porr C, Kronfeld DS, Lawrenc LA, et al. Diet andconditioning influence bone evelopment. Equine Pract 2000; 22:18-21. 
Raub RH, Jackson SG, Baker JP. The Effect of Exercise on Bone Growth and Development of Weanling Horses J Anim Sci 1989; 67(10):2508-14.

Riggs BL, Wahner HW, Dunn WL, et al. Differential changes in bone mineral density of the appendicular and axial skeleton with aging: relationship to spinal osteoporosis. $\mathbf{J}$ Clin Invest 1981 Feb;67(2):328-35.

Riggs CM, Boyde A. Effect of exercise on bone density in distal regions of the equine third metacarpal bone in 2-year-old thoroughbreds. Equine Vet J Suppl 1999; 30:55560.

Rocha J, Lischer C, Kummer M, et al. Evaluating the measuring software package Metron-PX for morphometric description of equine hoof radiographs. J Equine Vet Sci 2004; 24:347-354.

Rubin CT, Lanyon LE. Regulation of bone formation by applied dynamic loads. J Bone Joint Surg 1984; 66-A:397-402.

Rubin CT, Lanyon LE. Regulation of bone mass by mechanical strain magnitude. Calcif Tissue Int 1985; 37:411-417.

Schaffler MB, Radin EL, Burr DB. Mechanical and morphological effects of strain rate on fatigue of compact bone. Bone 1989; 10(3):207-14.

Schryver HF. Bending properties of cortical bone of the horse. Am J Vet Res 1978; 39(1):25-8.

Sedlin ED. A rheologic model for cortical bone. A study of the physical properties of human femoral samples. Acta Orthop Scand Suppl 1965; Suppl 83:1-77.

Sedlin ED, Hirsch C. Factors affecting the determination of the physical properties of femoral cortical bone. Acta Orthop Scand 1966; 37(1):29-48. 
Skerry TM, Lanyon LE. Interruption of disuse by short duration walking exercise does not prevent bone loss in the sheep calcaneus. Bone 1995; 16:269-274.

Smallwood JE, Holladay SD. Xeroradiographic anatomy of the equine digit and metacarpophalangeal region. Vet Radiol 1987; 28:166-173.

Smith RT, Sunde ML, Smith EL. The influence of dietary calcium and exercise on the mechanical properties of bone. Med Sci Sports 1985; 16(2):164.

Sprawls P. Physical Principles of Medical Imaging. Rockville, MD: Aspen Publications, 1987.

Stover SM, Pool RR, Johnson BJ, et al. An association between complete and incomplete humeral fractures in the racehorse. Proc A Assoc Equine Practnr 1991; 37:581-582.

Stover SM, Martin RB, Pool RR, et al. Contribution of microfractures to dorsal metacarpal disease. Proc Am Assoc Equine Practnr 1992; 38:3-4.

Stover SM, Ardans AA, Read DH, et al. Patterns of stress fractures associated with complete bone fractures in racehorses. Proc Am Assoc Equine Practn 1993; 39:131132.

Strotzer M, Gmeinwieser J, Volk M. Clinical application of a flat-panel X-ray detector based on amorphous silicon technology: image quality and potential for radiation dose reduction in skeletal radiography. Radiology 1995; 196(2):565-8.

Szulc P. Bone density, geometry, and fracture in elderly men. Curr Osteoporos Rep 2006; 4(2):57-63.

Tabensky AD, Williams J, DeLuca V, et al. Bone mass, areal, and volumetric bone density are equally accurate, sensitive, and specific surrogates of the breaking strength of the vertebral body: an in vitro study. J Bone Miner Res 1996; 11:1981-8. 
Thomas T, Vico L, Skerry TM. Architectural modifications and cellular response during disuserelated bone loss in calcaneus of the sheep. Am J Physiol 1996; 80:198-202.

USDA. “National Economic Cost.” Centers of Epidemiology and Animal Health; 2001.

Vinther A, Kanstrup IL, Christiansen E, et al. Exercise-induced rib stress fractures: influence of reduced bone mineral density. Scand J Med Sci Sports 2005; 15(2):95-9.

Walmsley R. The development and growth of the intervertebral disc. Edinb Med J 1953; 60(8):341-64.

Warden SJ, Hurst JA, Sanders MS, et al. Bone adaptation to a mechanical loading program significantly increases skeletal fatigue resistance. J Bone Miner Res 2005; 20:809-16.

Weaver JK, Chalmers J. Cancellous bone: its strength and changes with aging and an evaluation of some methods for measuring its mineral content. J Bone Joint Surg Am 1966; 48(2):289-98.

Welch RD. Diseases of the metacarpus and metatarsus. In Equine Medicine and Surgery. St. Louis, MO: 1999; 1586-1594.

White JM, Mellor DJ, Duz M, et al. Diagnostic accuracy of digital photography and image analysis for the measurement of foot conformation in the horse. Equine Vet $\mathbf{J}$ 2008; 40:623-628

Williams JA, Wagner J, Wasnich R, et al. The effect of long distance running upon appendicular bone mineral content. Med Sci Sports Exercise 1984; 16(3):223.

Wilson JH, Jensen RC, Robinson RA. Racing injuries of two year old Thoroughbreds and Quarter Horses. Pferdeheilkunde 1996; 12(July August):582-587. 
Woo S, Kuei SC, Amiel D, et al. The effect of prolonged physical training on the properties of long bone: A study of Wolff's law. J Bone Joint Surg 1981; 63A(5):780-787.

Yaffe MJ, Rowlands JA. X-ray detectors for digital radiography. Phys Med Biol 1997; 42:1-39.

Zahringer M, Krug B, Kamm KF, et al. Detection of Porcine Bone Lesions and Fissures: Comparing Digital Selenium, Digital Luminescence, and Analog Film-Screen Radiography. Am J Roentgenol 2001; 177(6):1397-1403. 